\title{
THE EFFECT OF EXIT EXAMS ON COLLEGE ENROLLMENT: A STATE LEVEL ANALYSIS
}

A Dissertation
presented to
the Faculty of the Graduate School
at the University of Missouri
In Partial Fulfillment
of the Requirements for the Degree
Doctor of Philosophy
JUDE KYOORE
Dr. Bradley Curs, Dissertation Advisor
DECEMBER 2019


The undersigned, appointed by the dean of the Graduate School, have examined the dissertation entitled

\section{THE EFFECT OF EXIT EXAMS ON COLLEGE ENROLLMENT: A STATE LEVEL ANALYSIS}

presented by Jude Kyoore,

a candidate for the degree of doctor of philosophy, and hereby certify that, in their opinion, it is worthy of acceptance.

Professor Bradley Curs

Professor Pilar Mendoza

Professor James Sebastian

Professor Eric Parsons 


\section{DEDICATION}

I dedicate this dissertation to my family. First, I want to thank my parents particularly Baba Pasi for always encouraging me to go higher. Second, I thank my wife, Esther who has been a rock during this phase of my life. Third, to my precious daughters Mwinbom and Nomunuo, thank you for not crying all the times when I left to go to the library at odd hours of the night. Your wholehearted support has made a world of difference in my life! I love you all forever! 


\section{ACKNOWLEDGEMENTS}

I owe words of gratitude to many people who have supported me through this journey. I say big thank you to all.

I am most grateful to Dr. Bradley Curs, my advisor, who has provided constant support and inspiration ever since I started my program. Your willingness to go the extra mile to help me was what made it possible for me to complete this dissertation. I definitely could not have reached this point without you. I am forever indebted to you for the kindness, generosity with time, understanding and guidance over the years.

To my wonderful committee members, Dr Pilar Mendoza, Dr. James Sebastian, and Dr. Eric Parsons, thank you so much for your willingness to serve on my committee. Your suggestions and willingness to provide me with extra materials on various issues have helped shaped my academic and career journey. Like we say it in my local Ghanaian language, 'Ni barka' meaning 'thank you'.

Finally, huge thanks go to my dear family, friends, colleagues at Missouri Department of Higher Education and Workforce Development (DHEWD) who have given me endless love and encouragement during this process, I say thank you to you all. I will always remember you. 
TABLE OF CONTENTS

ACKNOWLEDGEMENTS....................................................... ii

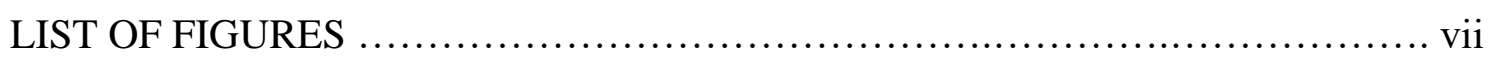

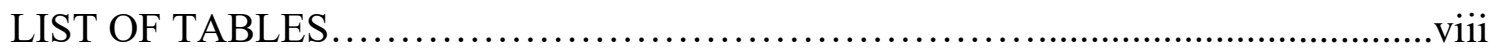

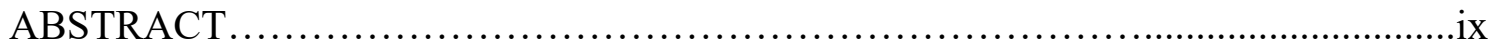

Chapter

1. INTRODUCTION .......................................................

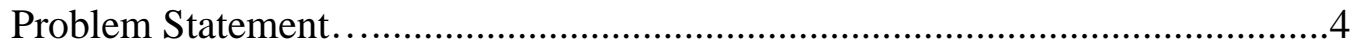

Research Purpose And Research Questions ................................6

Overview of Research Study ...............................................................

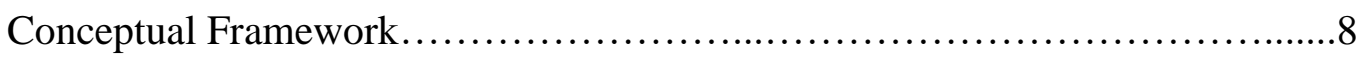

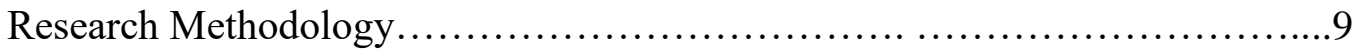

Significance of The Study ................................................. 10

Contribution to the Literature.............................................. 11

Contribution to the Policy ..................................................

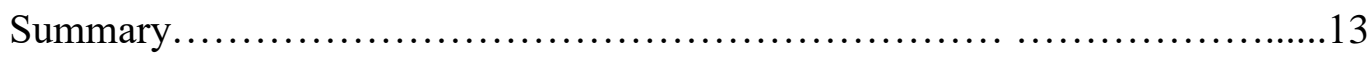

2. LITERATURE REVIEW AND THEORETICAL FRAMEWORK................15

Evolution of Exit Exams Policies and the Role of Government ................. 15

Educational Reforms in the 1980s and 1990s...........................16

The Era of No Child Left Behind (NCLB) Act of $2001 \ldots \ldots \ldots \ldots \ldots \ldots \ldots . \ldots 18$

The Common Core Standards........................................... 19

Research on the Relationship of Exit Exams and Student Outcomes............20 
High School Outcomes...........................................20

College Level Outcomes.................................................23

Enrollment in Any Institution of Higher Education.................23

Type of Exit Exams and Enrollment by Sector.....................25

Exit Exams and Students Migration................................26

Labor Market Outcomes..........................................27

College Enrollment Decisions...........................................27

Individual Habitus............................................... 30

School and Community Context.....................................30

Higher Education Context........................................32

Social, Economic and Policy Context.................................34

Conceptual Framework...................................................... 36

The College Readiness Component of Exit Exams......................39

The Stress Component of Exit Exams...............................41

Opportunity Cost Component of Exit Exams........................42

Research Hypotheses..............................................44

Prediction on College Enrollment................................44

Prediction on Enrollment by Institution Type.................44

Prediction on Enrollment by Place of Enrollment..............45

Prediction on Enrollment by Different Types of Exit Exams............45

Summary........................................................46

3. RESEARCH DESIGN AND METHODOLOGY ....................... 48

Potential Identification Strategies...................................49 
Experimental Design

Comparing the Treated to the Untreated.......................................51

Pre-post Comparison Design..................................53

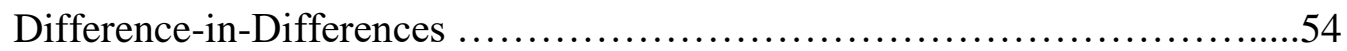

Data Definitions and Sources........................................58

Dependent Variable............................................58

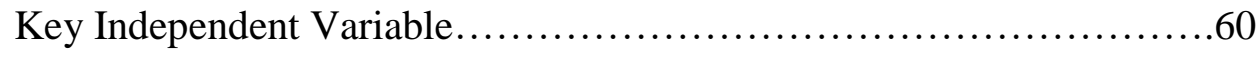

Control Variables................................................65

Sample...........................................................68

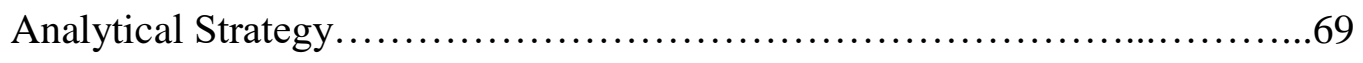

Summary....................................................... 72

4. RESEARCH RESULTS .......................................... 73

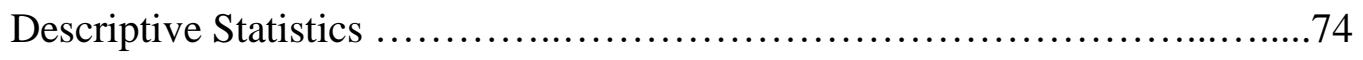

Statistical Results.................................................. 84

Parallel Trend Assumptions........................................84

Overall Effects of Exit Exams....................................91

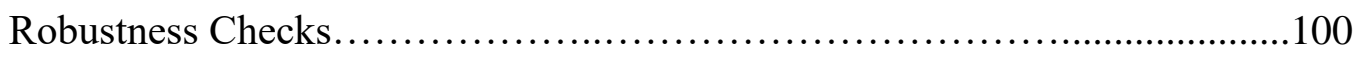

Summary ...................................................... 105

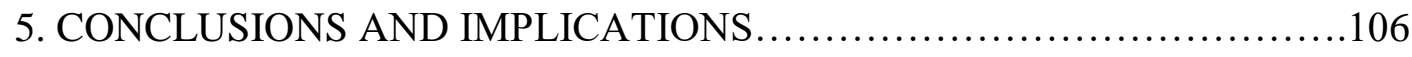

Overview of the Study............................................. 106

Discussion of the Research Findings............................... 108

Research Question One.......................................108

Research Question Two.......................................111 
Implications for Theory and Institutional Policy......................111

Implications for Student choice Model............................111

Implications for State Policy..................................113

Limitations of This Study and Implications for Future Research...........114

Conclusion....................................................... 116

REFERENCES ........................................................ 118

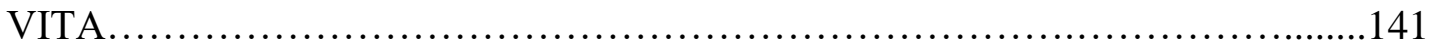




\section{LIST OF FIGURES}

Figure $\quad$ Page

1. Average Enrollment of First-Time students by Type of Institutions............75

2. Average Enrollment of First-Time students by Place of Enrollment.............76

3. Number of States with Exit Exams by Year and Type....................... 80

4. Geographical Distribution of State with Exit Exams as at $1996 \ldots \ldots \ldots \ldots \ldots \ldots . . . . . .11$

5. Geographical Distribution of State with Exit Exams as at 2006.................82

6. Geographical Distribution of State with Exit Exams as at 2016.................82

7. Early Adopters vs. Never Adopters................................. 86

8. Early Adopters vs. Late Adopters before Late Adopters become treated.........87

9. Late Adopters vs. Never Adopters..................................... 888 


\section{LIST OF TABLES}

Table

Page

1. Descriptive Statistics of Dependent Variable.............................. 77

2. States and the Years Exit Exams Policies went into Effect......................79

3. Descriptive Statistics of Variables of Control Variables.......................83

4. Relationship between Exit Exams and Adoption of 4 units of Maths.......... .90

5. Relationship between Exit Exams and Adoption of 3 units of Maths ...........90

6. Effects of Exit Exams on College Enrollment............................92

7. Effects of Exit Exams on 4-year and 2-year Institutions .......................94

8. Effects of Exit Exams on Instate and Out-of-State enrollment..................95

9. Effects of Different types of Exit Exams on Enrollment.......................97

10. Effects of Exit exams on College Enrollment with Dynamic model...............99

11. Effects based on Timing of Treated States................................102

12. Effects of exit exams using random Assignment of treatment.................. 104 


\title{
THE EFFECT OF EXIT EXAMS ON COLLEGE ENROLLMENT: A
}

\section{STATE LEVELS ANALYSIS}

\author{
Jude Kyoore
}

Dr. Bradley Curs, Dissertation Supervisor

\begin{abstract}
Efforts to better prepare students for college and workforce have always been a priority of state governments, and exit exams have been used as one of the tools to accomplish those goals. This study aims to examine the relationship between exit exams and college enrollment. By adopting student choice model as the theoretical framework to guide the research design, the study utilized information on first-time degree/certificate seeking students as the outcome variable from 1992-2016. With information on the implementation year of exit exams from the Center of Education Policy, the study employed quasi-experimental research design difference-in-differences. The results show that exit exams are positively related to enrollment in 4-year institutions only. When disaggregated by types, the study showed that end-of-course exams only have a positive and significant relationship with enrollment in 4-year institutions. However, the study indicated that there is no relationship between adopting exit exams and the number of students enrolling in out-of-state institutions. The findings of this study have important implications for the student choice model, policy-making, and future research.
\end{abstract}




\section{CHAPTER ONE: INTRODUCTION}

The lifetime earnings of individuals with a college degree continue to rise overtime (Ashenfelter \& Krueger, 1994; Baum, Ma \& Payea, 2013; Psacharopoulosa \& Patrinos, 2018). In 2015, bachelor's degree recipients working full time with no advanced degree had $67 \%$ higher median earnings than those with only a high school (Ma, Pender, $\&$ Welch, 2016). For the second quarter of 2018, the median weekly earnings of full-time workers aged 25 and above with only bachelor's degree increased by 13\% from 2013 as compared to only 9\% increase for those with only a high school diploma (Bureau of Labor Statistics, 2019). These differences do not only show that bachelor's degree holders earn higher than their counterparts with only a high school diploma, but that the gap between different educational credentials keep widening.

Beyond the economic benefits of higher education for individuals with college degrees, society also realizes gains through increased workforce productivity, reduced dependency on social programs, lower crime rates, higher civic engagement, and healthier society (Baum \& Payer, 2004; Baum, Ma \& Payea, 2013; Rouse, 1999). These social benefits provide basis for an ongoing effort at the federal, state, and local government levels to initiate policies aimed at increasing college access.

Despite the enormous benefits of obtaining college education to the individual and society, a report in 1983 titled "A nation at Risk" revealed that America's education foundation at the time was being eroded by sub-standard educational practices that ill prepared high school graduates to succeed in college and in the labor market. The report cited low academic standards as the cause of few students, especially those in urban schools, graduating from high school with less than sufficient competence for advanced academic pursuits and workforce success (The National Commission on Excellence in 
Education, 1983). Hence the National Commission on excellence in education recommended that "high school graduation requirements be strengthened to require 4 years of English, 3 years of mathematics, 3 years of science, 3 years of social studies and 1.5 years of computer science" (p 24). These became requirements for high school graduation and ushered in an era of exit exams as prominent policy in American educational history to promote rigorous high school curriculum.

Since 1983, states began raising their academic standards and high school graduation requirements to enhance the career or college readiness of all students (Long et al., 2012). Rigorous curriculum, not only positively influence the level of college readiness (e.g. Attewell \& Domina, 2008) but also has significant impact in college level outcomes including the type of program and performance in those programs (Altonji, 1995; Levine \& Zimmerman, 1990). By requiring students to take a specific math course or testing knowledge of high school content in Maths and English, exit exams was seen as a tool to ensure that all students were exposed to rigorous high school curriculum irrespective of their career or college plans. While all states believed that exposure to rigorous curriculum had significant positive effects on students' college enrollment, there was no consensus on the means to achieve that goal. Thus, the specific requirements that states began imposing on high school graduation differed greatly. Some states required that high school students pass end-of-course exams such as Algebra 1 and others required students to take and pass a set of standardized tests prior to graduation (Bishop \& Mane, 2001; Nomi, 2012). Each of these forms of exit exams was aimed to provide intellectually challenging course work that were not constrained by the students' background, ability, performance or future goals in life (Allensworth, Nomi, Montgomery, \& Lee, 2009; Gaertner, Kim, DesJardins, \& McClarty, 2013). By exposing 
all students within the state to similar rigorous contents, exit exams was seen as a policy to ensure that all students' career and academic skills were developed (Bishop \& Mane, 2001).

Over the next three decades, more than 20 states passed legislation imposing higher graduation requirements for high schools making college preparation courses the default for all high students (Gaetner et al., 2013). Within that period, exit exams which were tests that students had to take and or pass to graduate from high school begun to be used as implicit or explicit assessment of college readiness of high school graduates (Center of Education Policy, 2012). Exit exams comprised of comprehensive exams (i.e. Standard-Based and Minimum Competency) and end-of-course exams which primarily assessed knowledge in particular course such as algebra. Standard-based exams were aligned with content knowledge in high schools while minimum competency exams focused on content below high school level (Baker \& Lang, 2012). Based on the procedure for including states in this study, only 2 states required high school students to pass exit exams in 1992. By 2012, the number had increased to 23 states. Since 2012 however, the number of states that required high school students to pass exit exams started to decline. Only twelve states still required students to pass exit exams to graduate from high school in the 2016-17 academic year.

While exit exams across the country bore similar implementation procedures, there also existed significant differences on implementation. Almost all states provided opportunities for students to retake exit exams up to a certain number after the first attempt while still in high school and unlimited number of times to pass exit exams after the $12^{\text {th }}$ grade. The state of Rhode Island offered only two opportunities for students to retake before end of course work in high school while Oregon and Maryland gave 
students up till 12 times to attempt to pass exit exam while still in high school (Center of Education Policy, 2012). The subject tested primarily were Maths and English though science and social studies contents had been part of the comprehensive exams in Alabama, Georgia, Ohio, and Texas. In 12 states, students who had college entrance exams such as SAT and ACT could substitute it for exit exam requirement. All other students except English language learners were required to take and or pass exit exams to receive their diploma from high school. Few states such as California enacted laws that offered alternative path to students with disability. Beyond English language learners and students with disability, appeals and waivers were limited and hardly utilized often due to the lengthy and laborious process (Center of Education Policy, 2012).

\section{Problem Statement}

Amid recent discussions about the relevance of exit exams in preparing students to be college ready, some states that previously required high school students to pass exit exams were either in the process of redesigning or planning on new tests, delaying the implementation of new tests or had suspended their exit exams requirement (Hylop, 2014). In states such as California, Georgia, South Carolina, and Arizona, state officials had awarded thousands of diplomas retroactively to students who were denied a diploma due to unsuccessful completion of exit exams requirement since the year 2012 (Hyslop, 2014). In place of exit exams, some states have begun to participate in the Partnership for Assessment of Readiness for College and Careers (PARCC) while others have adopted SAT, ACT or a WorkKeys Assessment (Center of Education Policy, 2012). Yet, as at 2016, significant number of states still maintained exit exams as requirement for graduation. 
Despite the plethora of data collected and analyzed on the effect of exit exams on students' outcomes, less attention had been paid to the effect of exit exams on college enrollment at the aggregate state level. Thus far, the majority of studies on exit exams had been largely concentrated on the effect of exit exams on high school outcomes such as graduation and dropout rates (e.g. Bishop \& Mane, 2001; Catterall, 1989; Dee \& Jacob, 2006; McDill, Natriello, \& Pallas, 1986; Reardon \& Galindo, 2002; Warren \& Edwards, 2005). Overall, these studies found that exit exams increased dropout rate at high schools (e.g. Baker \& Lang, 2013; Dee \& Jacob, 2006; Hyslop, 2014).

On higher education outcomes, the current research has produced inconsistent results. While one strand of literature found that exit exams increase the achievement level of high school graduates which then translate into a higher proportion of high school graduates enrolling in college (e.g. Altonji, 1995; Attewell \& Domina, 2008; Bishop \& Mane, 1999; Chaney, Burgdorf, \& Atash, 1997; Geartner et al., 2013), other studies revealed that imposing additional requirement reduces the college going rate of all students (e.g. Bishop \& Mane, 2001; Clark \& See; 2014; Hylop, 2014). The third category of literature showed that exit exams had no noticeable effect on college enrollment (e.g. Caves \& Balestra, 2016; Chaney et al., 1997). Thus, based on the existing literature, there was no consensus on how exit exams affect college enrollment overall and at different type of sectors. At the same time, knowledge on the impact of different types of exit exams had been limited.

Students migration had long been studied and one of the predictors of the probability of enrolling in an out-of-state institution is the level of rigorous curriculum a student had been exposed to which is often reflected in high scores in college entrance exams and any standardized test (Kyung, 1996; Tuckman, 1970). When students take and 
pass advanced mathematics courses such as algebra II, it extends their pool of colleges to include out-of-state institutions (Kyung, 1996). With states such as Virginia and

Oklahoma whose end-of-course exams include passing of algebra II (Center of Education Policy 2012), then exit exams could potentially increase the pool of students who enroll in institutions in other states other than their own. Thus far, no study has specifically addressed the extent to which exit exams might impact out-of-state enrollment.

\section{Research Purpose and Research Questions}

The purpose of this study was to examine the effects of adoption of exit exams on college enrollment in the United States of America. The study was motivated by the dearth of research of exit exams on going to college. The existing research concentrated on pre-college outcomes and the few that attempted to measure post-secondary education outcomes relied on national sample data such as the National Education Longitudinal study of 1988 (NELS88) to predict the probability of enrollment based on whether the individual lives in a state that has a mandatory requirement for high school graduation or not (Baker \& Lang, 2013; Bishop \& Mane, 2001; Plunk, Tate, Bierut, \& Grucza, 2014). While these provided insight about exit exams from individual level analysis, they were limited in that the samples might have not be representative of the population. For those studies that were not individual level analysis, they often had limited scope such as one district or state (Allensworth et al., 2009; Iatarola \& Rubenstein, 2007; Teitelbaum, 2003). Thus, this study filled the gap by providing aggregate level analysis of exit exams across different states and with different adoption times on college enrollment. This study also used more recent data than previous studies, which made the results more meaningful to present times. Thus, the research questions were as follows: 
1. What was the relationship between state-level adoption of high school exit exams and postsecondary enrollment?

a. Did the adoption of exit exams have a differential relationship with enrollment at different postsecondary institutional types (i.e. 4-year and 2-year institutions)?

b. Did the adoption of exit exams have a differential relationship with instate and out-of-state postsecondary enrollment?

2. Was the relationship between exit exam adoption and enrollment different for different types of exit exams?

\section{Overview of Research Study}

This research attempted to provide understanding of the relationship between exit exams and college enrollment. More specifically, how did the adoption of exit exams affect the number of students who attend college. The need to evaluate the relationship between exit exams and college enrollment from statewide perspective was necessitated by the limited and inconclusive higher education research on the subject, as well as over reliance of K-12 outcomes as justification for recent trends in exit exams. This research provides another perspective for guidance for policy makers on decision making regarding exit exams. In order to effectively do that required understanding of how individuals make decisions regarding the length of time to put in education as well as understanding the basis for the method employed in this study. In the next section, I briefly describe the conceptual framework and method adopted to answer the research questions. 


\section{Conceptual Framework}

The study relied on the framework of Desjardins and Toutkoushian (2005) which underscores how individuals make decisions that maximize their utilities in a pool of different possible choices. The theory posits that students will choose the most attractive combinations of education and other goods from a set of options that will maximize their utility. This applies to both the initial decision to enroll, and the subsequent type of institution in which to enroll. According to this theory, the utility that an individual receives from attending college is a function of the financial factors associated with attending that particular college, the financial circumstances of the individual student, and non-financial student characteristics.

Exit exams primarily act through the non-financial student characteristics which can positively or negatively impact the overall decision to attend. Based on the conceptual framework proposed by Desjardins and Toutkoushian (2005), I identified three primary components of exit exams that are likely to alter the cost-benefit ratio associated with the college going decision. Holding other things constant, the theory suggests that the ultimate decision to enroll is based on relative values of the different weights associated with each component of exit exams.

Higher graduation requirements in the form of exit exams influence the level of college readiness through both increase in time of study and mastery of rigorous content which they otherwise would not have freely chosen (Lillard \& DeCiccca, 2001). As students become more college ready, their utility matches the utility of making a positive decision to enroll, and thus their probability of attending college increases (Desjardins \& Toutkoushian, 2005). At the same time, exit exams increase the indirect cost based on extra stress in passing difficult exams, and loss of potential income as a result of the need 
to spend time studying and not working. These two factors, according to the theory, reduces the utility of going to college which has a negative impact.

The net effect of exit exams on college enrollment based on the rational choice model can be positive or negative. When the impact of increase in college readiness resulting in a positive utility outweighs the negative utility associated with loss of wages and increase in stress, then the overall impact is positive, and the vice versa. The overall effect depends on the relative proportions of the different utilities on various components of exit exams. Thus, theory hypothesizes that the implementation of exit exams will have a positive impact on enrollment if it makes students more college ready and associated with higher utility (Desjardins \& Toutkoushian, 2005).

\section{Research Methodology}

This study employed a difference-in-differences identification strategy which utilizes the staggered implementation of exit exams across the country. It is a quasiexperimental method that uses observational data to determine the effect of a policy between treatment group and a comparison group (Angrist \& Pischke, 2009). The method allows the researcher to reduce the bias that could result from differences between control and treatment groups as well as bias associated with time trends (Shadish et al., 2009). The difference of pre-reform and post-reform enrollment in states that adopted exit exams policies is subtracted from the difference of pre-reform and post-reform enrollment in the states that didn't adopt exit exams. The difference-in-differences result could be interpreted as the estimation of the effect of the reform (Angrist \& Pischke, 2008; Meyer, 1995).

The traditional difference-in-differences approach often uses two time periods (i.e. before and after) and two groups (i.e. treatment and nontreatment) to determine the 
effect of a policy. With exit exams that had different times of adoption by each state, the study utilized staggered difference-in-differences proposed by Dynarski (2004) which takes into consideration the variation in timing of adoption. Thus, the use of staggered difference-in-differences procedure allowed states that adopted exit exams later to serve as control for those that adopted it earlier. This method allows any state to be both in the control and the treatment group at different times. I demonstrated the parallel trend assumption by exploring the different times of adoption between early adopters vs. never adopters, early adopters vs. late adopters before late adopters became part of treatment, and late adopters vs. never adopters. To ensure that the relationship between exit exams and college enrollment at the state level is accurate, I included the other factors that are likely to influence college enrollment based on the literature and conceptual framework. These factors mainly relate to cost of attendance and economic conditions.

I obtained information of exit exams status of each of the 50 states from Center for education policy (CEP) and Education Research data Sharing Initiative (ERDSI). Enrollment figures came from the NCES which contain information on first time enrollment and by state for every other year from 1992 to 2016.

\section{Significance of the Study}

The existing literature on the effect of exit exams on college enrollment is limited and inconsistent (Baker \& Lang, 2013; Bishop \& Mane, 2001; Plunk, Tate, Bierut, \& Grucza, 2014). Most of them rely on individual level analysis of national representative population (e.g. Bishop \& Mane, 2001) with little to no evidence of how exit exams affect enrollment at the aggregate state level. This research aimed to provide understanding of the effect of exit exams across the country using state level analysis. 
Secord, the educational landscape has changed significantly since the first exit exams policy was initiated and the data that were used to analyze outcomes in previous analysis dated back to the 1980s and 1990s. By using more current data, this research presented results that can be used for policy makers regarding higher education enrollment. The objective of the research is to add another perspective to the existing literature on the subject and to provide policy makers with additional viewpoints for consideration in proposing policy changes on exit exams.

\section{Contribution to the Literature}

The current knowledge of exit exams originates mainly from studies of outcomes

at K12. These often concentrate on high school dropout rate, and time to graduate, as well as the peer effect of exit exams (Bishop \& Mane, 2001; Long et al., 2012). The few studies that have attempted to study the effect of exit exams on college outcomes were limited in a number of ways.

Several of these studies performed cross-section individual level analysis data based on representative national longitudinal surveys such as National Education Longitudinal Study (NELS), Educational Longitudinal Survey (ELS), Current Population Surveys, and Public Use Microdata. For example, Bishop and Mane (2001) used NELS data to predict college enrollment for students who were in $8^{\text {th }}$ grade in 1988. A limitation of such studies is that they were unable to provide any valuable college level outcomes for any cohort of students except for that specific cohort considered. Secondly, these studies relied on data from the 1980s and 1990s (Bishop \& Mane, 2001; Warren et al., 2006; Lillard \& DeCiccca, 2001) which fail to account for recent changes in the educational landscape including but not limited to the implementation of No child left Behind (NCLB) and the increased popularity of end-of-course exams since the 2000s. 
Failure to capture such developments makes the results less valid to present contexts. Even when more recent data have been used to analyze the effect of exit exams (Baker \& Lang, 2013; Papay, Murnane \& Willett, 2010), they often rely on a single state analysis that only produces results limited to one state, and thus cannot be generalized. In this study, I provided information on the relationship between exit exams and college enrollment that are not limited to one state or one school district but to all states, thus making the results generalizable. By also using more recent data as compared to prior studies, the results of this study are more relevant to present time decision making process regarding higher education policy.

The few studies that analyzed outcomes relating to higher education (e.g. Bishop \& Mane, 1999) had solely used minimum competency exams, or unintentionally combined different types of exit exams which failed to properly identify the differences that exist among exit exams. Meanwhile, differences in outcomes exist when exams are separated by different types (Jacob \& Dee, 2006). This study explored not only the combined effect of exit exams on enrollment as prior studies have examined, but also evaluated the relationship between different types of exit exams and college enrollment.

\section{Contribution to the Policy}

The rapid increase in the number of exit exams from 1992-2012 coincided with an unprecedented increase in college enrollment. Between 1990 and 2013, a total of 17.5 million students representing an increase of $46 \%$ were enrolled in degree granting postsecondary institutions (National Center for Education Statistics, 2014). The increase was witnessed in all types of institutions, including community colleges. Within this period, policies regarding exit exams implementation underwent different changes with more states adopting more rigorous content as default standards for exit exams. From 2012, the 
landscape of exit exams began to shift towards complete elimination or at least not withholding students' diploma in the cases where they do not successfully pass the exit exams (Center for Education Policy, 2012).

This study provided empirical analyses that took into consideration these recent changes to allow policy to be made on the basis of well-defined and rigorous econometrical procedures. By the use of the statistical procedure outlined and differentiating exit exams by type, this study eliminated some of the limitations in earlier research, thereby presenting much more precise relationship between exit exams and college enrollment. With the use of more recent data in the analysis, this study also presented another piece of evidence of the effect of exit exams on college enrollment. On the basis of that, the evidence contained in this study allows states that were considering changes of their exit exams to see another perspective of such policy proposals.

\section{Summary}

In the last few decades, many industries that once required only high school education for entry level jobs now use college education as a minimum requirement (Crosby \& Moncarze, 2006). There is no indication that this trend is going to change in the future. As a result, states have increasingly been changing their requirement for high school graduation in order to ensure that high school graduates have what it takes to enroll and eventually graduate from college to take advantage of the changing trends in the market place. While so many states have been modifying their exit exams in recent times, the extent to which these changes impact college enrollment at the aggregate level are yet to be seen. This research aimed at understanding the relationship between exit exams and college enrollment. Not only did the evidence of this study extend the discussion on exit exams, but it served as resource for states who were in the process 
either adopting more rigorous exit exams or dropping exit exams altogether to gain another perspective.

This study was organized in five chapters. The first chapter provided a statement of the problem, the research purpose and research questions and overview of study. Chapter 2 explored key studies that are relevant to this study and a theoretical framework. Chapter 3 outlined the research design and methodology. Chapter 4 described the findings while chapter 5 summarized these findings, and gave recommendation with regard to policy. 


\section{CHAPTER TWO: LITERATURE REVIEW AND THEORITICAL \\ FRAMEWORK}

The need to improve college and career readiness of high school students upon graduation has driven federal, state, and local governments to adopt exit exams as one of the means to improve the standards and quality of education of students who graduate from high school (Levy \& Murnane, 2004). In this review, I explored the existing knowledge of exit exams and college choice from reports and published papers. I provided a comprehensive summary of available literature on the subject from a variety of sources with different set of approaches, data, time periods, and jurisdictions.

The first section described the chronological evolution of exit exams since the report of 1983, in order to provide a timeline context for exit exams as a policy. This section focused on the phases of exit exams at different times and the gradual and yet forceful involvement of federal government in the K-12 education in recent times. I emphasized greatly on No child Left behind (NCLB) given its scale as the greatest federal policy decision on K-12 in recent time (Fraser, 2014). The next section reviewed prominent studies that examined the effects of exit exams on high school, college, and career outcomes. This is followed by a description of the factors that impact college going decision and the various research findings that support each context. Finally, I

described the conceptual framework adopted in this study in order to explore the relationship between exit exams and college enrollment.

\section{Evolution of Exit Exams Policies and the Role of Government}

Public education has gone through different modes of operation, evaluation and supervision ever since the colonial era. Exit exams as mainstream educational policy started in the late 1970s with the state of New York as a pioneer in setting minimum 
standards for high school graduation (Jacob, 2001). Despite the differences in the form, type, and requirements, all exit exams were adopted to ensure that students obtain the necessary competence at high school in order to increase college and career readiness of all students (Bishop \& Mane, 2001). With enactment of laws to impose higher graduation requirement for high school graduation, legislators also began to consider who should be held accountable if students in particular schools consistently do not meet the minimum threshold as required by law to graduate. As exit exams began to spread across states, school accountability gained prominence in the American PK-12 (Figlio \& Loeb, 2011). I described various key reforms in recent decades that sought to improve and increase college readiness of students.

\section{Educational Reforms in the 1980s and 1990s}

Prior to the 1980s, few states had any formal requirement of courses that students needed to complete in order to graduate from college (Bishop \& Mane, 2000). The 1980s was a defining moment in American education history that set the pace for most of the later reforms and current reforms governing the nature and state of PK 12 education (Fraser, 2014). Prior to the 1980s, educational polices hinged primarily on practices regarding whether all students needed to be exposed to the same content, or whether they should have different tracks based on their goals. Up until the 1980s, US education was believed to be the best within all industrial economies. The report of the nation at risk brought national attention to the need for reform of the K-12 educational sector after it revealed lower performance of US high school students as compared to their peers from other developed countries. The report by the National Commission on Excellence (1983) cited lower standards for the poor performance of US high school students and revealed 
that US high school graduates were inadequately prepared to meet the demands of the labor market. It read in part:

We report to the American people while we can take justifiable pride in what our schools and colleges have historically accomplished and contributed to the United States and wellbeing of its people, the educational foundation of our society is presently being eroded by a rising tide of mediocrity that threatens our future as a nation and a people. What was unimaginable a generation ago has begun to occurothers are matching and surpassing our educational attainments (National Commission on Excellence, 1983, p. 58).

The report lamented the poor state of education in America, with President Reagan noting that there are only few areas in American life as important as education of kids (Fraser, 2014). The National Commission on excellence in education (1983) recommended that 'high school graduation requirements be strengthened to require 4 years of English, 3 years of mathematics, 3 years of science, 3 years of social studies and 1.5 years of computer science' (p. 24). These were seen as necessary to stop and reclaim American leadership in education. These metrics have since developed in different shapes and forms and provided the basis for exit exams since then. The early forms of exit exams comprised of a measure of basic skill knowledge of content material from k-9. To measure whether students had gained knowledge from the recommended material, testing began to emerge partly as an external accountability measure of students' knowledge (Lee, 2017; Perna \& Thomas, 2007).

The hype about using testing to ensure that students have the required knowledge continued well into the 1990s with increase in the number of states which had developed some evaluation metrics. Even with so many changes, Goal 2000 which bore similar 
justification as 'the nation at risk' report was adopted by congress in response to the relatively poor academic performance in math and science of students in the US as compared to other students in developed countries (Fraser, 2014). It intended to ensure that all students attained their maximum potential by using world class standards to measure students' progress and provide remediation when needed. The law established targets on student graduation, academic performance, and left the decision on how to attain such goals to states and local districts. About 400 billion was set aside to support states that have adopted policies and programs targeted at obtaining these goals as a way of motivation (Lee, 2017).

\section{The Era of No child Left Behind (NCLB) Act of 2001}

This act has been considered as one of the greatest involvements of state and Federal government in the control over curriculum and instructional issues in the US public K-12 education in the last 40 years (Dee \& Jacob, 2011). It served as the basis for high stake testing and the unprecedented use of exit exams to satisfy state and federal requirement in an era of accountability (Clark \& See, 2011). Its objective was to increase student proficiency in reading and mathematics across all states, and closing extant academic achievement gaps between identifiable subgroups of US students (Lee \& Reeves, 2012). NCLB was therefore to ensure that "all children will have a fair, equal, and significant opportunity to receive a high-quality education and reach, at a minimum, proficiency on challenging state academic achievement standards and state assessments" (Hursh, 2007, p 8). Advocates of standards and robust accountability systems as contained in the law of NCLB insist that any program to close the achievement gap should ensure that all students are held to uniformly high-performance standards (Reed, 
2009). As a result, most states in 2004 used their existing exit exams policies to satisfy the requirement for high school graduation.

The Grand theory of Action of NCLB is made up of three conceptual components, namely standards, assessment, and stakes (Peterson \& West, 2003). Standards provide the basis for measuring progress by setting objective and clearly defined expectations for all schools to ensure that all students are held to a uniform and high-performance expectation (Cawthon 2007; Reed, 2009). Under NCLB, every state, with the approval of the federal Department of Education, determines for every test, in what knowledge and skills students need to demonstrate proficiency (Hursh, 2007). It relies on high-stakes testing of students to ensure that schools make Adequate Yearly Progress (AYP) toward the goal of $100 \%$ student proficiency in these subjects by 2014 (Lee \& Reeves, 2012). Assessment is used to measure a school's effectiveness in teaching students standardbased material (Linn, 2010). This measure of effectiveness is based on the test scores of students in core areas of reading and mathematics under NCLB.

\section{The Common Core Standards}

The traits of testing embedded in exit exams continued into the Obama era following the adoption of Common Core State standards in English and Mathematics. Like previous policy initiatives, the common core standards were developed to address American perceived lower academic standards in the developed economies (Nomi \& Allensworth, 2013). The policy makers recommended creating common educational standards and increasing the rigor to prepare all students for college and career opportunities. Prior to common core, there was diversity of standards across state lines which Councils of Chief state school officers and National Governors Association thought was impeding educational quality in the country. The justification for common 
core standards included creating common educational standards, preparing students for college (or careers), stressing quality education for all students, and increasing rigor in schools. Standards and rigor have since gained national attention. The new standards with associated test was endorsed by the then government which initiated race to the top, a federal policy in 2009 , to provide extra education funding and relief to states who according to it, have demonstrated true measurable outcomes (Fraser, 2014).

\section{Research on the Relationship of Exit Exams and Student Outcomes}

As state policies regarding exit exams continue to evolve amidst uncertainty about the future of exit exams in American educational policy, it remains a considerable policy that affects high school students across the country (Center for Education Policy, 2012). American educational landscape will always have some semblance of exit exams as a means to better prepare students for college and career. According to McDill, Nariello and Pallas (1986), "raising standards leads students to work somehow harder, at least when standards are originally quite low and that greater student effort will lead to somewhat higher student achievement" (p. 146). On the other hand, imposing higher graduation requirements has a negative effect on graduation rate of average students (Baker \& Lang, 2013; Bishop \& Mane, 2001; Dee \& Jacob, 2006). Outcomes associated with exit exam have been in the frontline since the first exit exams were introduced in 1979. For this section, I described the literature regarding the effects of exit exams on high school outcomes, college outcomes, and labor wage outcomes.

\section{High school level outcomes}

The issue of dropout has always been a topical issue given its social, academic, and educational implications particularly with regards to students at risk (Hoffer, 1997; Geartner et al., 2013). As states began to adopt exit exams since the report of nation at 
risk became public, researchers began to investigate the extent to which imposing additional requirements affected students' ability to graduate. The evidence thus far on the effect of exit exams on dropout come from a variety of data and research methodologies.

An overwhelming amount of research has found that exit exams increase the dropout rate of vulnerable students irrespective of the unit of analysis and statistical methodology employed (Görlitz \& Gravert, 2016; Iatarola, \& Rubenstein, 2007; Long e tal., 2012). These are generally average students and students from a lower socioeconomic status. Bishop and Mane (2001) found below average students were more likely not to graduate from high school following the adoption of exit exams. Similarly, Reardon (1996) and Reardon and Galindo (2002) found that large urban schools with high concentration of low-income students with exit exams showed evidence of sharp dropouts when the state imposed additional requirements for graduation. Jacob (2001) utilized state level aggregation across different states with and without exit exams and found evidence to support the notion that at-risk students are disproportionally affected by exit exams. When students fail the test the first time, they often consider the effort needed to pass the exams too high, and that negatively impacts their academic aspirations (Costrell, 1994; McDill, Natriello, \& Pallas, 1996).

Unlike previous studies that did not discriminate between different types of exit exams and the degree of difficulty, Dee and Jacob (2006) recognized that the content of the exit exams may have significant effect on the academic outcomes. Employing logistic regressions, the study concluded that exit exams that test high school material was associated with higher rates of dropout than similar tests that are aligned to middle school content. Similarly, Hemelt and Marcotte (2013) isolated the different types of exit exams 
based on materials tested, and focused more on standard-based exams and end-of-course exams to determine their effect on school dropout. As with the previous findings, the study found that exit exams increased dropout the more difficult the material tested was. Baker and Lang (2013) also explored the stepwise adoption process of exit exams across the country to determine the effect of different types of exit exams on dropout. It concluded that exit exams that test understanding of high school material had a negative effect on graduation, while less rigorous ones did not have any effect. Despite the contribution of this study in terms of the rigor of the method, it made a strong assumption based on the limitation of the data that the current residence of the students is where they attended high school. Yet based on recent literature, there is evidence that students' migration in recent times is a huge (Mat \& Moncur, 2003; Zhang, 2007) and this could ultimately have altered the results.

Warren and Edwards (2005) found contrary results that exit exams increased the probability of dropout for low achieving ability. This study concluded that exit exams is not associated with dropout rate even for students from low economic status or low performing or low achieving rate. Lillard and DeCiccca (2001) similarly used NELS data as well as aggregate data from US census population but adopted quite a different approach from previous work. In spite of the variation in different populations and students' ability, their results show no relationship between exit exams and dropout rate.

Most of the research on exit exams concentrates on the role it plays in increasing dropout rate. The literature thus far has provided evidence of negative impact of exit exams on high school graduation. Though few studies did not find evidence of this, the general consensus is that exit exams increase dropouts. 


\section{College level outcomes}

A limited yet growing number of research studies have examined the role exit exams and high school graduation requirement in general have played on influencing college outcomes. Imposing higher requirements is seen as means to prepare graduates for college (Hubert, 2000; Long el al., 2012; Reardon, 1996). Adelman (1999) cites that rigorous curriculum is the single most important determinant of college attendance. Among all subjects, math courses have been the most targeted measure of rigor of curriculum (Cortes, Joshua \& Nomi, 2015). This section described the effect of course curriculum and exit exams in particular on college outcomes.

\section{Enrollment in Any Institution of Higher Education}

Earlier research to understand the impact of rigorous course content was based on analysis of the number of years in schooling based on different course curriculum of students. Altonji (1995) was a seminal research that attempted directly to link course curriculum to college level outcome. The study measured rigor of curriculum based on the curriculum of an average student in a particular high school, using data from the National Longitudinal Survey of Youth (NLSY72). Thus, the completion of courses of a typical high school student was used as an instrument to measure the rigor of course curriculum across schools. The study found that an extra year of rigorous curriculum was associated with an increase of 0.37 in years of schooling. The results, though modest, were consistent using both OLS and instrumental variable approaches. By using the school level analysis, the study failed to account for the individual family characteristics that drive the course taking patterns of most students (Cabrera \& La Nasa, 2001).

Levine and Zimmerman (1990) also adopted instrumental variable approach but in addition to the NLSY72, also analyzed the data using High School and Beyond 1980 
cohort. Rather than using the average curriculum of a student in high school, the study used the number of math classes in order to determine the rigor of high school curriculum. Levine and Zimmerman (1995) found that rigorous curriculum increases the probability of attending higher education, which translates into higher future wages. The use of number of math classes as opposed to the sequence and difficulty level of particular classes does not truly measure rigor of curriculum. The use of this instrument designated a student as having taken rigorous curriculum who repeatedly took a failed course and wrongly classified a smart student who took only one high advanced course as having less rigorous curriculum. Rather than using the number of math courses to measure rigor of curriculum, Bets and Rose (2004) adopted a similar approach but used specific math courses rather than a number of math classes to determine the rigor of the curriculum. The results indicated an increase in the probability of enrolling in college following the implementation of rigorous curriculum. Bishop and Mane (1999) studied the effect of Minimum competency exams in predicting probability of attending college, using the High School and Beyond (HSB). By controlling for individual student characteristics and school characteristics, the study found significant results that attending school in a state with exit exams positively increases the probability of attending college. One advantage of this study is that it was able to differentiate specific math courses (i.e. algebra II) which represents a better measure of rigor than using the number of math classes.

A common trend in the earlier research on this subject was that they relied on representative national sample surveys that explicitly didn't measure the effectiveness of a particular intervention. By the use of that dataset, these studies all sought to understand the implications of taking what was considered a rigorous curriculum. More resent papers 
attempted to explore the exogenous policy changes. Clofelter, Hemelt, and Ladd (2019) analyzed the effect of North Carolina adopting end-of-course exams on college enrollment. The study found that enrollment rose about 15 percent following a state-wide law that required students to take and pass algebra to receive their high school diploma. Similarly, Long, Conger and Iatarola (2011) studied the impact of Florida exit exams on college enrollment and found that exit exams do have a positive impact.

\section{Type of Exit Exams and Enrollment by Sector}

While most research has performed aggregate analysis of exit exams and course curriculum in general, a little has extended the scope to determine the differences in enrollment based on the types of exit exams. Chang et al. (2005) found evidence that the more rigorous a particular exit exam, the higher the probability of increasing college enrollment. For example, exit exams that required courses such as algebra II had a greater effect than courses that required basic mathematics. The study found that higher sequence of math and science closely predicts college attendance more than any other combination of course sequence even after controlling for SAT test. At the same time, a more rigorous curriculum diverts students from attending 2-year institutions to 4-year institutions. Advance courses in mathematics especially divert students from 2-year institution to 4-year institutions (Clofelter et al., 2019). Similarly, students who take advanced math course are $17 \%$ more likely to attend college and $20 \%$ more likely to choose a 4-year institution than a 2-year institution (Aughinbag, 2012).

Not all studies found a positive relationship between exit exams and college enrollment. Those who argue against this projection of positive effect of exit exams state that the increase in proportion of high school students who attend college is a direct result of increasing the number of students who dropout rather than actual increase in those 
attending college. Bishop and Mane (2001) found that exit exams significantly decrease the number of students enrolling in college, using individual level data. The effect was even greater for students from lower income backgrounds and for minority students. Chaney et al. (1997) found no effect of exit exams on college enrollment. The study argues that students' behavior is not affected in anyway by the presence of exit exams as it relates to college enrollment. Similar conclusions were reached in Florida that imposing exit exams had no noticeable effect on college enrollment (Clark \& See 2011). As Allenworth et al. (2009) noted, exit exams exacerbates the achievement gaps between students from different socio-economic status.

\section{Exit Exams and Students Migration}

The direct link between exit exams and students' migration has not been explicitly explored in the literature. Most of the studies on student migration have examined the push and pull factors of out-of-state enrollment (Alm \& Winters, 2009; Morgan, 1983; Noorbakhsh \& Culp 2002; Tuckman, 1970). Few studies have explored and compared the characteristics of students who attend instate and out-of-state institutions. Fenske, Scott and Carmody (1972) studied the characteristics of students who attend out-of-state institutions. The study found that students who attend out-of-state institutions are generally more academically talented, come from high income families and have higher aspirations. Similarly, Ferriss (1973) also found that students who attend out-of-state institutions have higher average ACT composite scores than their counterparts who attend instate institutions. Kyung (1996) examined the in-migration students to the state of New York and found that their academic ability was the most important significant factor in their decision to enroll in a higher education institution in New York. As noted by Bishop and Mane (2001) and Caves and Balestra (2016), requirement for exit exams 
do not affect the behaviors of talented students who will attend college anyway. Exit exams have the greatest impact on low to average students who are more likely to attend in-state institutions (Caves \& Balestra, 2016). By inference, enrollment in out-state institutions is not impacted by the implementation of exit exams.

\section{Labor Market Outcomes}

A rigorous standard develops students' soft skills that increase their earning potentials in the labor market (Long et al., 2012). Students who undertake high rigorous curriculum are expected to earn more in later years than their counterparts who took a less rigorous curriculum. This hypothesis has been tested using different units of analyses, dataset, and methodology and the results consistently show that high rigorous curriculum has positive effects on wages and earnings (Altonji, 1995; Levine \& Zimmerman, 1995; Attewell \& Domina, 2008). Additional math courses more than any other subject have the greatest positive impact on the wages of female college graduates and increases the probability that women college graduates will enter into technical fields (Levine \& Zimmerman, 1995). On the contrary, Geartner et al. (2013) found no significant wage effect of taking rigorous curriculum on those who went straight into the work force from high school. For college graduates, the effect was found to be highly significant. Thus, the effect of exit exams on labor market outcomes is at best modest.

\section{College Enrollment Decisions}

College enrollment decision is made up of a complex set of conditions that are intertwined and yet have different degrees of influence on different groups of people based on social, economic, and cultural dynamics (Heller, 1997; Hossler, Braxton \& Coopersmith, 1989). Perna (2006) developed a conceptual model that integrates the constructs of both economic and sociological models to establish a comprehensive 
understanding of how students make choices about college. This integrated model recognizes the influences of various levels of contexts, and how they shape the college decision making of individuals. Perna (2006) summarized these layers into four interrelated categories: habitus, school and community context, higher education context and social, economic, and policy context. In the rest of this section, I discussed the various layers and relevant research studies within each context.

\section{Individual Habitus}

The habitus emphasizes the role of individuals' demographic, cultural and social capital in influencing college enrollment decisions. Habitus encompasses household characteristics such as parents' educational status, income level, social standing, and educational aspiration which reflects the cultural and social capital of any individual student (Perna 2006). With different resources manifested in differences in knowledge about college application process, value of college education, students' college choice varies with low SES attending college in lower proportions than people from high SES (Cabrera \& La Nasa, 2001; Wells \& Crain, 1994).

The decision to attend college is affected by students' and their families' economic status. College attendance imposes significant financial burden on individuals despite significant investment in financial aid over the years (The College Board, 2004). The individual habitus context suggests that college choice and access are stratified by SES status and race/ethnicity (Perna, 2006). Significant evidence supports the findings

that students from lower income backgrounds, African Americans and Hispanics are less likely to enroll in college as compared to white students and students from high SES backgrounds (Baum \& Payea, 2004; Heller 1997). Due to the relatively higher cost of 
attendance based on institutional type, minority students are more likely to enroll in community colleges as opposed to highly selected 4-year institutions (Heller, 1997).

Students from certain backgrounds tend to develop educational aspirations early on and consistently have been associated with positive educational outcomes (Cabrera \& LaNasa, 2001; Heller, 1999). Lee (2001) found that students' educational attainment is significantly affected by their immediate social and cultural norms. For example, students from Asian background tend to have higher college enrollment rates over blacks and Hispanics partly due to cultural differences in the value of education among different race (Heller, 1997). In Asian culture, there is expectation of upward academic mobility, emphasis on parental sacrifices and the need to fulfill academic achievement, respect for authority, and family comparison in terms of academic success (Lee, 2001). As cultural traits and social capital accumulate, they tend to reproduce themselves over a period of time (Bourdieu, 1975). Differences in enrollment patterns in college disappear after controlling for social and cultural capital (Perna, 2006).

The level of academic preparation of an individual has positively been associated with decision on college choice and access (Adelman, 1999). With high level of academic preparation resulting from taking rigorous college preparatory courses, the probability of enrolling in college is very high (Attewell \& Domina, 2008; Long, 2008; Long et al., 2012; Wang, 2013). Adelman (1999) finds evidence that the level of exposure to rigorous math curriculum is the single most accurate predictor of college choice. The level of academic preparation of a student by the time they are in 12 th grade increases the probability that they will put more value to college degree than will be the case otherwise (Lee, 1993; Muller, 1993; Zick, Bryant, \& Osterbacka, 2001). 
Parental encouragement and support have similarly been found to positively promote college enrollment decisions (Cabrera \& La Nasa, 2000; Horn, 1998; Hossler, Schmit, \& Vesper,1999; Perna, 2000; Gandara, 1995, Ovando, 1997). Research has found evidence that the level of parental encouragement is positively associated with the level of education of parents (Hossler \& Stage, 1992). Parents with higher education levels are more likely to encourage their children to pursue higher education on their own (Sharp,

Johnson, Kurotsuchi, \& Waltman, 1996). Additionally, parents with college degrees are able to provide and guide their children with information regarding how to acquire college education (Hossler, Braxton \& Coopersmith, 1989). However, evidence also shows that parents who themselves have not achieved higher levels of education do not necessarily translate into lower support for their children to pursue higher education (Ceja, 2004; Delgado-Gaitan, 1992; Perez, 1999). In fact, several studies have found that despite low SES status of parents, parents have provided support and encouragement to their children to hold educational aspiration high (Alva, 1995; Gandara, 1992; Vesper 1997).

\section{School and Community Context}

The second level of factors that influence college enrollment are high school and community factors. School factors primarily are quality measures which include but are not limited to quality of teachers, resources availability, advising opportunities and courses offered whereas the community context usually indicate the SES status of surrounding environment from which students attend schools (Perna, 2006). School and community context emphasize the role of social structures and level of resources in the community that either facilitate college going aspirations among high school students or negatively affect college choice (McDonough, 1997). 
Availability of resources is a reflection of the SES of families who live around the school (Lee \& Ekstrom, 1987). Neighborhoods with high SES are often associated with abundance of quality teachers, well-resourced libraries and science laboratories, lower teacher-student ratio, and lower counselor to student ratio (McDonough, 1997). The availability of such resources increases the probability that a student has a higher probability of being exposed to rigorous academic curriculum that will increase the level of academic preparation. Adelman (1999) suggests that students who are exposed to rigorous curriculum partly due to the environment are more likely to enroll in college. On the other hand, schools in low SES school communities usually face tremendous constraints in providing the appropriate guidance and counselling to students (Perna, 2006). Even when the appropriate resource personnel such as school counselors are available, they are particularly over stretched in low SES schools and typically engage in other activities rather than providing specific college information to students about college opportunities (McDonough, 1997; Perna, Rowan-Kenyon, Thomas, Bell, Anderson \& Li, 2008).

Within the school and community context is the influence of peers in forming academic aspirations (Alwin \& Otto, 1977). Research found evidence of the positive role peers play to influence each other about college (Alexander, Eckland, \& Griffin, 1975; Alwin \& Otto, 1977; Nolfi et al., 1987). Through associations, students are able to consciously and unconsciously influence each other's educational outcomes through group events, common project work, educational projects, and completing homework together (Pascarella \& Terenzini, 1991). Influence of peers sometimes is greater than the role parents' support can create (Steiberg, 1996). 


\section{Higher Education Context}

This layer focuses on the role higher education institutions play in influencing students' college enrollment decisions (Perna, 2006). It describes the conventional college level factors and institutional characteristics that positively or negatively impact students' college decision. These primarily involve the techniques of marketing and recruiting that institutions adopt, policies regarding cost of attendance, and the general institutional characteristics (Perna, 2006; McDonough, 1997).

For some students, higher education institutions are themselves the primary source of information to high school students regarding college choice (Reynold, 2007). All institutions have some kinds of initiatives and traditions of reaching out to local high schools using different mediums to promote their programs to potential college students and their families (Carol, 2017). Institutional recruitment processes have a direct correlation with students' college choice (Reynold, 2007). As such, institutions continuously revise their on-campus marketing strategies including campus tour and outreach programs to better serve to favorably influence college choice of potential students (Reynoles, 2007). Vigorous marketing strategies are associated with increase awareness and high probability of enrolment at an institution.

Higher education institutions influence college choice through policies relating to cost of attendance primarily through tuition and financial aid. As a normal good, the demand for higher education is negatively related to the price all things being equal. As the tuition rises, individuals are more likely to demand less of higher education which will reflect in a negative choice for higher education (Heller, 1997). Existing literature has consistently demonstrated the negative relationship between tuition and students ability to enroll (e.g. Baryla \& Dotterweich, 2006; Curs \& Singell, 2002; Heller, 1997; 
Jackson, 1978; Leslie \& Brinkman, 1987; Zhang, 2007). This is consistent across

individual level analysis (Perna, 2000) aggregate institutional level (Leslie \& Brinkman, 1987; Heller, 1997) or aggregate state level (Morgan, 1983; Mixon, 1983; Zhang, 2007) or national level analysis (Rouse, 1999; Perna, 2000; Zhang \& Ness, 2010).

The cost of attendance is mitigated by the presence of institutional financial aid. Institution ability to offer financial aid reduces the out of pocket payment and positively influences students' decision to enroll (Heller, 1997). Many studies have found evidence of a positive relationship between financial aid and the decision to enroll (Heller, 2017). Few other studies have found that enrollment decision of people at the lower end of the income chain is not so much affected by the availability of financial aid (Hansen 1983; Leslie \& Brinkman, 1988). One of the reasons cited for financial aid being seemingly ineffective was that information on financial aid awards are usually not available at the time students make the decision on whether to attend or not (Leslie \& Brinkman, 1988). Heller (1997) argued that earlier studies failed to disaggregate different types of financial aid, and therefore the results may not reveal their individual impacts. Among the different types of financial aid namely loans, tuition remission, work study, grants seem to be the most important one in affecting students' behavior (Heller, 1997).

When institutional characteristics match with student preferences, then the student is more likely to make a positive decision to enroll. Research has found a relationship between quality of instructional programs, campus climate, quality of faculty, instructional ranking, nature of athletic programs, institutional type, and students' choice to enroll (Austin, 1988; Baker, Creedy, \& Johnson, 1996; Pyvis \& Chapman, 2007). When an institution is perceived as of high quality, there is a strong positive relationship to enrollment decision (Baryla \& Dotterweich, 2006). 


\section{Social, Economic and Policy Context}

This layer focuses on the role that public policy, and economic and social factors, play directly or indirectly on students' choice about higher education. It examines the extent to which changes in the economic and social environments impacts on whether students will decide to enroll or not to enroll. Some of the changes are introduced by government agencies for some desired outcomes while others are unintentional consequences of economic conditions. This layer delves primarily into the role of the state in changing cost of attendance, and the state of the general economy.

Direct appropriations to institutions of higher education in each state determine in part tuition charges and financial aid availability but may have their own differential effect on enrollment (Perna \& Titus, 2004). Institutions of higher education respond to recent reduction of state appropriations by increasing tuition and reducing financial aid packages (Ehrenberg, 2006). The consequences of these development is an inability of students from low income status to enroll in higher education (Lyall \& Sell, 2006).

Overwhelming number of studies support the notion that increase instate appropriations reduces the financial burden of institutions, and expands their ability to increase access (Kane, Orzag \& Gunter, 2003; McLendon, Hearn \& Mokher, 2009; Wearts \& Ronca, 2006).

State financial aid laws often have a direct effect on cost of attendance, which ultimately affects whether students will choose to attend college or not (Kane, 2003). State ability to offer significant financial aid particularly to students increases the level of interest to participate in college (Cornwell \& Mustard, 2004). Since Georgia HOPE was adopted, over a dozen more states have developed similar programs to increase in state enrollment. There is significant evidence that these programs have positively increased 
college choices (Andrews, Desjardins \& Ranchhod, 2009; Cornwell \& Mustard, 2002; Cornwell \& Mustard, 2004; Dynarski, 2002 2004; Abraham \& Clark, 2006; St. John, et al., 2004). Existing research suggests that an increase in enrollment occurred as a result of the aid reducing the potential burden of cost of attending college and thereby positively changing the enrollment decision of those who would otherwise not enroll (Cornwell \& Mustard, 2002; Dynarski, 2004; Kane, 2003). Few studies have found that the jump in enrollment is due to the decrease in the number of students who traditionally would enroll in out-of- state and less of the impact of whether or not to attend (Cornwell et al., 2006).

The fiscal health of the state measured by unemployment and per capita income have also been found to affect enrollment in higher education. Abundant research supports the notion that weak labor market conditions encourage people to upgrade their skills through more schooling, resulting in increases the demand for college education. Increase in unemployment rate decreases the opportunity cost of enrollment (Gaertner et al., 2013; Kane, 1995). Few studies have on the contrary found evidence that suggests that weak economic conditions cause students to prefer work to schooling in order to support their families (e.g. Rumberger, 1987). Specific to community college enrollment, the unemployment rate affects enrollment differently, based on whether they run academic programs or occupational programs. In times of harsh economic conditions, enrollments are increased significantly in occupation-based programs (Nutting, 2008). Similar to unemployment, research has also consistently found that states with higher per capita income record higher enrollment than their counterparts (Cornwell, Mustard, \& Sridhar, 2009). As education is a normal good, an increase in income will increase its demand, which leads to higher enrollment (Heller, 1997). 


\section{Conceptual Framework}

The purpose of this study was to determine whether college enrollment is related to the adoption of exit exams across the country. To understand the effect of adopting exit exams on college enrollment requires examining how individuals make decisions regarding the amount of education to pursue. This study relied on the student choice model proposed by DesJardins and Toutkoushian (2005) which posits that students will choose the most attractive combinations of education and other goods from a set of options that will maximize their utility. According to economic theory, utility is defined as the amount of satisfaction that an individual will derive from consuming a set of goods and services. Utility inherently involves making choice including decision on whether or not to attend college, and type of college to attend based on subjective satisfaction the individual expects to derive (DesJardins \& Toutkoushian, 2005). The student choice model inherently includes traits of human capital framework (Becker, 1975) which has traditionally been used as basis for understanding the amount and level of education an individual will seek.

Human capital are skills and attributes that are either endowed at birth or acquired through education and training which increase the productivity of an individual at the work place (Becker, 1975). Higher levels of education are associated with higher productivity, higher earnings and low unemployment which raises the benefits of pursuing additional education (Baum, Ma \& Payea, 2013). The human capital postulates that an individual will evaluate the direct costs (net tuition) and indirect costs (forgone earnings) that they will incur going to college, and compare this to the expected financial benefits in terms of higher earnings in the future (Becker, 1975; Schultz, 1961). When the utility from the expected benefits outweigh the cost, the student makes a positive decision 
to acquire more education (Schultz, 1961). Similarly, the model predicts that in selecting the type of college to enroll, individuals will weigh the expected benefits and cost associated with attending each institution and choose the one with the maximum net benefit utility. Human capital theory provides the framework to understand students' choices and predicts students' behavior. It assumes that rational individuals have full knowledge of the present value of future stream and perfect knowledge of the true cost of attending college in order to evaluate the net benefit which is affected by factors such as tuition and financial aid. However, research has demonstrated that students may not have full knowledge of the cost of education and forgone income that they would have earned if they participated in the labor force rather than obtaining more education (Kane, 1999). By only focusing on the tangible items such as tuition, financial aid and other measurable economic factors, the human capital model is limited in its scope to accurately describe student choices.

DesJardins and Toutkoushian (2005) choice model extends the human capital model to include non-tangible and non-economic cost and benefits used in deciding whether to attend college. It expands the input collection beyond the economic factors in determining students' college decision. Based on the concept of utility, it argues that individuals may not choose to attend college even though they expect on an average to benefit more financially due to preferences for different types of work other than the ones compatible with college degrees. For those individuals, going to college will result in a lower utility and worse level of wellbeing (DesJardins \& Toutkoushian, 2005). The theory also suggests that individuals who follow certain family traditions and gain higher utility in certain occupation types handed over from generation to generation may not require any college education degree to be happy. These and other cases illustrate the 
extent to which college decision making process extends beyond tangible and measurable economic factors.

DesJardins and Toutkoushian (2005) recognize the role of utility and personal preferences that influence initial decision to attend college and subsequent decision about which type of college to attend in their model by including non-financial individual characteristics and preferences. They argue that students' college going decision should include both the measurable and non-measurable factors. This has been espoused by the college choice model developed by Perna (2006) which highlights the role of individual habitus in the college going decision. The habitus include both financial and measurable characteristics such as family income, race and ethnicity, gender as well as the nonmeasurable elements of the family namely parental encouragement and support, aspirations, and mentorship. The college going process is nonlinear interplay of these family characteristics that positively or negatively influence the decision to enroll (Perna, 2006).

According to DesJardins and Toutkoushian (2005), the utility that an individual receives from attending college is a function of the financial factors associated with attending that particular college, the financial circumstances of the individual student and non-financial student characteristics that may influence the monetary returns. This is expressed as follows:

$$
U(\text { college })_{i j}=U\left(F_{j}, F_{i}, S_{i}\right)
$$

Where $U(\text { college })_{i j}=$ the utility that individual i receives from attending college $\mathrm{j} ; \mathrm{Fj}$ measure the direct financial cost in attending institution $\mathrm{j}$ which include tuition, scholarships, fees, room and board, Fi represent the financial factors associated with the 
student $\mathrm{i}$ and $\mathrm{S}_{\mathrm{i}}$ represents the non-financial student characteristics that influence their decision to attend a particular college.

On the basis of rationality assumption which is the expectation that individuals will always choose from a series of choices that will maximize their utility, the model also predicts that the students will choose that combination of schooling that gives them the greatest satisfaction. The choice of the student reveals their preferences in that if $U_{i 1}$ $>U_{i 0}$, where $U_{i 1}$ is attending college and $U_{i 0}$ is not attending college, then student $\mathrm{i}$ values college more important than the alternative of not going to college. Similarly, if $U_{i 0}$ denotes alternative collect choice such as attending a 2-year college and $U_{i 1}$ denotes the utility of attending a 4-year institution, then $U_{i 1}>U_{i 0}$, reveals that the individual perceives greater utility by attending a 4-year institution than by attending a 2-year institution. Thus, utility is maximized by attending a particular college that gives the highest utility as compared to the utility obtained from an attending alternative college or not going to college at all. This is represented as $U_{i j}>U_{i k}$, which means that the utility for attending college $\mathrm{j}$ is greater than alternative college or non-college options.

In the rest of this section, I described how the conceptual framework is used as basis to understand the mechanism by which adoption of exit exams alters the college going decision of students, and subsequently which type of college to attend. Within this theory, exit exams influence the non-financial factors associated with the student $\left(\mathrm{F}_{\mathrm{i}}\right)$ and the non-financial student characteristics ( $\mathrm{Si}$ ) that influence their decision to attend a particular college.

\section{The College Readiness Component of Exit exams}

The mechanism by which the college readiness component of exit exams affect enrollment is pretty direct. Exit exams leads to increased college prep course taking 
which increases the level of college readiness for all students irrespective of their background. Taking rigorous college prep courses is associated with higher probability that the student will enroll in college (Adelman, 1999; Hubert, 2000; Reardon, 1996). Base on the purpose of exit exams to expose students to rigorous curriculum, exit exams therefore act as a means to encourage students to take the necessary course work that that increases their probability of success at the higher education institution.

Within this framework, exit exams improve students' desirability of college education thereby positively impacting the predisposition and search stage of the student choice model proposed by Hossler and Gallegher (1987). The model suggests that a student decision to attend college consists of three stages namely predisposition, search and choice. In the predisposition stage, a student arrives at a decision of whether or not to continue their formal education beyond high school and it usually occurs between the $7^{\text {th }}$ and $10^{\text {th }}$ grades. After that decision is made, the student progresses to the search stage where information on colleges are sought for through various means including campus visits, internet searches, and college fairs. This is the stage when the student looks for attributes and values of post-secondary institutions and how they fit into their personal goals including the type of major, and location. The choice stage is when the student decides which college to attend based on the search stage.

The decision to attend college or not (i.e. predisposition stage) is a function of a student personal attributes including academic ability (Hossler \& Gallegher, 1987). I posited that by taking high rigorous courses, students' academic ability will improve, and this positively influences the effect of non-financial individual characteristics ( $\mathrm{Si}$ ) on college going decision. Hemelt and Marcotte (2013) explain that the presence of exit exams has an intrinsic motivation for students particularly those at the margin to work 
harder than they would have otherwise. By virtue of passing exit exams, it changes the utility balance between going to college represented by $\mathrm{U}\left(F_{1}, F_{i}, S_{i}^{E}\right)$ and the alternative of not going to college represented by $\mathrm{U}\left(F_{0}, F_{i}, S_{i}\right)$. Thus, $U\left(F_{1}, F_{i}, S_{i}^{E}\right) \geq$ $U\left(F_{0}, F_{i}, S_{i}\right)$ meaning the utility associated with going to college is higher than not going to college. Through the participation in high level college preparatory course, students' personal characteristics begin to match college success attributes and increase the value of college. The utility of attending any college whether a 2-year college (i.e. $\left.U\left(F_{2}, F_{i}, S_{i}^{E}\right) \geq U\left(F_{2}, F_{i}, S_{i}\right)\right)$, or a 4-year college (i.e. $U\left(F_{4}, F_{i}, S_{i}^{E}\right) \geq U\left(F_{4}, F_{i}, S_{i}\right)$ ) increases while the utility of not going to college remains the same given as (i.e. $\left.U\left(F_{0}, F_{i}, S_{i}^{E}\right)=U\left(F_{0}, F_{i}, S_{i}\right)\right)$. By being exposed to exit exams, the utility associated with attending either a 2-year institution or 4-year institution is higher relative to not attending any institution. The theory predicts that students will make a positive decision to attend college.

However, whether the student will choose a 4 year or a 2 -year institution is ambiguous according to the theory. If the probability of succeeding is the same across the different types of institutions and all things being equal, then the utility of attending a 4year institution will be greater making it a more likely choice for the student. This is represented as $U\left(F_{4}, F_{i}, S_{i}^{E}\right) \geq U\left(F_{2}, F_{i}, S_{i}^{E}\right)$. On the other hand, when the student believes that exit exams have made it possible to succeed only at the 2-year institution, then the utility associated with attending 4-year institution will be less as the following $U\left(F_{4}, F_{i}, S_{i}^{E}\right) \leq U\left(F_{2}, F_{i}, S_{i}^{E}\right)$

\section{The Stress Component of Exit Exams}

Additional requirements to take and pass exams comes with certain a level of stress particularly for average students (Blinde \& Chan, 1984; McDill, Natriello, \& 
Pallas, 1986). When students are already struggling to pass regular exams, imposing extra requirement doubles the stress level and makes them unlikely to graduate from high school (Ahm, 2013; Papay; Murnane \& Willett, 2010). As such, the utility associated with the decision to attend college is lower than the decision not to attend depicted as

$U\left(F_{1}, F_{i}, S_{i}^{E}\right) \leq U\left(F_{0}, F_{i}, S_{i}\right)$ as a result of increase in stress. According to DesJardins and Toutkoushian (2005), once the utility associated with stress negatively impacts students' decision to enroll, the theory predicts that the probability that the student is likely to enroll is small. In that case, the utility of attending any college, whether a 4-year institution $U\left(F_{4}, F_{i}, S_{i}^{E}\right)=U\left(F_{4}, F_{i}, S_{i}\right)$ or a 2-year institution $U\left(F_{2}, F_{i}, S_{i}^{E}\right)=$ $U\left(F_{2}, F_{i}, S_{i}\right)$ remains unaffected while the utility of not attending any higher education institution increases given by $U\left(F_{0}, F_{i}, S_{i}^{E}\right) \leq U\left(F_{0}, F_{i}, S_{i}\right)$ signaling that the utility from pursuing extra course requirements is less when exit exams are imposed than they would have without exit exams. Costrell (1994) explains that students consider the effort needed to pass the exams too high and thus give up on obtaining a diploma as a goal. I posited that the stress component of exit exams has a negative effect on the probability of enrolling in college. Graduation requirement increase the stress level of students which may have long term effects on their perception about their ability to succeed in further education (Plunk, Tate, Beirut \& Grucza, 2014).

\section{Opportunity Cost component of Exit exams}

The opportunity cost component of exit exams relates to the loss of income resulting from hours of study to pass exit exams. Since most states allow taking of exit exams during summer breaks and after $12^{\text {th }}$ grade and during summer (Center of Educational Policy, 2012), students are constantly faced with the choice of working or spending time to study for exit exams. Thus, the opportunity cost of taking the exams is 
the forgone income for not working in order to study to pass exit exams. Lillard and DeCicca (2001) put it more succinctly this way:

As students are required to take more courses in specific subject areas, they pay directly in terms of time spent in courses they would not have freely chosen. If the extra courses are more challenging, students will also have to expend more effort to pass them. Consequently, they forego earnings and thus indirect costs arise. (p. 461).

I therefore posited that as the economy improves and wage increases, the utility associated with the financial factor relating to the student (fi) reduces and this leads to a negative decision on college enrollment. When jobs are available and the economy is booming, the opportunity cost of exit exams is high. Any 1 hour spent studying could mean loss of income as a result of not working. As such, the utility of attending college is lower as compared to not attending. This is illustrated as $U\left(F_{1}, F_{i}^{E}, S_{i}^{E}\right) \leq U\left(F_{0}, F_{i}, S_{i}\right)$ indicating that the utility of not attending college is higher than attending it. Irrespective of the type of institution, the utility for not attending rises relative to attending one. This is shown as $\mathrm{U}\left(\mathrm{F}_{4}, \mathrm{~F}_{\mathrm{i}}^{\mathrm{E}}, \mathrm{S}_{\mathrm{i}}\right)=\mathrm{U}\left(\mathrm{F}_{4}, \mathrm{~F}_{\mathrm{i}}, \mathrm{S}_{\mathrm{i}}\right), \mathrm{U}\left(\mathrm{F}_{2}, \mathrm{~F}_{\mathrm{i}}^{\mathrm{E}}, \mathrm{S}_{\mathrm{i}}\right)=\mathrm{U}\left(\mathrm{F}_{2}, \mathrm{~F}_{\mathrm{i}}, \mathrm{S}_{\mathrm{i}}\right)$ and $\mathrm{U}\left(\mathrm{F}_{0}, \mathrm{~F}_{\mathrm{i}}^{\mathrm{E}}, \mathrm{S}_{\mathrm{i}}\right) \leq \mathrm{U}\left(\mathrm{F}_{0}, \mathrm{~F}_{\mathrm{i}}, \mathrm{S}_{\mathrm{i}}\right)$ which indicates that the utility for attending either 2-year or 4year college remains the same while the utility associated with not going to college increases. Therefore, as the direct cost increases relative to benefits, the expected utility for choosing to acquire more education falls and consequently will influence the student towards a different outcome than going to college. 


\section{Research Hypotheses}

On the basis of student choice model adopted in this study, the net positive impact of exit exams suggests that the positive value of college readiness outweighs the negative impact of stress and the opportunity cost. Exit exams affect the financial and nonfinancial components of the utility function of an individual. The negative impact of increase in stress and loss of income as a result of having to spend more time to study to pass exit exams has a negative impact on the value students place on higher education but less than the value associated with the positive impact of exit exams on college readiness. Thus, as these factors operate within the utility model, holding all things constant, enrollment is expected to be positive. On the basis of the student choice model, the following hypotheses were formulated.

\section{Prediction on College Enrollment - Hypothesis 1}

If the theory predicts that taking exit exams increases the skills and knowledge that is comparable with success in college, then adoption of exit exams is expected to positively be related to enrollment. By spending more time on the materials that are tested in exit exams, it increases the chances that exit exam will positively the utility associated with going to college. As a result, there is a positive relationship between adoption of exit exams and college enrollment. The more rigorous exit exams are, the higher the impact on preparing students for exit exams (Adelman, 1999).

Prediction on Enrollment by Institution Type- Hypothesis 1a. If exit exams improves the college going attributes of students, then adoption of exit exams is expected to increase the college going behavior at both the 2-year institutions and 4-year institutions. However, due to the fact that exit exams usually test knowledge of higher 
academic pursuits, then the impact on a 4-year institution will be greater than the impact on 2-year institutions which in many cases are open enrollment.

Prediction on Enrollment by place of enrollment-Hypothesis 1b. If exit exams improves the college going of students all students, then there is a positive relationship to out-of-state enrollment. Existing research shows that exit exams improves the college going attributes of students at the margin rather than high ability students who are expected to go to college anyways, then the adoption of exit exams will not affect out-ofstate enrollment but potentially can affect instate enrollment. Most average to low ability students are more likely to enroll in their home state institution than travel out-of-state. Since most students who attend college out of state are usually high ability students and have other aspirations, then the expected impact of exit exams on out-of-state enrollment is expected not to be significant.

\section{Prediction on Enrollment by Different Types of Exit Exams-Hypothesis 2.}

Based on the student choice model, the more rigorous a particular exit exam is, the higher the college level preparedness associated with it. Exams that test basic knowledge are less likely to have greater impact on college enrollment as compared to those that test knowledge in advanced courses. On the basis of that, end-of-course exams and standard-based exit exams are expected to have a positive impact on college enrollment than no exit exams. When a student associates' higher satisfaction from attending college as a result of increased college readiness from taking exit exams, the expected effect is positive on college enrollment. Thus, the sign and magnitude of the relationship between exit exams is based on the relative values of utility students associate to different components of the model. 


\section{Summary}

Based on a review and synthesis of prior literature and the conceptual framework, students college choice decisions are shaped by multiple theoretical perspectives and four contexts. These interrelated factors act both individually and collaboratively to influence student college choice.

The innermost layer of integrated model is the greatest predictor of college choice. The level of academic preparation and family SES status have significant positive effect on the decision of whether to go to college or not (Perna, 2006). The higher the SES status and level of academic preparation, the greater the probability of attending college (Heller, 1997). Both social and cultural capital that an individual has also positively influences their college choice. When an individual comes from families where education is valued and parents support educational aspirations through seeking and providing information for college attendance, the likely hood of attending college are high. Social and cultural capital such as parental involvement promotes college attendance (McDonough, 1997; Perna \& Titus, 2004). Students from minority background particularly African Americans and Hispanic families usually have lower social and cultural capital that affects their ability to attend college. The aggregation of the individual level characteristics reflect the resources available for students at high school.

The review also suggests the cost of education is negatively related to college enrolment. The higher the cost (either through increase in tuition or lowering of grants), the less the probability college enrollment. The presence of financial aid particularly grants whether at the institutional, state or federal source have a positive effect on college 
attendance. On the other hand, increases in tuition decreases the number of enrolled students.

Finally, the ability of states to support higher education through increase in direct appropriations, establishment of state financial aid program and promulgation of laws that improve college enrollment have significant effect of affection college choice (Kane, Orzag \& Gunter, 2003; McLendon, Hearn \& Mokher, 2009; Weerts \& Ronca, 2006). Other economic factors such as weak economy have somewhat an ambiguous relationship with college choice. During times of economic recession, some individuals may choose to go back to update their skills while others will move from part time school to full time jobs in order to meet their basic needs (Gaertner et al., 2013; Kane, 1995; Rumberger, 1987). 


\section{CHAPTER THREE: RESEARCH DESIGN AND METHODOLOGY}

In order to establish the relationship between exit exams and college enrollment, the researcher adopted a quantitative research design using state level data for all states within the United States (excluding Washington DC). The two research questions investigated were as follows:

1. What was the relationship between state-level adoption of high school exit exams and postsecondary enrollment?

a. Did the adoption of exit exams have a differential relationship with enrollment at different postsecondary institutional types (i.e. 4-year and 2-year institutions)?

b. Did the adoption of exit exams have a differential relationship with instate and out-of-state postsecondary enrollment?

2. Was the relationship between exit exam adoption and enrollment different for different types of exit exams?

Quantitative research provides the means to test objective theories and examine the relationship among variables (Creswell, 2009). A quantitative approach better fits the theoretical framework of student choice model which predicts that a rational individual will maximize utility by enrolling in college if the utility derived from attending college is greater than the utility of alternative choices. Thus, a quantitative approach was the appropriate research design to test the hypotheses based on assumptions of a theory, eliminating alternative explanations, and having the ability to generalize results (Creswell, 2009). Further, since the aim of the study was to evaluate the relationship between a policy initiative and a desired outcome, a quantitative research allows the 
researcher to determine both the direction and magnitude of an intervention (Shadish et al., 2009). Thus, a quantitative research design rather than a qualitative approach provided more comprehensive approach to evaluate the relationship between exit exams and college enrollment.

In the rest of the section, the study described potential identification strategies that could be used to analyze the relationship between exit exams and college enrollment. It identified the advantages and disadvantages associated which each method and the extent to which the results could be generalized. This is followed by a general description of difference-in-differences strategy and the modified version of staggered difference-in differences identification method which is the most suitable method based on research questions and the data used for the study. Finally, the study described the data collection procedures, definition of major variables, analytical method and summary.

\section{Potential Identification Strategies}

Within the quantitative approach, various methods can be used to establish the relationship between exit exams and college enrollment. Each method has its own set of assumptions that affect the internal and external validities of the estimates (Angrist \& Pischke, 2009; Imbens \& Woodridge, 2009).

\section{Experimental Design}

The ideal procedure to produce unbiased estimates of the treatment effect of exit exams on college enrollment would be a randomized experimental design. In using this analytical strategy, the participation in the program is randomized across units and the assignment of treatment is only based on chance (Angrist \& Pischke, 2008). As a result, each unit has the same chance of being in the treatment or in the control group resulting

in a nonzero probability of assignment to either condition (Shaddish et al., 2002). Under 
this design, a group of states are randomly selected to participate in the program (treatment). Due to randomization, pre-treatment characteristics between treatment group and untreated groups are expected to be identical and the only difference between the two groups is that one receives the treatment and the other group does not. Thus, the untreated group provides an ideal counterfactual for the treated group in all characteristics except the treatment status. Thus, the difference in the mean outcome between states that participated and those that did not will be the causal effect of adopting exit exams on college enrollment. This is because it reduces the plausibility of alternative explanations for observed effects of the treatment (Shaddish et al., 2002). Given that they were randomly selected, unobserved factors will also be uncorrelated with the treatment and outcome. This minimizes the threats to validity of the estimates from confounding factors and eliminates selection bias (Angrist \& Pischke, 2008; Duflo, Glennerster \& Kremer, 2008). This method yields unbiased estimates of the average treatment effect (Rosenbaum, 1983; Shaddish et al., 2002).

In spite of the huge potential benefits of using randomization, there were practical limitations to its use in answering the research question for this study. The method requires a researcher or another party (such as the government) to have the ability to randomly assign treatment status to each state. This is not practical because educational policies historically rest on state and local authorities who formulate policies based on their own unique position (Fraser, 2014). Each state determines its own policy and when to implement within its own jurisdiction. For example, most southern states implemented exit exams as a boost to academic preparation and subsequently increase enrollment (Dee \& Jacob, 2006). 
Secondly, it is not possible to manipulate events that occurred in the past and therefore using this method retroactively may not satisfy the assignment of units based on chance (Shadish et al., 2002). Typically, randomization design requires setting up the experiment before administering treatment (Shadish et al., 2002). Given that exit exams are already in play across the country, it is impossible to assign treatment based on chance.

\section{Comparing the treated to the untreated}

A simple linear Ordinary Least Squares (OLS) regression technique that utilizes simple differencing between treatments versus control estimator technique could be used to determine the relationship between adopting of exit exams and enrollment in college. It only relies on posttest observations between participants and non-participants. This design compares the average difference in outcomes between the treated group and the control group (Shadish, e tal., 2009; Pomeranz, 2017). Using OLS regression, the notation for simple differencing that involves posttest only design is written as follows:

$$
Y_{i t}=\alpha+\beta 1 \text { Exit_Exams }_{i}+\varepsilon_{i t}
$$

Where the $Y_{i t}$ is the number of students from state $i$ at time $(t=1)$ who are enrolled in higher education and Exit_Exams is an indicator variable that shows whether a state $\mathrm{i}$ has exit exams in place, $\mathrm{N}=$ number of states and $\varepsilon_{s}$ is the error term.

For states with exit exam (Exit_Exams $=1$ ) given that $\mathrm{t}=1$ to signal posttest observation, $\beta 1$ indicate the correlation coefficient of exit exams and enrollment. The coefficient, $\beta 1$ is the measure of the relationship between exit exams and college enrollment, which comes from comparing college enrollment of states that participated in exit exams to those that did not participate. Using this method, the assumption is that those who did not participate act as valid counterfactual for those that participated and a 
simple difference between the two is seen as a measure of the impact (Angrist \& Pischke, 2009). In the absence of the treatment (Exit_Exam=0), the coefficient of treatment dummy (i.e. $\beta 1=0$ ) which means there is no difference in the mean of those who obtained the treatment and those who did not (Meyer, 1995). More formally, this assumption states that the conditional mean of the error term does not depend on the value of the treatment (Wooldridge, 2010). The zero-conditional mean assumption implies that all the independent variables are exogenously determined and that there is no correlation between the X's and the error them (Angrist \& Pischke, 2009).

Using simple differences, equation (1) could suffer from selection bias because states that had exit exams could fundamentally be different from states that did not have exit exams in terms of the motivation or needs. If the treated and the comparison groups were different in any way prior to the adoption of exit exams, the results would be biased, which is the difference between the parameter to be estimated and actual estimator and statistically. In the South for instance, a number of states adopted exit exams because they were all motivated by lack of sufficient academic preparation at the high school level (Dee \& Jacob, 2006). At the same time, most southern states had also introduced large scale state level financial aid in an attempt to boost college enrollment (Cornwell \& Mustard, 2004; Domina, 2009; Heller, 1997; Slater \& Iler, 1991; Zhang \& Ness, 2010). Failure to recognize and include prior academic preparation and financial aid policy in the estimation procedure will lead to estimates that are not the true effect of the relationship between exit exams and college enrollment. Thus, without fully specifying all the observable variables that affect the outcome variable, the estimates of the variables will not be the true relationship between the dependent variable and variable of interest (Woodridge, 2010). Even when these confounding factors are controlled, many more 
factors that are unique to treated group that affect enrollment are not observable to the researcher which still will lead to biased results.

\section{Pre-post comparison design}

A simple linear OLS regression technique compares pre and post-enrollment patterns of only states that have adopted exit exams to determine the relationship between adopting of exit exams and enrollment in college. It compares the average difference in outcome before and after treatment for only participants (Shadish et al., 2009; Pomeranz, 2017). Instead of using a different group for control, the same group is used to measure the change overtime. Using OLS regression, the notation for this simple differencing is written as follows:

$$
Y_{t}=\alpha+\beta 1 \text { Exit_Exams }_{t}+\varepsilon_{t}
$$

Where the $Y_{i t}$ is the number of students from state $\mathrm{i}$ in a period $\mathrm{t}$ where $\mathrm{t}=(0,1)$ and $\mathrm{i}=1 \ldots \mathrm{N}_{\mathrm{t}}$. Exit_Exam $\mathrm{t}$ is a dummy variable for being in the treatment group and $\varepsilon_{i s}$ is the error term.

If Exit_Exam ${ }_{t}=1$, then $\beta 1$ is the measure of the true effect exit exams have on college enrollment.

The above equation shows that given any state ( $\mathrm{i}$ ) and time period $(\mathrm{t}=1$ and $\mathrm{t}=0)$, the model measures the change overtime by comparing enrollment before and after adoption of exit exams. A key assumption of this approach is that the program is the only factor that influenced a change in outcomes over that period and without the program the outcome would have remained the same (Shadish et al., 2009). This tends to lead to positive bias as the effect of exit exams is likely going to be overestimated. For example, normal development of students from one period to the other inevitably increases their ability to do well in several academic outcomes irrespective of any treatment offered to 
them (Shadish et al., 2009). Other general trends that could cause results from this analysis to be biased include economic conditions such as employment which may change between the two periods. Without recognizing this change condition, the results of simple difference evaluation based on pre-post comparison analysis are most likely to be bias.

\section{Difference-in-Differences}

This study utilized quasi experimental strategy of difference-in-differences to determine the effect of adoption of exit exams on college enrollment. Difference-indifferences strategy is a statistical procedure that attempts to mimic experimental design using observational data by examining the differential effect of a policy on a treated group versus the comparison group (Bertrand, Dufflo, \& Mullainathan, 2004; Athey \& Imbens, 2006). It is defined as the difference in average outcome in the treatment group before and after treatment minus the difference in average outcome in the control group before and after treatment (Angrist \& Pischke, 2008; Ashenfelter \& Card, 1984; Card \& Krueger, 1993).

The method reduces the bias in the estimated coefficient as a result of permanent differences between the control and treatment groups and differences as a result of time trends (Bloom, 2003; Butsic, Lewis, Radeloff, Baumann \& Kuemmerle, 2017). Thus, difference-in-differences reduce omitted variable bias even if the treatment is correlated with time invariant factors (Butsic et al., 2017). The key to using difference-indifferences is its ability to project what the outcome would have been in the absence of the reform known as the counterfactual. Valid estimates of an intervention are obtained only by comparing actual enrollment levels to the counterfactual (Bloom, 2003). Since each unit at any point in time can only receive or not receive a treatment at any point in 
time, finding a perfect clone for treated states can be daunting. Thus, some assumptions must be met in order for difference-in-differences to be valid prediction of an intervention.

The key assumption of difference-in-differences is the parallel trend which implies that in the absence of the treatment, the difference between the treatment and control group are constant over time (Meyer, 1995; Butsic et al., 2017). By this condition, there would be no difference in the mean of those in the treatment and those in the control group and therefore the conditional mean of the error term does not depend on treatment status (Meyer, 1995). In other words, the treatment and control group would have experienced similar changes in outcome over a period of time in the absence of treatment (Butsic et al., 2017). This condition requires that irrespective of whether a state adopts exit exams or not, enrollment trends must be similar for those that adopted exit exams and those that did not adopt prior to the intervention. By extension, the method requires that the factors affecting outcome variable for treated and control groups are balanced within the time frame of consideration (Angrist \& Pinchke, 2009). The parallel trend assumption is not directly testable but can be evaluated using visual or graphical illustrations (Bertrant et al. 2004). Following the approach of Goodman (2018), the study explored the differential timing of adoption to test this assumption.

The second assumption of difference-in-differences is that there is clear and welldefined exogenous treatment (Card \& Kruger, 1992). Exit exams implementation fulfilled this condition because there was no theoretical basis to suggest simultaneity exist between exit exams implementation and college enrollment which will lead to endogeneity. It is unlikely that states with already high enrollment would adopt exit exams in order to further positively impact enrollment. On the other hand, it is possible 
that states with low college enrollment may raise standards in order to solve the low enrollment. This suggest that enrollment follows implementation and not the other way around.

The standard difference-in-differences strategy is expressed as follows:

$Y_{i t}=\alpha+\beta$ Exit_Exams $_{i}+\delta A$ fter $_{t}+\gamma\left(\right.$ Exit_Exams $_{-} *$ After $_{i t}+\varepsilon_{i t}$

Where $Y_{i t}$ is the number of students from state s who are enrolled in higher education in year $t$ and Exit_Exams is an indicator variable that shows whether a state $\mathrm{s}$ at time $\mathrm{t}$ has exit exams in place, After is the period following the adoption and $\varepsilon_{s t}$ is the error term. The coefficient of the product (Exit_Exams*after ${ }_{\mathrm{t}}$ ) is the interaction term that indicates the difference in average outcome in the treatment group before and after treatment minus the difference in average outcome in the control group before and after treatment. This indicates whether or not the intervention measures the effect and therefore represents the causal inference of the outcome being studied provided all the assumptions have been met (Wooldridge, 2010). Difference-in-differences estimator captures the average intended treatment effect across multiple events the same as it would across a single law or policy event (Shawn, 2016).

In standard difference-in-differences estimation, a lower-order binary term would treat all before-policy observations and all after-policy observations the same, ignoring important state and time variation among them (Wooldridge, 2010). The differential timing in the adoption of exit exams across states requires a modification of the standard difference-in-differences to account for state fluctuations in policy and between-year variation. Bertrand and Mullainathan (2003) in analyzing impact of antitakeover laws, suggested using form of difference-in-differences model that accounts for state fluctuations in policy and between year variations. In modified difference-in-differences 
model, instead of lower-order terms measuring average differences in the before-policy treatment group and after-policy control group, fixed effects are specified to account for variation in both groups (Bertrand \& Mullainathan, 2003).

If all exit exams were adopted at the same time, the standard difference-indifferences would be the appropriate design to determine the enrollment effect of exit exams. In reality, states have adopted exit exams at different times over the course of the study. To isolate the effect of the policy, this study made use of the staggered implementation of exit exams across the country following the work of Dynarski (2004). This method allows states that adopt exit exams later to serve as control for those that adopted it earlier. This method allows any state to be both in the control and the treatment group at different times. Thus, the relationship between enrollment and exit exams is expressed as follows.

$$
Y_{i t}=\alpha+\beta(\text { Exit_Exams })_{i t}+\delta S_{i t}+\delta_{i}+\delta_{t}+\varepsilon_{i t}
$$

Where, $Y_{i t}$ measures the outcome variable of the number of recent high school graduates from state $\mathrm{i}$ who are enrolled in college at time t, Exit_Exams is the variable of interest that represents whether a state had adopted exit exams in period $t, S_{i j}$ are state characteristics that affect enrollment. $\delta_{i}$ and $\delta_{t}$ represents state and time fixed effect respectively which are included to control for time and state invariate factors that affect enrollment. This variation also allows the researcher to include observations from states that never adopted exit exams as part of the control group, which is important to weigh against researcher-driven sampling bias (Bertrand \& Mullainathan, 2003).

Since the data set collected repeatedly across time for both dependent and independent variables, the issue of serial correlation is a concern in the estimation of difference-in-differences. Serial correlation occurs in time-series studies when the errors 
associated with a given time period carry over into future time periods (Bertrand et al., 2004). In this case, an overestimation of the effect of exit exams in one year is likely to affect the estimates in the succeeding year. As a result, the efficiency of the model is affected even though the model remains unbiased and consistent (Bertrand et al., 2004). This will lead to smaller standard errors than they really are and more likely to cause the null hypothesis to be rejected when they really are not to be rejected. In other words, serial correlation if not corrected has a tendency to show effect of a policy when in reality there are no effects. Given that the last model above contains lagged and succeeding terms, serial correlation cannot be addressed by traditional methods such as Durbin Watson tests. The study utilized recommendation of Bertrand, Duflo and Mullainathan (2004) which suggests limiting analysis to a shorter time period cluster the errors at the state level.

\section{Data Definitions and Sources}

Following research on exit exams on college outcomes (e.g. Liliard \& DeCeicca, 2009), the study utilized state level data for the years 1992-2016 gathered from a variety of sources. I collected information on the number of first-time students enrolled in college from each state in each year and other state level characteristics that influence college enrollment based on the theoretical framework and the literature review. The rest of the section described the variables, their sources and how they have been operationalized in the study.

\section{Dependent Variable}

The dependent variable was intended to measure the number of recent high school graduates from each state who were enrolled in higher education institutions. More precisely, it measured all fall first-time degree/certificate-seeking undergraduates 
enrolled at a higher education institution in any state who had graduated from high school in the previous 12 months by state of residence or jurisdiction. For example, in table 259 of the Digest of Education, in fall 2010, there were 43, 633 first-time degree seeking undergraduate students from Missouri who were enrolled in college at home or elsewhere on continental US. The dependent variable was subsequently divided by sector and by instate and out-of-state enrollment.

The Digest of Education, under the National Center for Education Statistics (NCES), compiled state aggregate data on first-time degree/certificate enrollment for all 50 states. Among other things, the data is disaggregated by sector and residence. NCES obtained this information from the Integrated Postsecondary Education Data System (IPEDS) managed by the US Department of Education. IPEDS is a system that conducts annual surveys on every college, university, and technical and vocational institution that participates in the federal student financial aid programs. Since 1987 , over 6,700 institutions each year submit completed information on enrollment, completions, faculty and other aspects of higher education. IPEDS has been a source of information for analyzing different post-secondary outcomes and college access in particular over the years whether at the individual college level, state, or national aggregate level.

NCES publishes the total number of all first-time degree/certificate-seeking undergraduates in degree granting postsecondary institutions who graduated from high school in the previous 12 months for both overall and by sector. My choice to use the total first-time enrollment who had graduated from high school in the previous 12 months over all first-time enrollment from each state was to be able to associate the exit exams requirement that any cohort of students faced at the time prior to enrollment. This condition excluded adult students who may had faced different standards at their time of 
graduation but who were counted as first-time in the NCES data. It also did not include GED awardees who were not necessarily subjected to standard requirements for high school diploma.

Most student-demand studies conducted at the state level have variously used this variable wholly or some part of it based on the focus of the study. For instance, to analyze nonresident enrollment demand, Zhang (2007) used the same variable of fall first time degree/certificate -seeking undergraduates enrolled in higher education institution but only limited it to nonresident students as the dependent variable. Similarly, Zhang, Hu and Sensenig (2013) employed this variable in the study of the effect of Florida's Bright future program on college enrollment.

\section{Key independent variable}

The statewide implementation of exit exams was the treatment or variable of interest for this study. It measured whether a cohort of students entering college from any particular year in any state excluding Washington DC was subjected to mandatory exit exams requirement or not. This variable was expected to measure the rigor of high school graduation in each state as defined by the exit exams policy in its statutes. For this study, states were recognized as having adopted exit exams when the policy was state level statute, applied to all public high school students statewide and went to affect the same year for each state. In addition, students must not only be required to take the exams but must pass before they cauld be awarded a diploma for the comprehensive exams (i.e. minimum competency and standard-based). For end-of-course exams which do not have pass or fail options rather used as part of student's final GPA, the last criteria for inclusion was relaxed. Thus, states such as Iowa where some local districts had independently set graduation requirement were not counted as exit exams states in this 
study. Also, where each district had its own requirement beyond what the state mandated, the state one surpassed in determining whether or not exit exams policy was in place.

The primary source for information on exit exams comes from Education Research Data Sharing Initiative (ERDSI) and the Center of Education Policy (CEP) which individually gathers information on specific high school graduation requirements across the country. Together, the two sources provided information by state on years of implementation of exit exams, the type of exit exams, the grade alignment and the firstclass cohort in each state that was required to pass the exams in order to graduate. From 1977-2010, ERDSI provided information on various attributes of exit exams for over 22 states that have mandated students to pass exit exams in order to graduate from High school. Since 2001, CEP has also detailed the different types of exit exams administered across the country.

ERDSI has been used in a wide variety of research across different number of contexts and spans different time periods to promote secondary and post-secondary outcomes particularly in STEM related issues (Warren et al., 2010). Warren and Edward (2005) used this dataset to examine across states how adoption of these exams was related to the chances that a student obtained a high school diploma, acquired a General Educational Development (GED) or left school without any of them. Their results indicated that exit exams were not related to any of the outcomes even for low achieving students. Similarly, Warrens and Jenkins (2005) relied on ERDSI to examine dropout rates in Texas and Florida following the adoption of Texas Educational Assessment of Minimum Skills which later became Texas Assessment of Academic Skills and Florida State Student Achievement Test and subsequently High School Competency Test. Based on this dataset, they found that adoption of exit exams did not have any significant rate 
on dropout rate between 1971-2000. Other studies used this dataset to examine differences in completion across states (Warran et al., 2006), and state spending following enactment of exit exams (Warren \& Kulick, 2007). More recent studies have used this database to examine differences in labor market outcomes (Warren, Grosky \& Lee, 2008) and testing and accountability that comes with exit exams (Grodsky, Warren \& Felts, 2008; Hanushek, Warren \& Grodsky, 2012).

Similarly, CEP had been data source for a number of projects that aimed to examine a student's development path following state adoption of exit exams. The center has grown into a prominent major information hub for examining public education and effective schools (Caves \& Balestra, 2016). CEP itself, since 2002, has collated and published annual information on high school exit exams and information on changes in structure, content, and grade alignment of exit exams. Ever since its first annual report on exit exams published in 2002, it has published information that exposes achievement gaps in exit exams across the country (Center for Education Policy, 2005), and highlighted the effectiveness of alternative pathways to graduation for students who struggle to pass exit exams (Center for Education Policy, 2009). Other prominent studies have relied on this dataset to determine the effect of exit exams on mathematics achievement (Shuster, 2012), and effects on graduation rates (Caves \& Balestra, 2016).

Based on the information from ERDSI and CEP annual report (2012), this study classified states into exit exam states and non-exit exams states. When a legislature is enacted as a law, it often applied to an incoming freshman in high school at a future date. For example, in 1997 when the state of Alaska enacted a law that all students were required to pass the Alaska High school Graduation Qualifying Exam, it was said to begin with the incoming freshman class of 2000-2001. Therefore, the graduating class of 
2004 was the first class to be treated for the state of Alaska. For any state in the treatment, authorities of the public high school must have known about the requirement at least four years prior to their students graduating from high school. This ensured that every student whether part of the first graduating class required to pass it or several years thereafter had equal chance of passing the exams (Warren, 2010).

Exit exams were divided into different types, based on content of material tested and whether or not the test assessed multiple subjects on the same test. Following the classification approach of Baker and Lang (2013), this study divided exit exams into three types based on the contents of the material that were tested and the grade alignment. The first type-Minimum Competency Exams-is described as any test that measured students' knowledge in basic skills such as ability to read, write, and compute simple arithmetic problems (Baker \& Lang, 2013). This test was usually based on knowledge acquired during elementary and middle school and administered between $9^{\text {th }}$ and $12^{\text {th }}$ grade with the opportunity to retake. Minimum competency exams were taken at one sitting and usually tested all the material including but not limited to reading, writing, and language. Minimum Competency exams were the first wave of exit exams intended to ensure that students who graduated from high schools possessed minimum competencies to function well in society (Long et' al., 2012). This type of exams became the norm to address the poor quality of high school graduates following the report of nation at risk. For some, this type of exams was seen as a social policy to address long existing inequalities that long existed (Holme et al., 2010; Long et al., 2010). Consequently, minimum competency exams were the most popular type of exams in the 1980s and 1990s among educational policy makers, but their prominence had decreased over time. 
Standard-based exit exams as the second type of exit exams test students' knowledge beyond basic reading, writing and simple computation (Baker \& Lang, 2013). They were often considered more rigorous because they were aligned to material taught to students from $9^{\text {th }}$ to $12^{\text {th }}$ grade. Like MCEs, Standard-based exit exams required single comprehensive test and could be taken multiple times to obtain a pass grade. Baker and Lang (2013) describe Standard-based exit exams as those that test students' knowledge beyond basic reading, writing and simple computation. They are often considered more rigorous because they are aligned to material taught to students from $9^{\text {th }}$ to $12^{\text {th }}$ grade. Proponents believed that this type of exams encouraged students to learn harder because of the relative difficulty in passing those exams which gave greater value to the high school diploma. Standard-based exams became more popular in the mid-1990s and early 2000s following the educational reform which prioritized standard academic standards and accountability in K-12 education. Many states in this era used standard-based exams to meet the conditions of No child Left Behind though the law itself did not require exit exams. Like minimum competency exams, standard-based exit exams required a single comprehensive test and can be taken again.

Finally, exit exams were classified as end-of-course exams when they tested knowledge in a particular subject for grades 10 and above. Unlike standard-based and minimum competency exams, end-of-course exams are not comprehensive and only assess mastery of a particular course such as algebra or trigonometry. This type of exit exams allowed states to test students understanding of a particular subject. End-of-course exams started gaining prominence in in the early 2000 s. 


\section{Control Variables}

The control variables identified were based on DesJardins and Toutkoushian (2005) choice framework that explains how decisions about college going are made. According to the model, the utility function in college decision making is a function of financial factors associated with attending college, financial factors associated with the individual student and non-financial factors associated with the individual. Based on the theory, the control variables included tuition, financial aid, percapita income, number of high school graduates, unemployment rate, and percent minority. In the following section, I described these factors and presented sources of information for them.

Tuition. Tuition is the major component of the financial factors relating to cost of attending an institution as described in the conceptual framework. As an input in the decision-making process, tuition influences the enrollment decision by either lowering or raising the utility associated in going to college. According to the student choice model, when the cost of attending a college increases relative to the benefits of alternative decisions such as fully participating in the labor market, the student utility of attending college decreases. Student demand studies have overwhelmingly shown that when tuition increases which raises the cost of attendance, enrollment falls and the vice versa (Jackson \& Weathersby 1975; Leslie \& Brinkman, 1987, Heller, 1997).

This variable is primarily obtained from the college board annual survey of colleges which provides annual average instate and in district published tuition and fees by state for public institutions. The average published tuition and fees represent a fixed amount of money charged to full-time undergraduate student by an institution and covers tuition and required fees to represent the cost of attendance. Specifically, it is the average published tuition and fees charged by public institutions in each state in current dollars 
for full time students enrolled at 4-year and 2-year community college. For earlier years, I relied on IPEDS institutional characteristics survey reports which provides the same information regarding the cost associated in attending a particular institution every year. Zhang (2010) used the same variable from IPEDS to perform student demand analysis for nonresident students.

Financial Aid. Financial aid affects college decision making just like tuition but in the opposite direction (Heller, 1997). Financial aid is a discount to tuition and increases the utility of attending college as the net benefits increases relative to alternative decisions. Financial aid affects college attendance decision and type of college to attend (Heller, 1997). It measures the out of pocket expenditure which is tuition less financial aid. Financial aid reduces how much individuals pay for their cost of education. The availability and presence of financial aid to students incentivizes students to take advantage of lower net tuition (Cornwell \& Mustard, 2004; Dynarski, 2003; Mak \& Moncur, 2003).

Information on the amount of financial aid awarded in each state was obtained from the National Association of State Student Grant and Aid Programs (NASSGAP) which publishes survey report of state-administered student financial aid each year. For this study, I used the average need and merit-based aid for each state and each year.

State Appropriations. The level of state support of a higher education institution affects the cost of attending a particular institution through higher tuition and fees. With increasing cost of operating the university, support from the state is key to the success of increasing enrollment (Weisbrod, Ballou \& Asch, 2008). Greater support from state has been found to be associated with higher enrollment (St John, 2003). 
Information on the level of state support to higher education comes from Grapevine reports, which publishes aggregate state tax appropriations to higher education institution. From the survey, I extracted the amount of appropriations for each state in each fiscal year.

Per Capita Income. The students' family income is yet another input factor described in the model. Students of different financial backgrounds have different utilities which affect their decision to go to college. As income increases, individuals' ability to afford higher education increases and thereby increases the utility of attending college. The demand for higher education as a normal good increase as household income rises (Buss, Parker, \& Rivenburg 2004; Heller, 1997). Students from high income status are more likely to view college education more positively than students from lower income status. Students from low SES households tend to enroll in college at a far lower rate than their counterparts from middle to high income households (NCES, 2004)

This information is obtained from the Bureau of Economic Analysis which gathers economic indicators across states. I extracted information for each state from 1992 to 2016 for the month of April values which were all adjusted by the consumer price index to reflect real values.

Number of High School Students. The number of students who enroll in college is proportional to the number of high school graduates each year (Warren, 1999). This normalize enrollment data between large states such as Massachusetts and Pennsylvania and small states such as Rhode Island and Delaware. Data on the number of high school graduates is obtained from common core data administered by NCES. It published information on the number of diplomas awarded in public high schools in each school 
district in all states. I aggregated this figure to obtain the number of students in each state who were awarded a diploma in each year.

Percent Minority Students. Historically, due to unequal opportunities, students of certain racial background tend to have different social and cultural capital which influences their college going choices (Hassler e tal., 1989). Minority students tend to enroll in college at a lower rate than their peers (Heller, 1997). Therefore, the percent of minority students in each state is related to the college going attitudes in the state. From common core data, I was able to extract information on the total number of students enrolled for each state, and then calculated the percentage of minority students for each state and each year.

\section{Sample}

Ideally, this study should include annual enrollment from each state and Washington DC for the entire period that exit exams have existed which dates back to the 1970s. However, IPEDS only began to collect information on the resident status of students at the time of enrollment from 1992 and it does that every other year since then. This allowed for only analysis of information from even years from 1992 to 2016 resulting in 13 state year cohort data points. The outcome variable represented first-time enrollment for all institutions, only 4-year and only 2-year institutions for the fall semester which measured the dependent variable. The dataset excluded students from foreign countries and the outlying areas of the US (American Samoa, Federated States of Micronesia, Guam, Marshall Islands, Northern Marianas, Palau, Puerto Rico, and Virgin Islands) whose requirements standards for high school graduation were not available. For this study, the year referred to the graduating year rather than the calendar year of any cohort. For instance, the year 2008 will refer to the graduating class of 2008. 


\section{Analytical Strategy}

The statistical analysis of the data is conducted by using the staggered differencein- differences. As outlined above, this is modified differences-in -difference which allowed the researcher to estimate the effect of adoption of exit exams on college enrollment by making use of the stepwise adoption of exit exams across the country. By using this strategy, it allows states that adopt exit exams later to act as control for earlier states that adopted exit exits. More specifically, the equation is as follows:

$$
Y_{i t}=\alpha+\beta(\text { Exit_Exams })_{i t}+\delta S_{i t}+\delta_{i}+\delta_{t}+\varepsilon_{j t}
$$

Where:

$Y_{i t}$ is a measurement of total number of students enrolled in (a) any higher education institution anywhere, (b) enrolled in a 4-year institution and (c) enrolled in a 2- year institution from state $\mathrm{i}$ and at time $\mathrm{t}$ who graduated from high school in the previous 12 months and enroll student at a fouryear institution $i$ in an academic year $t$.

Exit_Exams $_{i t}$ is the key independent variable, a measure whether state $\mathrm{i}$ has exit exams in place in year $t(t=1)$ or does not have exit exams $(t=0)$

$S_{i t}$ is measure of variant factors within a state that affect enrollment (tuition, financial aid, household income, percentage minorities, institutional type etc.)

$\delta_{i}$ is state -specific fixed effects.

$\delta_{t}$ is year effects.

$\mathrm{e}_{i t}$ is the model error clustered at the state level.

Bertrand and Mullainathan (2003) suggested using form of a difference-indifferences model that accounts for state fluctuations in policy and between year 
variations. In difference-in-differences model, instead of lower-order terms measuring average differences in the before-policy treatment group and after-policy control group, fixed effects are specified to account for variation in both groups (Bertrand \& Mullainathan 2003). Fixed effect account for invariate state and time factors that affect the outcome (Woodridge, 2010). Fixed effects regression is an efficient way to capture time effects and allow for multiple data points of the same variable to be compared to itself in the same analysis (Cellini, 2008). Fixed effects in this equation allowed the researcher to be able to control variables that are not measurable but are unique to each state or each year. The data was analyzed using the SAS enterprise which was a convenient package for analyzing educational data.

Based on the theoretical framework examined earlier, the coefficient of exit exams is expected to be positive suggesting a greater weight of college preparation component of the conceptual framework. However, I expect tuition to have a negative coefficient based on existing theory of student demand. Financial aid and level of students' state appropriations are expected to be positive apriori. For other control variables, their signs are expected to follow the trend of traditional student demand literature.

The basic analysis included states that never adopted exit exams as part of the comparison group. Following the strategy of Dynarski (2004), the researcher created a variable that indicated the year and the state in which exit exams was in place. This allowed the researcher to test the effect of exit on college enrollment as a whole, by sector as well as by instate or out-of-state status. 


\section{Robustness Checks}

Any quasi experimental analysis has a limitation in its ability to support causal findings (Shadish et al., 2002). The use of multiple comparison groups strengthens the estimates and reduces the possibilities of biases or random variation in the use of just one single comparison group (Meyer, 1995). Robustness checks allowed the researcher to test whether the estimates are truly capturing the effect of the policy. The more similar the potential comparison group is to the treatment group, the better their use in validating the estimates in the primary analysis (Shadish et al., 2002; Meyer, 1995). In this section, I described various alternative analysis that were performed to examine various threats to validity in this research by considering three robustness checks for the analysis.

Only States with Exit Exams. This sensitivity analysis ensured that the counterfactual used in the primary analysis were truly representative of what would have happen to the treated states had they not been in the treatment. As in any quasi experiment, when treatment states are thought to be different from nontreatment states, then non-treatment states form a poor comparison group (Dynarski, 2004). This approach drops all the states that do not have exit exams from the sample and estimate only treated states using the staggered timing of adoption of exit exams. Thus it is limited to only states that have adopted exit exams at some point during the policy exams. In 1992, there were only two states and the number rose to 23 by 2012. Results from this analysis are not expected to be so different from the primary estimates. The assumption of this that when states move from control to treatment, it is uncorrelated to any state specific factor and therefore represents a quasi-random check (Dynarski, 2004).

Random assignment of treatment. Falsification test are used as a tool to test whether the estimates are truly capturing the effect of the policy (Meyer, 1995). There is 
potential bias in non-experimental methods and falsification method ensures that the treatment are truly related to the outcome variable (Meyer, 1995). This method is done by randomly assigning treatment and measuring the impact on college enrollment. In using this method, the number of states that are randomly selected for treatment for each year must be directly proportional to the actual values (Muñoz, Harrington, Curs \& Ehlert, 2016).

\section{Summary}

In this chapter, I demonstrated the research methodology for this study by presenting alternative strategies that could be used to answer the research question. With varying levels of threats to validity, I presented the different methods and showed how staggered difference-in-differences is the most appropriate strategy based on the research question and data. I described the variables and their sources for this study. The primary source of data for the enrollment comes from the digest of education which has traditionally has been use in variety of context in higher education research whether at the institution, state or national level. By using the population of all states, this study potentially broadens the scope of knowledge in examining the relationship between exit exams and college access beyond the individual or a single state analysis that had characterized our source of understanding of exit exams. The key independent variable which was the exit exams implementation was gathered from two sources which together provide information on year, type and version exams since they introduced first in New York in 1977. Finally, I outlined some of the limitations based on the data and how I partially addressed some of the inherent problems. 


\section{CHAPTER 4: RESEARCH RESULTS}

The purpose of this study was to examine the relationship between adoption of high school exit exams and college going rate of students in the United States. A difference-in-differences estimation strategy was used to investigate whether postsecondary enrollment trends changed following the adoption of exit exams to determine if exit exams impacted the college enrollment in the United States. Thus, the research questions were as follows:

1. What was the relationship between state-level adoption of high school exit exams and postsecondary enrollment?

a. Did the adoption of exit exams have a differential relationship with enrollment at different postsecondary institutional types (i.e. 4-year and 2-year institutions)?

b. Did the adoption of exit exams have a differential relationship with instate and out-of-state postsecondary enrollment?

2. Was the relationship between exit exam adoption and enrollment different for different types of exit exams?

This chapter presents descriptive and inferential analysis of the research questions based upon data from all US states (excluding Washington DC). The dependent variable came from NCES which published information on the number of students from each state who enrolled in institutions of higher education each year from 1992 to 2016.

Information on exit exams by state came from the CEP Annual Report (2012) which gathered historical information about exit exams across the country. To understand if exit 
exams were related to college enrollment, I examined changes in enrollment following adoption of exit exams. This study utilized the staggered difference-in-differences strategy that provided an average treatment effect on the treated.

The rest of the chapter is written as follows: First, a descriptive analysis of the data provides summary data of both the outcome variable and the control variables. Second, the formal statistical analysis of the relationship between enrollment and exit exams are described. Third, the results of robustness checks to validate the results obtained as the true reflection of the status of exit exams are explained. Finally, a summary of the major results of the study is provided.

\section{Descriptive Statistics}

This section presents the summary display of the background characteristics and demographic description of the data used for this study. The objective was to present an overview and provide in-depth knowledge about both the outcome variable and the independent variables used in this study. By utilizing the measures of central tendency such as the mean in conjunction with the standard deviation, this section describes the distribution and spread of each of the variables. The descriptive statistics are separated by the types of variables-continuous or discrete-to further describe the data.

The balanced panel is 650 state-year records from 50 states (excluding Washington DC) and 13 years. Below is the presentation of summary statistics for the dependent variable (enrollment), followed by the key independent variable (exit exam adoption), and finally, the control variables. 


\section{Enrollment}

Figure 1 shows the trend of the average number of first-time students by year from 1992-2016 for all states irrespective of whether they eventually became an exit exam state or not. In general, average enrollment grew by $62 \%$ for all types of institutions. The highest growth was witnessed in 4-year institutions which grew by $77 \%$ while the average enrollment in 2-year institutions grew by $35 \%$ from $1992-2016$. The data shows that the largest growth period was witnessed between 2004 and 2008 and thereafter remained constant except for 2-year sector which slightly decreased after 2010 . The relative differences in average enrollment between 4-year and 2-year had largely been constant except years after 2010 .

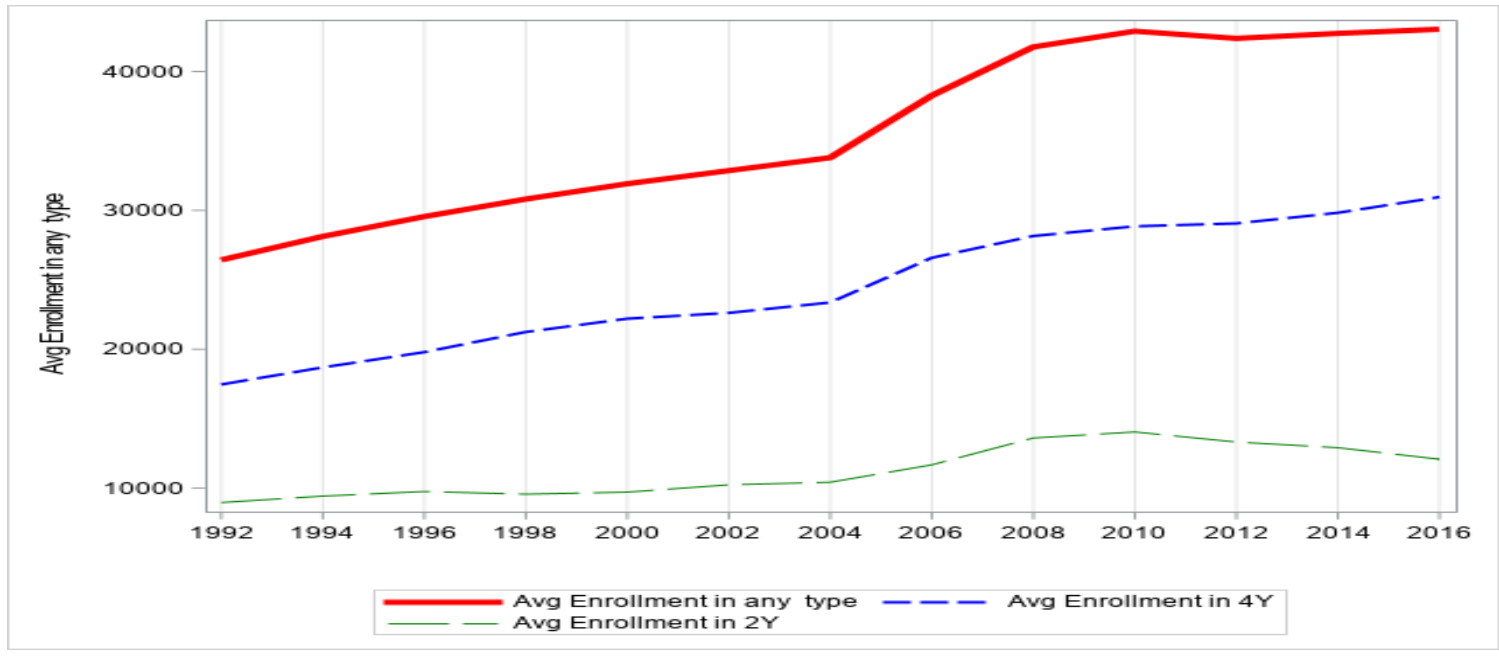

Figure 1. Average Enrollment of First-time students by Type of Institutions

Figure 2 displays the disaggregated enrollment by students' residency.

Specifically, the figure separates the average enrollment of first-time students by whether their postsecondary enrollment was within state or outside of their own state. As shown in the figure 2, 2.8\% of all first-time students enrolled in out-of-state institutions. The instate average enrollment mirrored the overall average enrollment. Figure 2 shows a 
steady increase in the average out-of-state student from $17 \%$ to $20 \%$ of all first-time student enrollment from 1994 to 2016.

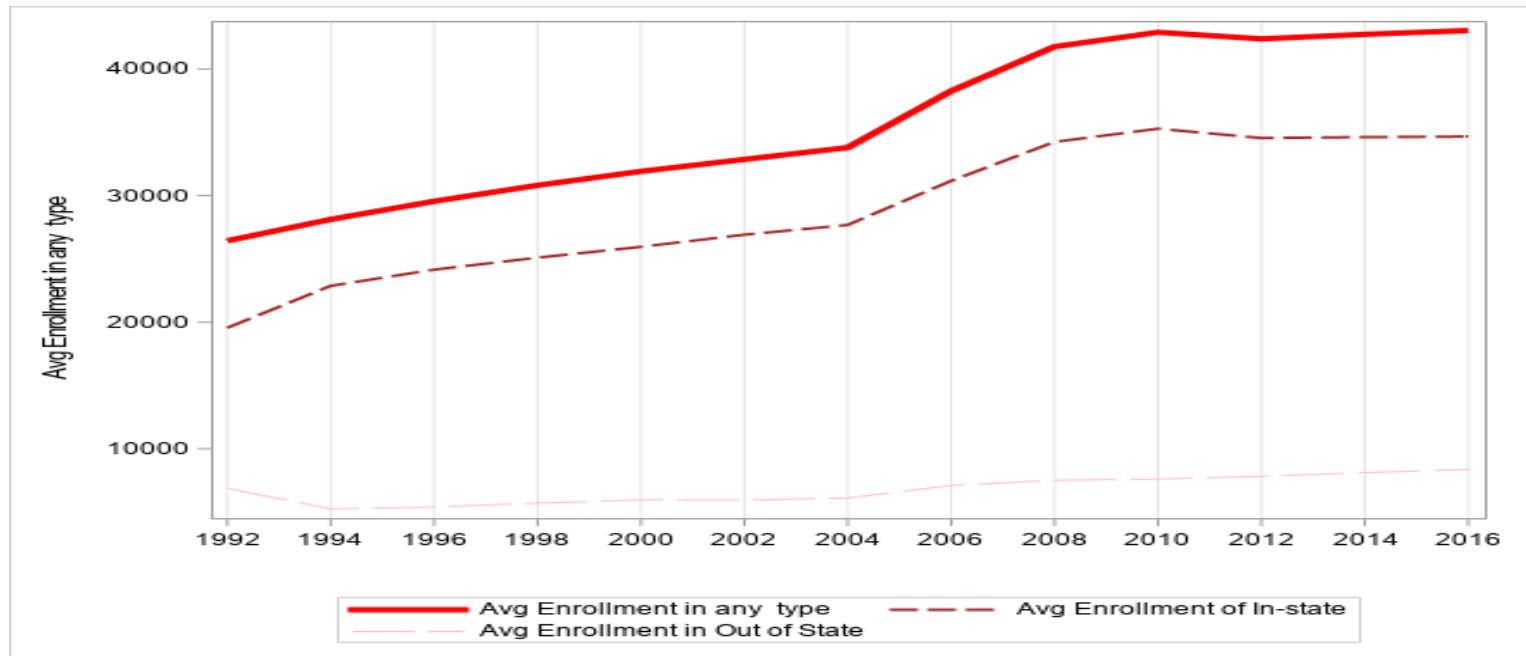

Figure 2. Average Enrollment of First Time Students by Place of Enrollment

Table 1 presents the descriptive statistics of the dependent variable. It displays the mean enrollment across states and years by type of institutions and by place of enrollment. Table 1 shows that the mean enrollment for all freshmen from each state who attend college anywhere was 35,746. Twice as many students on average attended 4-year institution than 2-year institution. Enrollment in 2-year institutions tended to be relatively more similar and closer to each other than the enrollment in 4-year institution given by their respective standard deviations. Table 1 shows large disparities in enrollment across different types of institutions.

When separated by sectors, there was more variability in the four-year institutions than 2-year institutions. This implied that there were great differences in the total number of students who enrolled as first-time students in 4-year institution within a state than 
those that enrolled in 2-year institutions. With states such as Alaska with relatively low number of first-time students as compared to California, this variability was expected.

Table 1 also shows the variation in enrollment between instate students' enrollment and out-of-state enrollment. In spite of the great differences in terms of the number of students who enrolled instate and out-of-state, the standard deviation showed little spread within instate and out-of-state enrollment.

Table 1

Descriptive Statistics of Dependent Variable: First Time Enrollment, by type and Place

\begin{tabular}{lcrrrr}
\hline Variable & N & Mean & Sd Dev. & Minimum & Maximum \\
\hline $\begin{array}{l}\text { Overall } \\
\quad \text { All First-time Students }\end{array}$ & 650 & 35,746 & 40,225 & 2,227 & 274,295 \\
$\quad$ By Type of Institution & & & & & \\
$\quad$ Enrolled in 4Y institutions & 650 & 24,530 & 25,347 & 1,411 & 166,305 \\
$\quad$ Enrolled in 2Y institutions & 650 & 11,216 & 16,767 & 83 & 143,752 \\
$\quad$ By Place of Enrollment & & & & & \\
$\quad$ Enrolled in In state institution & 650 & 28,987 & 34,722 & 820 & 245,051 \\
$\quad$ Enrolled in out-of-state institution & 650 & 6,759 & 8,044 & 744 & 112,508 \\
\hline
\end{tabular}

\section{State Adoption of Exit exams}

This section describes the data relating to exit exam adoption as a policy, the growth of exit exams over the years, and the geographical distribution of exit exams across the country. The purpose of this section was to provide in-depth understanding of the patterns associated with exit exams and the timing of adoption.

Since 1992, twenty-three states had passed exit exams laws and they are displayed in table 2. For each state that ever became part of the treatment group, the table gives information about the year exit exam policy went into effect and the type of exit exams 
that was implemented. States that were never in the treatment were designated as 'Never' for type for type of exit exams.

For the scope of this research, exit exams had narrowly been defined to only include policies which were statewide and where students were required not only to take but to pass exit exams in order to receive a high school diploma. Without passing the comprehensive tests, students' diplomas were withheld. The effective year was measured by the first year the penalty of withholding certificates was applied in each state for states that eventually became exit exam states. That requirement was relaxed for end-of-course exams which by design did not necessarily have pass or fail but often used as part of the grade point average of the student. For the 23 states that adopted exit exams at one point in time within the period of study, over 50 percent of them first adopted such policies in the early 2000's. Most of those states that adopted exit exams in the 2000's were standard-based type of exit exams. This coincided with the No Child Left Behind movement which saw many states use exit exams to satisfy the accountability purposes of NCLB (Shuster, 2012). The early adoptees were primarily few and were mostly minimum competency exit exams. End-of-course Exams (EOC) became prominent in the early 2002s following the NCLB act. 
Table 2

States and the Years Exit Exams policies went into effect

\begin{tabular}{|c|c|c|c|c|c|}
\hline state & Year & Type & state & Year & Type \\
\hline Alabama & 2001 & Standard & Montana & & Never \\
\hline Alaska & 2004 & Minimum & Nebraska & & Never \\
\hline Arizona & 2006 & Standard & Nevada & 2003 & Standard \\
\hline Arkansas & 2014 & EOC & New Hampshire & & Never \\
\hline California & 2006 & Standard & New Jersey & 2003 & Minimum \\
\hline Colorado & & Never & New Mexico & 1993 & Minimum \\
\hline Connecticut & & Never & New York & 2000 & EOC \\
\hline Delaware & & Never & $\begin{array}{l}\text { North } \\
\text { Carolina }\end{array}$ & 1998 & Standard \\
\hline Florida & 2003 & Standard & North Dakota & & Never \\
\hline Georgia & 1994 & Standard & Ohio & 2007 & Standard \\
\hline Hawaii & & Never & Oklahoma & 2012 & EOC \\
\hline Idaho & 2006 & Standard & Oregon & 2012 & EOC \\
\hline Illinois & & Never & Pennsylvania & & Never \\
\hline Indiana & 2000 & Standard & Rhode Island & 2014 & EOC \\
\hline Iowa & & Never & $\begin{array}{l}\text { South } \\
\text { Carolina }\end{array}$ & 2006 & Standard \\
\hline Kansas & & Never & South Dakota & & Never \\
\hline Kentucky & & Never & Tennessee & 2005 & EOC \\
\hline Louisiana & 2003 & Standard & Texas & 2005 & Standard \\
\hline Maine & & Never & Utah & & Never \\
\hline Maryland & 2009 & EOC & Vermont & & Never \\
\hline Massachusetts & 2003 & Standard & Virginia & 2004 & EOC \\
\hline Michigan & & Never & Washington & 2008 & Standard \\
\hline Minnesota & 2010 & Minimum & West Virginia & & Never \\
\hline Mississippi & 2006 & EOC & Wisconsin & & Never \\
\hline Missouri & & Never & Wyoming & & Never \\
\hline
\end{tabular}

Figure 3 shows the historical pattern of adoption of exit exams as a whole and by type. Based on the strict scope of definition for states to be counted as having adopted exit exams, only two states qualified as exit exam states in 1996. As shown in figure 3, the total number of states with exit exams rose sharply from 2002 to 2008 . This is 
consistent with the period where a number of educational initiatives were implemented concurrently to raise students' outcomes (Lee \& Reeves, 2012). By 2012, a total of 23 states had adopted exit exams. Overall, as shown in figure 3, the number of states that required students to pass exit exams declined sharply from 2012 representing the largest significant policy change regarding exit exams since the 1990's.

Figure 3 also reveals noticeable differences in pattern amongst the different types of exit exams. As shown in figure 3, early adoption of exit exams were primarily minimum competency exams up till the year 2000 when standard-based exit exams became the most common type of exit exams. End-of-course exams began to gain prominence in the 2000's and by 2012 represented the type of exit exams that most states had adopted. By 2016, most states had either dropped their exit exams or suspended its enforcement awaiting further review leading to the lowest number of states with exit exams since 2002.

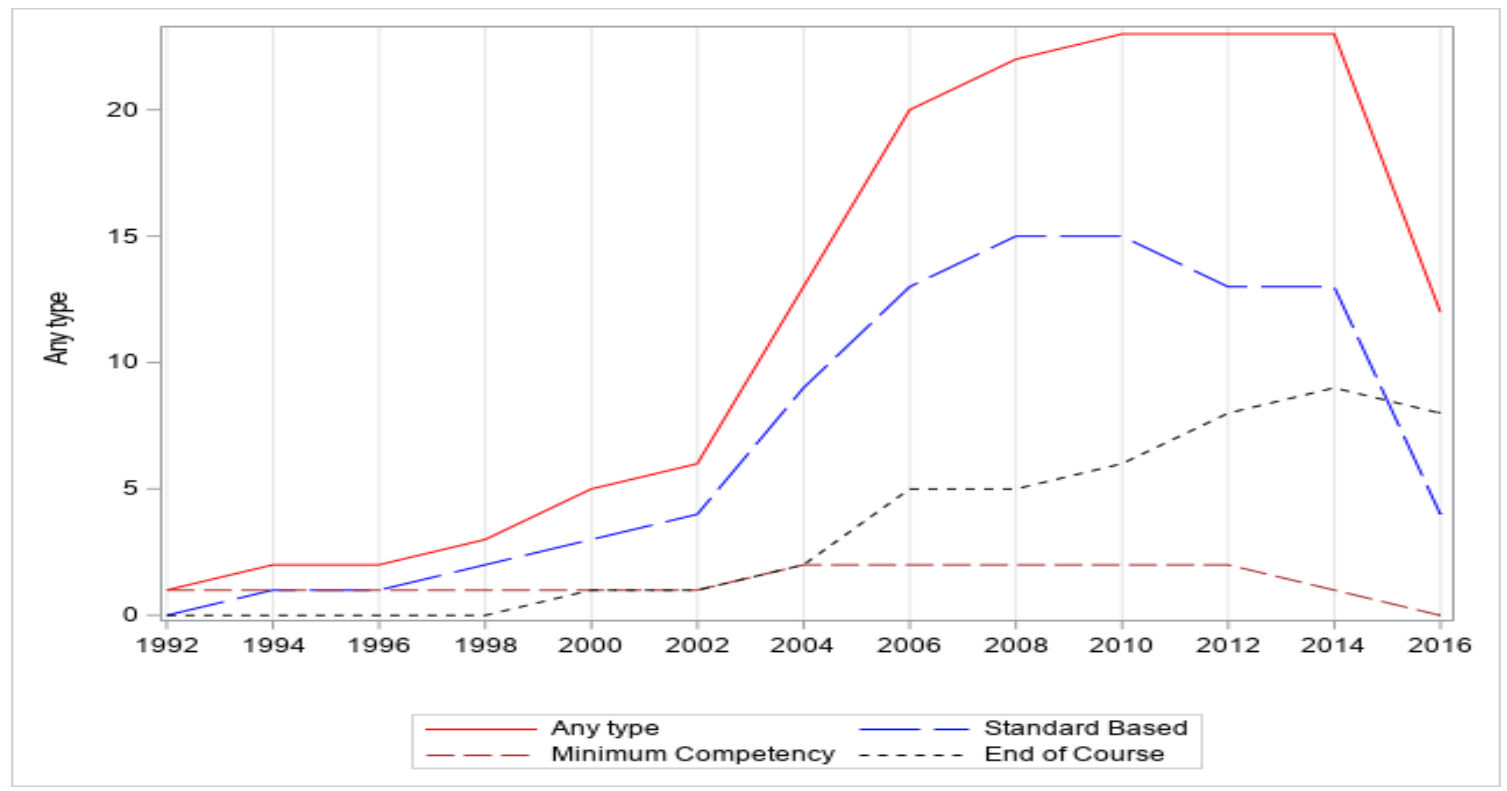

Figure 3. Number of States with Exit Exams by year and type 
Figure 4, 5, and 6 show the evolution of Exit exams laws overtime. Figure 4 shows states that had exit exams as of 1996. Though many states had some form of exit exams prior to the 1990s, they did not qualify as exit exams states based on the definition of exit exams adopted in this study. In 1996, only New Mexico and Georgia had exit exams that met the conditions of exit exams. Georgia in particular had been the pacesetter in many educational initiatives particularly in the 1990s including adoption of large state Merit aid program (Dynarski, 2004).

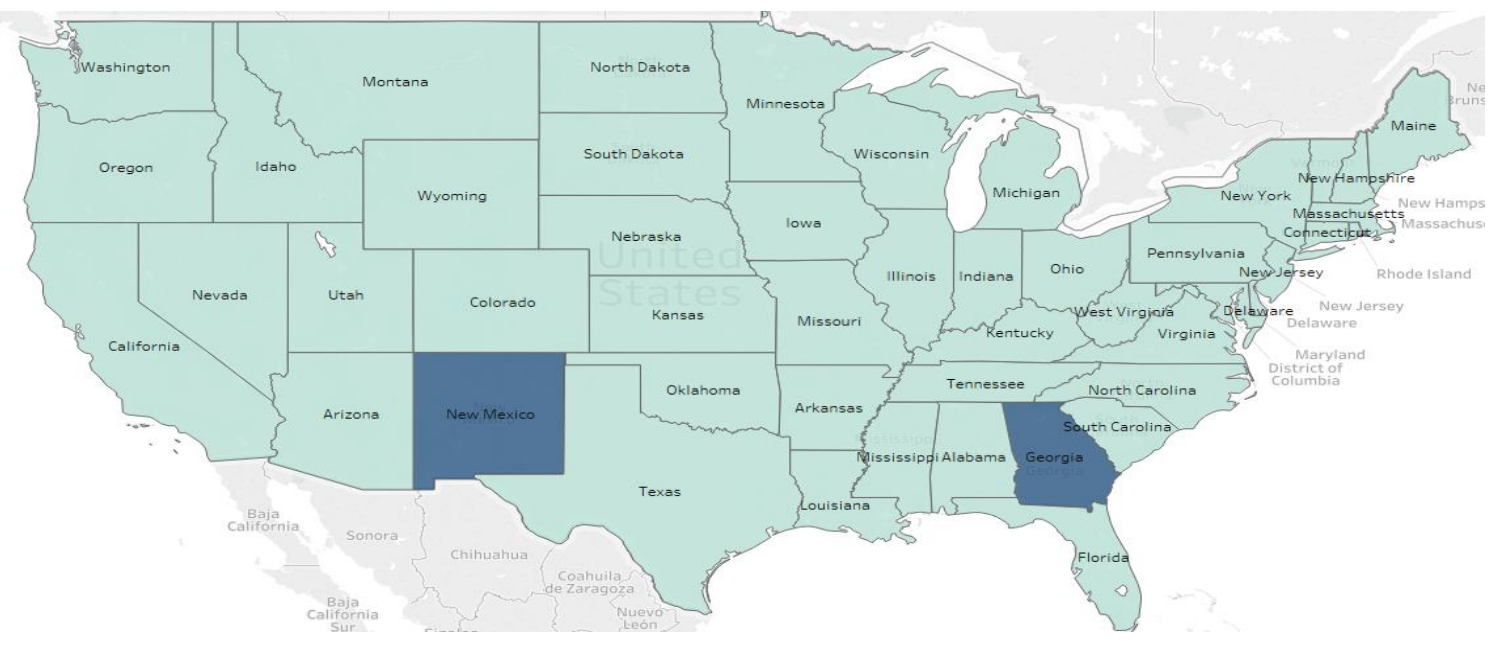

Figure 4. Geographical Distribution of State with Exit Exams as at 1996

Figure 5 shows the states that had added to Georgia and New Mexico as exit exams states by 2006. Many of the states' action were in response to the new accountability measures that were adopted in the early 2000s following the NCLB. The figure shows most coastal states from East to West had adopted exit exams as statewide educational initiative. A total of 18 states had adopted exit exams from 1996-2006. 


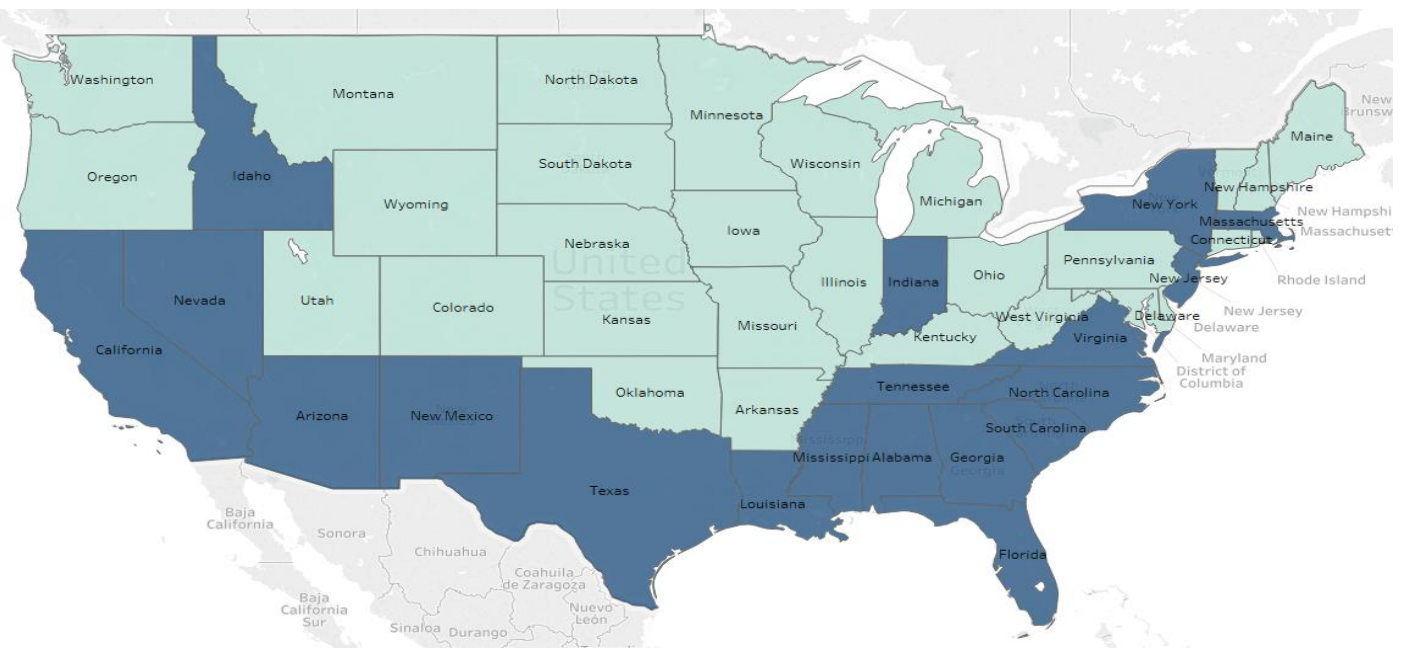

Figure 5. Geographical Distribution of State with Exit Exams as at 2006

Figure 6 shows those states that still had exit exams as at 2016. From 2012, states had begun dropping exit exams as statewide initiatives. States such as California, Arizona, New Mexico, Texas, Georgia, North Carolina, and South Carolina had dropped their requirement for high school students to pass exit exams prior to graduating. By 2016, half of all states that had adopted exit exams had abandoned the requirement or were in the process of reviewing them.

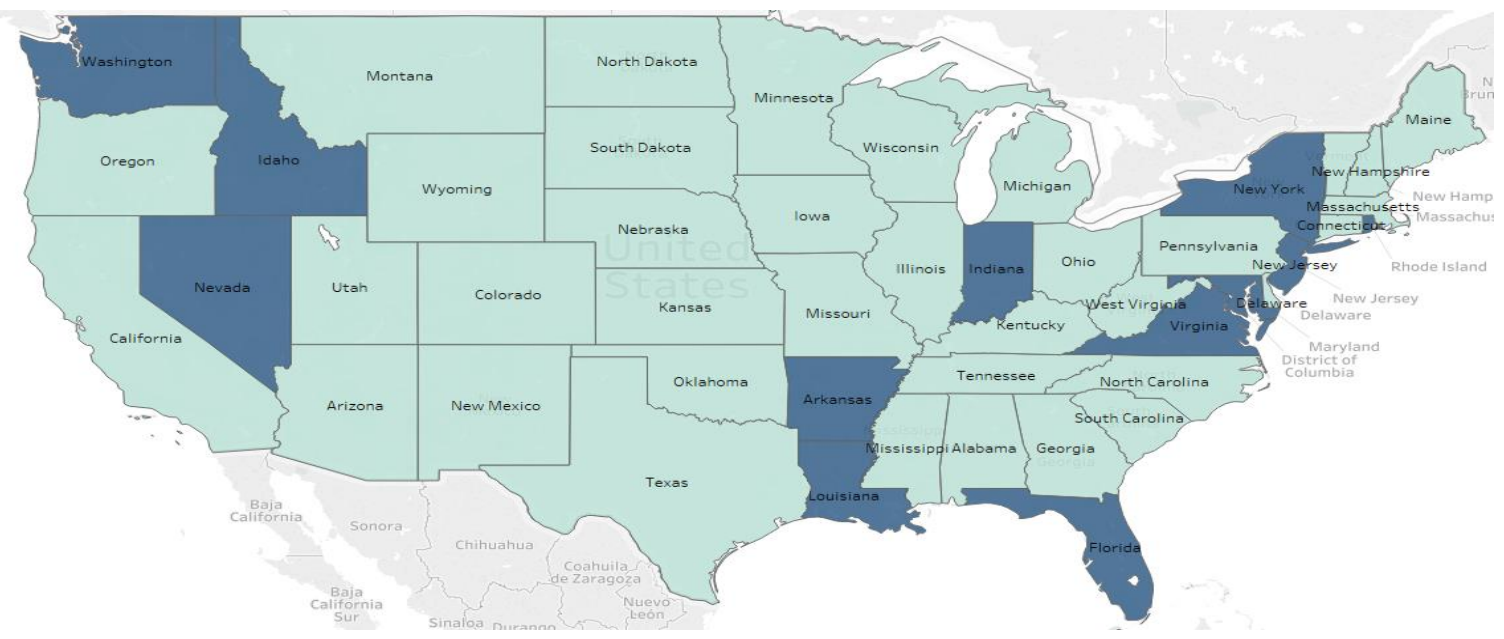

Figure 6. Geographical Distribution of State with Exit Exams as at 2016 


\section{Control Variables}

This section describes the other state level covariates that affect enrollment. These are the factors that have been determined theoretically and statistically as predictors of students' enrollment. The descriptive statistics provide better understanding of the data and the basis for transformation of the data.

Table 3 provides the mean, standard deviation, minimum, and maximum values associated with the control values. Tuition refers to the average undergraduate tuition and fees charged for full-time instate students in degree granting institutions. Average tuition across the entire data set was $\$ 5,333$ with a minimum $\$ 1,408$ and maximum of $\$ 15,537$. The standard deviation of tuition was high suggesting that tuition across years and states had high variability. Unemployment rate was as low as $2.3 \%$ to a high value of $13.3 \%$. There was little variability in unemployment rate across the county as seen in the table 3 . Financial aid packages ranged from zeros which was for states that did not have state financial aid to as high as $\$ 2$ billion dollars. The number of high school graduates on an average was about 60,040 students.

Table 3

Descriptive Statistics of control variables

\begin{tabular}{lccccc}
\hline Variable & $\mathrm{N}$ & Mean & Sd Devs. & Minimum & Maximum \\
\hline Tuition & 650 & $5,337.37$ & $2,869.95$ & 1408 & $15,537.44$ \\
High School Graduates & 650 & $60,326.78$ & $67,744.9$ & 5,494 & 484,169 \\
Unemployment rate & 650 & 5.57 & 1.82 & 2.3 & 13.5 \\
Per capita income & 650 & $33,711.14$ & $10,373.44$ & 14,827 & 69,311 \\
merit Based Aid & 650 & 30.70 & 85.22 & 0 & 766.98 \\
Need Based Aid & 650 & 96.17 & 200.96 & 0 & 2018.88 \\
State Appropriations & 650 & $1,301,478$ & $1,629,327$ & 53,222 & $13,773,357$ \\
Percentage Minority & 650 & 0.33 & 0.18 & 0.02 & 0.81 \\
\hline
\end{tabular}




\section{Results}

This section explores the relationship between exit exams and college enrollment. It statistically describes the relationship between the adoption of exit exams and college enrollment using a difference-in-differences estimation strategy. First, it examines the parallel trend assumption of difference-in difference identification strategy. The difference-in-differences analysis includes state-specific fixed effects and year effects. By including state fixed effects, this analysis uses within-state variation over time to estimate enrollment effects. To account for the possibility of serial correlation in the error term, standard errors were clustered at the state level. Also, as mentioned in Chapter 3, this study uses a log transformed method for convenient interpretation of the results. These statistical results are broken down by the different types of research questions.

\section{Parallel Trend Assumption}

Before establishing the impact of exit exams quantitatively, it was important to first determine that the research satisfied the main assumption of difference-indifferences known as the parallel trend assumption. Conditional on control variables, the deviation of outcome variable for the comparison state approximates the deviation from prior trends that treated states would have been had they not received the treatment (Chingos et al., 2010; Wooldridge, 2010). To fulfil this assumption, prior to adoption, the enrollment trends of states that adopted exit exams should mirror the trend of states that did not adopt. There is no direct measure of the parallel trend assumption but graphical representation of the data structure can satisfy the condition (Meyer, 1995).

The stepwise adoption of exit exams lend itself to graphically demonstrate the assumption of parallel trends by using groups or bins. Groups are collection of states that 
share common timing of adoption of exit exams. Within that, states were classified into three groups based on adoption status or differential adoption periods. The first group was called never adopters which represented states that were never in the treatment within the period of study. These were states which never adopted exit exams as a statewide initiative. The second group of states were called early adopters which represented those states that adopted exit exams in 2003 following the enactment of No child left behind. The third group comprised of those states that adopted exit exams from 2006 to 2010 and were referred to as the late adopters. Callaway and Sun (2018) and Goodman (2018) suggest partial aggregation where occurrences within certain period can be grouped as one bin. A parallel trend assumption is depicted by a higher intercept of post-policy as compared to the pre-policy era which shows the effect of the treatment. This is represented by the solid line and dotted line for treated groups and counterfactual respectively. The following comparisons were used to graphically illustrate parallel trends: early adopters vs. never adopters, early adopters vs. late adopters before late adopters became part of treatment, and late adopters vs. never adopters.

Figure 7 compares the pre-treatment average enrollment to after treatment between the groups between states that implemented the exit exams policy in the aftermath of NCLB to those that never implemented any exit exams policy. These are states that adopted exit exams in 2003 which were Florida, Louisiana, Massachusetts, New Jersey, and Nevada. The average enrollment in those states was higher than the never adopters group in both pre-treatment period and post-treatment era. The intercept appeared to have increased in the post treatment period for the early treated group as compared to the counterfactual. This suggested that in the period following their adoption of exit exams, enrollment of first-time students from those states increased. 
relative to those states that never adopted exit exams. Though modest, this illustration depicted that the parallel trend condition had been met.

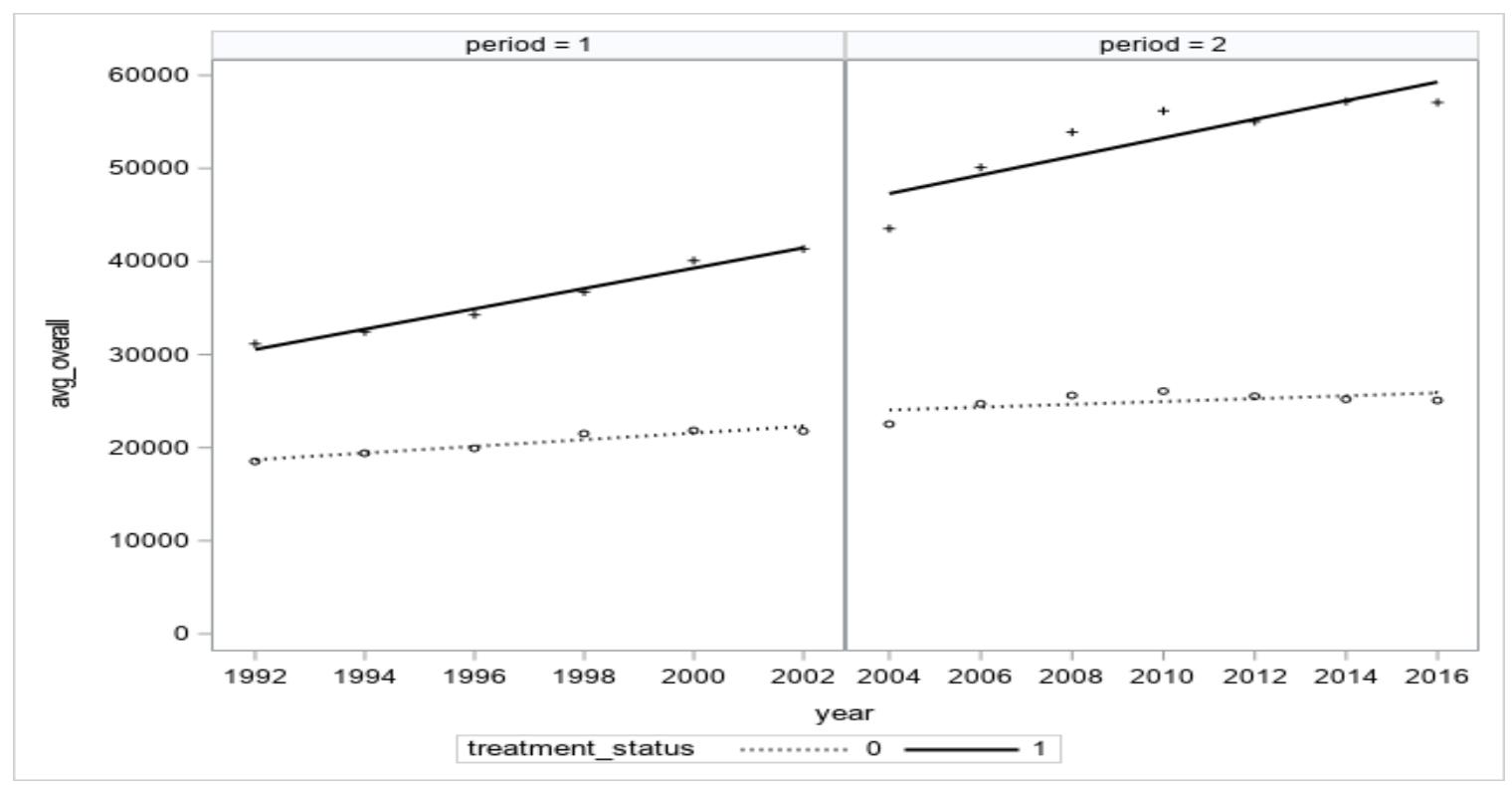

Figure 7. Early Adopters vs. Never adopters

Figure 8 compares the pre-treatment average enrollment to after treatment between states that implemented the exit exams policy in the aftermath of NCLB (i.e. early adopters) to those that implemented between 2006-2010 (i.e. the late adopters). The early adopters were states that adopted exit exams in 2003 which were Florida, Louisiana, Massachusetts, New Jersey, and Nevada. Late group were states that first adopted exit exams from 2006-2010 and comprised of Idaho, Washington, Maryland, Minnesota, and Ohio. Prior to 2003, both early adopters and late adopters had not adopted exit exams and this is shown in the period 1 . After 2003 when early adopters became part of the treatment group, the intercept of early adopters group appeared to have increased showing the impact of exit exams. The late adopters became the counterfactual illustrating what would have happened to the early group had they not received the treatment. When the early group adopted exit exams in 2003 , the 
counterfactual was the late adopters which remained untreated from 2003 to 2007. There appeared to be a sharp increase in the intercept for the early group as they became exposed to the treatment post 2003 while the intercept for the late adopters remained unchanged. This depicts the treatment effect of the difference-in-differences model. The dotted line represents the trend of late adopters while the solid line represents trends of early adopters.

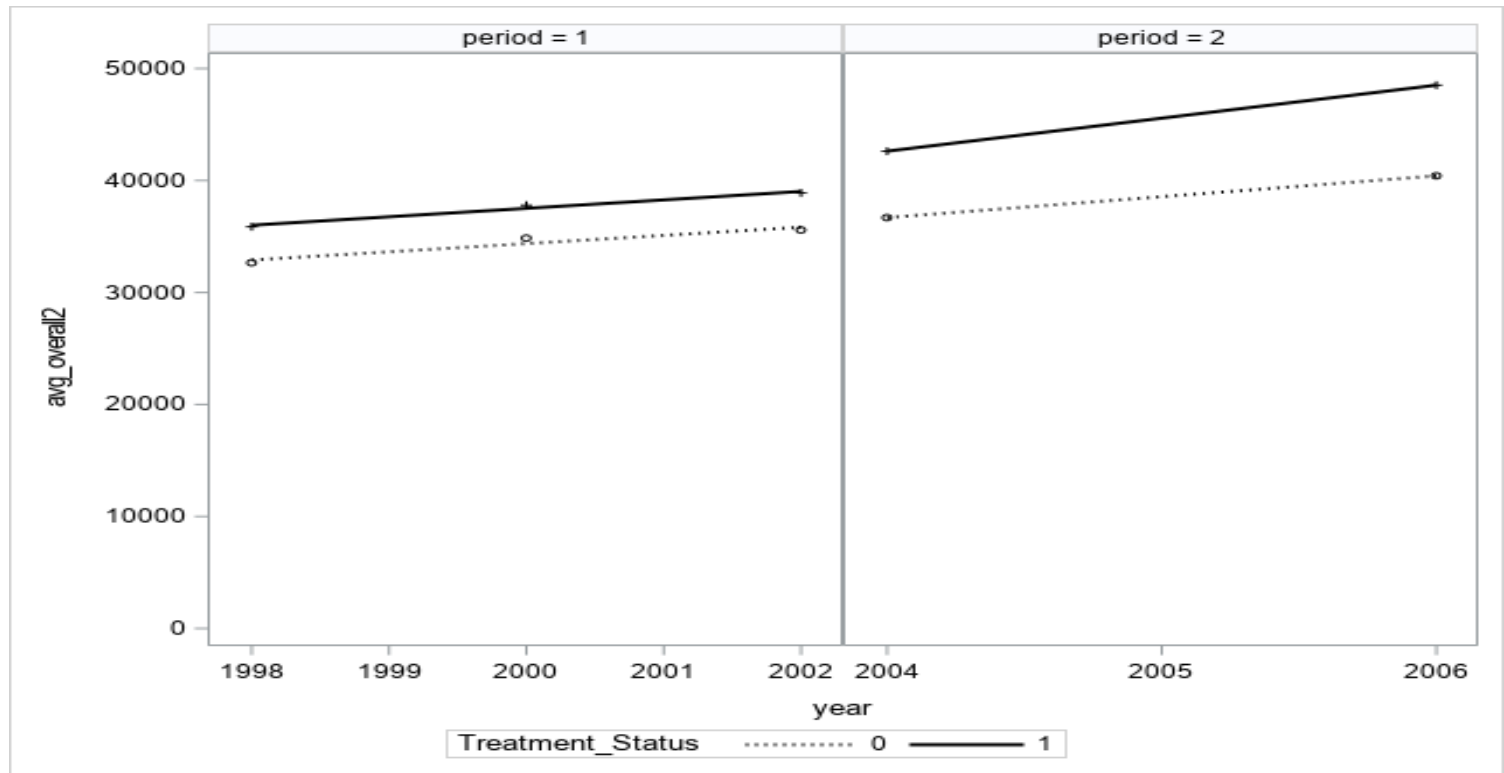

Figure 8. Early Adopters vs. Late adopters before late adopters became treated Figure 9 compared late adopters to never adopters to further test graphically the parallel trend assumptions. Late group comprised of states that first adopted exit exams from 2006-2010. These states were Idaho, Washington, Maryland, Minnesota and Ohio. The year 2010 was the first year all states described as late adopters became part of treatment group. The never treated group again was reflected by the dotted line and the two period signified before and after. The vertical line corresponds to the average enrollment per year. This graph did not perfectly illustrate the condition of parallel trend. 


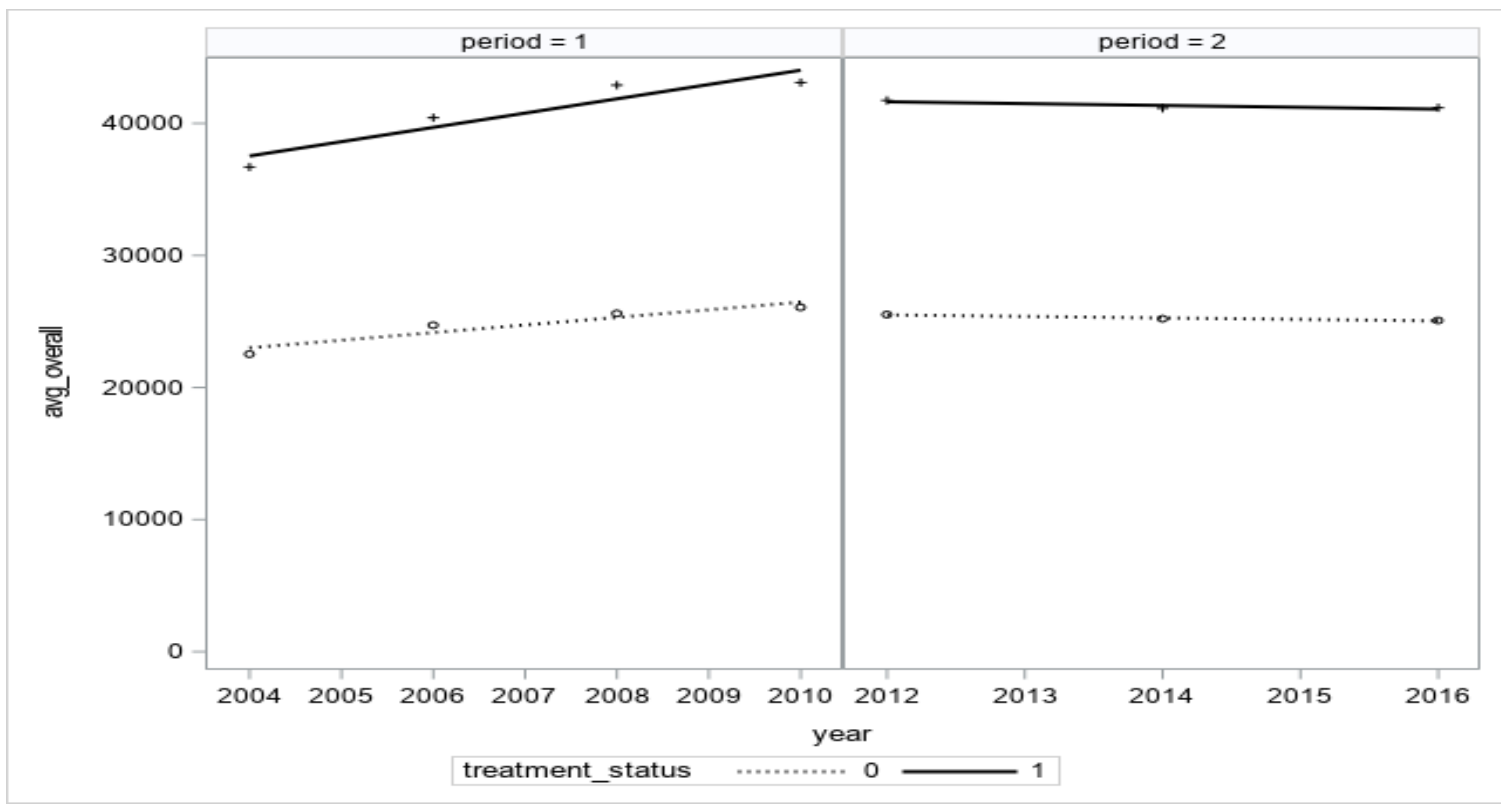

Figure 9. Late Adopters vs. Never Adopters

As noted earlier, difference-in-differences produce unbiased estimates when the parallel trend assumption holds. Figure 7 and 8 produced modest and strong evidence that the trend holds using the comparison between earlier adopters and never adopters and early adopters and late adopters before late adopters became treated states respectively. While these two suggest unbiased estimates for using difference-in-differences methodology the third scenario did not. A potential reason is that unlike the first two scenarios where states adopted the exit exams in the same year, the last case shows a wide variation of adoption period. Despite the fact that by 2011, all late adopters had then been part of the treatment group, there was not enough time for the effect to manifest. Based on the analysis of average enrollment in pre-adoption and post-adoption for the various scenarios, it became clear that the parallel trend condition was met. There appeared a significant increase in average enrollment in the treated group with the counterfactual remaining the same. These figures demonstrate graphically the impact of exit exams on college enrollment. 


\section{Exit Exams and State Requirement for Number of years of Mathematics}

The relationship between an outcome variable and a dependent variable could be undermined by the presence of a concurrent policy that is highly correlated with the variable of interest in this (Shadish et al., 2009). In the case of exit exams, the presence of another state level policy that improves the rigor of curriculum could bias the relationship between enrollment and the exit exams. Without specifically addressing this issue, the results of any relationship between exit exams and college enrollment could be misleading.

The report of nation at risk also ushered in the enactment of state laws that increased the number of mathematic courses that students needed to complete in order to graduate from high school (Baker \& Lang, 2013; Warren \& Jenkins, 2006). The number of Carnegie units of math courses that states required ranged from 2 to 4 with many states increasingly defining the type of courses and the sequence of course to be taken to fulfill this requirement. In 2012, twelve states had a requirement for 4 units of Carnegie units of math courses and by 2020 a total of 18 states would have required students to complete 4 years of math classes. This section presents the correlation analysis between exit exams policies and the minimum number of maths requirement adopted by states to graduate from high school. 
Table 4

Examining the relationship between Exit Adoption and Requiring 4 of Maths course

\begin{tabular}{|ccccccc|}
\hline Variable & $\mathrm{N}$ & Mean & Std Dev & Sum & Minimum & Maximum \\
\hline Any Exit Exam & 650 & 0.23846 & 0.42647 & 155 & 0 & 1 \\
4 Carnegie Units & 650 & 0.10769 & 0.31023 & 70 & 0 & 1 \\
\hline $\begin{array}{c}\text { Pearson Correlation } \\
\text { Coefficient }\end{array}$ & 0.28309 & & & & & \\
\hline
\end{tabular}

Table 5

Examining the relationship between Exit Adoption and Requiring 3 of Maths course

\begin{tabular}{|ccccccc|}
\hline Variable & $\mathrm{N}$ & Mean & Std Dev & Sum & Minimum & Maximum \\
\hline Any Exit Exams & 650 & 0.23846 & 0.42647 & 155 & 0 & 1 \\
3 Carnegie Units & 650 & 0.24615 & 0.4311 & 160 & 0 & 1 \\
\hline Pearson Correlation & & & & & & \\
Coefficient & 0.14118 & & & & & \\
\hline
\end{tabular}

The Pearson correlation coefficient between the adoption of exit exams and adoption of 4 Carnegie units of mathematics courses as state policies was 0.28 . This indicates low to moderate correlation between the two policies. Similarly, the Pearson correlation coefficient between the adoption of exit exams and adoption of 3 Carnegie units is 0.14 . This also indicates zero to moderate correlation between the states adoption of exit exams and adoption of 3 Carnegie units. In spite of the fact that the two policies started gaining grounds and have similar trends, there is no relationship between two policies. 


\section{Overall Effect of Exit Exams}

The visual demonstrations above seemed to suggest that exit exams have positive relationship with college enrollment. It is also quite clear that exit exam policy were not related to any other state level curriculum policy that could have potentially biased the results. Based on these evidence, I proceed to demonstrate whether exit exams were related to students based on more rigorous difference-in-differences methodology. Given the large variation in state sizes, this analysis used logged transformed variable for analysis for both dependent and the continuous independent variables. Table 4 represents the results of difference-in-differences for all types of institutions and for any type of exit exams. The first column outlined the effect using only the indicator for exit exams with both time and state fixed effects. The results in the first column suggest that as compared to states that have not adopted exit exams, there was a $10 \%$ increase in enrollment within a state following the adoption of exit exams.

When controls were added, the size of the impact got smaller. The second column shows estimates of the impact based on the staggered adoption of exit exams with control variables. It showed that the initial positive impact diminished and that exit exams did not have any impact on college enrollment overall. This is consistent with earlier research that find no impact of exit exams on college enrollment.

Column 2 demonstrates that a $1 \%$ increase in tuition will lead to $0.19 \%$ decrease in overall first-time enrollment within a state. This finding adds to the overwhelming body of literature that demonstrates that increase in tuition has a negative impact on enrollment. Unemployment rate also shows the expected sign as 1 percent increase in unemployment rate was associated with $0.08 \%$ decrease in enrollment. Perhaps the 
greatest factor that is associated with exit exams is the number of high school graduates. The results suggest that a $1 \%$ increase in number of high school graduates is associated approximately with $0.99 \%$ increase in enrollment. The results show no significant impact of merit aid and state appropriations on college enrollment.

Table 6

Effect of Exit exams on College Enrollment

\begin{tabular}{|c|c|c|c|c|}
\hline $\begin{array}{l}\text { Dependent Variable: } \\
\text { College Enrollment } \\
\text { Overall }\end{array}$ & $\begin{array}{c}\text { Staggered adoption } \\
\text { with Only Exit } \\
\text { Exams }\end{array}$ & & $\begin{array}{c}\text { Staggered } \\
\text { adoption with } \\
\text { Controls }\end{array}$ & \\
\hline Any Exit Exam & $\begin{array}{l}10.515 \\
(0.187)\end{array}$ & $* * *$ & $\begin{array}{c}0.039 \\
(0.026)\end{array}$ & \\
\hline Tuition & & & $\begin{array}{c}-0.190 \\
(0.040)\end{array}$ & $* * *$ \\
\hline Unemployment rate & & & $\begin{array}{l}-0.089 \\
(0.029)\end{array}$ & $* *$ \\
\hline Per capita income & & & $\begin{array}{l}-0.243 \\
(0.052)\end{array}$ & $* * *$ \\
\hline State Appropriations & & & $\begin{array}{c}0.109 \\
(0.050)\end{array}$ & $* *$ \\
\hline High School Graduates & & & $\begin{array}{c}0.993 \\
(0.046)\end{array}$ & $* * *$ \\
\hline Percentage Minority & & & $\begin{array}{c}0.033 \\
(0.024)\end{array}$ & \\
\hline Merit aid & & & $\begin{array}{l}-0.003 \\
(0.002)\end{array}$ & \\
\hline Need Based Aid & & & $\begin{array}{c}0.003 \\
(0.013)\end{array}$ & \\
\hline R-Squared & 0.26 & & 0.99 & \\
\hline $\mathrm{N}$ & 650 & & 650 & \\
\hline State Fixed Effects & Yes & & Yes & \\
\hline Year Fixed Effects & Yes & & Yes & \\
\hline
\end{tabular}


Impact of Exit Exams on Type of College to Attend. This section examines

whether adopting exit exams affected the decision of the type of college to attend. The NCES data contained information about total number of students from each state that attended a 4-year institution and total number of students who attended any college. Based on that information, though imperfectly, the study classified enrollment into 4-year institution and 2-year institutions. This made it possible to link the number of students who attended each type of institution and whether those students faced exit exams requirement. The results are shown in table 5. Using the same covariates, the results are contained below.

The results indicate that exit exams did affect college enrollment at the 4-year institution but not the 2-year institution. As compared to states without exit exams, enrollment of first-time students enrolled in a 4 -year institution increase by $0.1 \%$ as a result of adopting exit exams within a state. 
Table 7

Effect of Exit exams on different 4-Year and 2-Year Institutions

Dependent Variable:

College Enrollment by

\begin{tabular}{|c|c|c|c|c|}
\hline \multirow{2}{*}{$\begin{array}{c}\text { Type } \\
\text { Any Exit Exam }\end{array}$} & \multirow{3}{*}{$\begin{array}{c}\text { 4-Year Institutions } \\
0.100 \\
(0.035)\end{array}$} & \multicolumn{3}{|c|}{ 2-Year institutions } \\
\hline & & $* *$ & -0.113 & \\
\hline & & & $(0.093)$ & \\
\hline \multirow[t]{2}{*}{ Tuition } & 0.130 & $* *$ & 0.412 & $* *$ \\
\hline & $(0.052)$ & & $(0.134)$ & \\
\hline \multirow[t]{2}{*}{ Unemployment rate } & -0.156 & $* * *$ & -0.051 & \\
\hline & $(0.041)$ & & $(0.128)$ & \\
\hline \multirow[t]{2}{*}{ Per capita income } & -0.126 & $* *$ & -0.874 & $* * *$ \\
\hline & $(0.057)$ & & $(0.185)$ & \\
\hline \multirow[t]{2}{*}{ State Appropriations } & -0.111 & $*$ & 0.684 & $* *$ \\
\hline & $(0.066)$ & & $(0.194)$ & \\
\hline \multirow[t]{2}{*}{ High School Graduates } & 1.050 & $* * *$ & 0.575 & $* *$ \\
\hline & $(0.059)$ & & $(0.197)$ & \\
\hline \multirow[t]{2}{*}{ Percentage Minority } & 0.006 & & 0.142 & \\
\hline & $(0.030)$ & & $(0.096)$ & \\
\hline \multirow[t]{2}{*}{ Merit aid } & 0.004 & & -0.018 & $* *$ \\
\hline & $(0.003)$ & & $(0.006)$ & \\
\hline \multirow[t]{2}{*}{ Need Based Aid } & 0.029 & & -0.033 & \\
\hline & $(0.023)$ & & $(0.041)$ & \\
\hline R-Squared & 0.99 & & 0.99 & \\
\hline $\mathrm{N}$ & 650 & & 650 & \\
\hline State Fixed Effects & Yes & & Yes & \\
\hline Year Fixed Effects & Yes & & Yes & \\
\hline
\end{tabular}

Effect on Exit Exams on Where Student Choose to Attend. From the theory

college choice espoused earlier, exit exams can have either negative or positive impact on college enrollment based on the relative weight of the students' readiness benefit and the combined effect of the stress and opportunity cost. For exit exams to have a positive effect on either instate or out-of-state, the college readiness component of exit exams will be greater than the combined negative impact of stress and opportunity cost. Ultimately, more students will be much more college ready which translates into higher enrollment 
both at home state and out-of-state. Rigorous curriculum increase the ability of students who otherwise would not consider out of state institution to have higher chance of enrolling in an institution out of their own state. Students who attend out-of-state institutions students tend to be have higher academic abilities and potential (Cornwell et al., 2002). The results in table 6 show no significant effect of exit exams on instate enrollment or out-of-state enrollment.

Table 8

Effect of Exit Exam on Instate and Out-state enrollment

\begin{tabular}{|c|c|c|c|c|}
\hline $\begin{array}{c}\text { Dependent: Enrollment } \\
\text { by Where students } \\
\text { attend }\end{array}$ & $\begin{array}{c}\text { Enrollment in } \\
\text { Instate }\end{array}$ & & $\begin{array}{l}\text { Enrollment of } \\
\text { Out-of-state }\end{array}$ & \\
\hline \multirow[t]{2}{*}{ Any Exit Exam } & 0.014 & & 0.130 & \\
\hline & $(0.036)$ & & $(0.080)$ & \\
\hline \multirow[t]{2}{*}{ Tuition } & 0.231 & $* * *$ & 0.021 & \\
\hline & $(0.053$ & & $(0.122)$ & \\
\hline \multirow[t]{2}{*}{ Unemployment rate } & -0.053 & & -0.310 & $* * *$ \\
\hline & $(0.041)$ & & $(0.079)$ & \\
\hline \multirow[t]{2}{*}{ Percapita income } & -0.499 & $* * *$ & 0.404 & $* *$ \\
\hline & $(0.067)$ & & $(0.158)$ & \\
\hline \multirow[t]{2}{*}{ State Appropriations } & 0.417 & $* * *$ & -0.922 & $* * *$ \\
\hline & $(0.069)$ & & $(0.148)$ & \\
\hline \multirow[t]{2}{*}{ High School Graduates } & 0.729 & $* * *$ & 1.497 & $* * *$ \\
\hline & $(0.060)$ & & $(0.131)$ & \\
\hline \multirow[t]{2}{*}{ Percentage Minority } & -0.013 & & 0.302 & $* * *$ \\
\hline & $(0.038)$ & & $(0.082)$ & \\
\hline \multirow[t]{2}{*}{ Merit aid } & 0.003 & & -0.022 & $* *$ \\
\hline & $(0.002)$ & & $(0.009)$ & \\
\hline \multirow[t]{2}{*}{ Need Based Aid } & -0.021 & & 0.114 & $* *$ \\
\hline & $(0.015)$ & & $(0.048)$ & \\
\hline R-Squared & 0.97 & & 0.98 & \\
\hline $\mathrm{N}$ & 650 & & 650 & \\
\hline State Fixed Effects & Yes & & Yes & \\
\hline Year Fixed Effects & Yes & & Yes & \\
\hline
\end{tabular}




\section{Effect of Different types of Exit Exams}

The second research question determined if the different types of exit exams had differential effect on enrollment. The results are divided into overall enrollment, enrollment in 4-year institutions and enrollment into 2-Year institutions. The results indicated a significant impact of end-of-course exams relative to no exit exams for the overall enrollment. It shows that adopting end-of-course exit exams has a $0.079 \%$ increase to first-time enrollment over no exit exam within a state. Limiting to 4-year institutions only, the results indicate adopting end-of-course exams exams as compared to no exit exams is associated with $0.13 \%$ increase as compared to no exit exams within a state. For 2-year institution, no type of exit exams is significant. A possible reason is that many 2-year institutions have lower rigorous admission criteria compared to 4- year institutions and are generally open enrollment institutions. The results of table 7 indicates that only end-of-course exams did have impact on enrollment. Again, the other control variables do have their expected signs. Unlike Baker and Lang (2013) who found end-of-course and standard-based had positive effect on exit irrespective of type of institution, this study only shows positive impact for only 4-year institutions. This implies that end-of-course exams relative to no exit exams had effect on enrollment. With regards to standard-based and minimum competency exams, the results did not show any significant impact over no exit exams. 
Table 9

Effect of different type of Exit exams on Enrollment

\begin{tabular}{|c|c|c|c|c|c|c|}
\hline $\begin{array}{l}\text { Dependent Variable: } \\
\text { College Enrollment }\end{array}$ & Overall & & $\begin{array}{c}\text { 4-Year } \\
\text { Institutions }\end{array}$ & & $\begin{array}{c}\text { 2-Year } \\
\text { Institutions }\end{array}$ & \\
\hline \multirow[t]{2}{*}{ Min-Competency } & 0.014 & & 0.010 & & -0.013 & \\
\hline & $(0.042)$ & & $(0.071)$ & & $(0.141)$ & \\
\hline \multirow[t]{2}{*}{ standard-Based } & 0.023 & & 0.067 & & -0.207 & \\
\hline & $(0.034)$ & & $(0.048)$ & & $(0.107)$ & \\
\hline \multirow[t]{2}{*}{ End of Course } & 0.079 & $* *$ & 0.130 & $* * *$ & 0.042 & \\
\hline & $(0.031)$ & & $(0.050)$ & & $(0.133)$ & \\
\hline \multirow[t]{2}{*}{ Tuition } & -0.187 & $* * *$ & -0.124 & $* *$ & -0.416 & $* *$ \\
\hline & $(0.039)$ & & $(0.053)$ & & $(0.125)$ & \\
\hline \multirow[t]{2}{*}{ Unemployment rate } & -0.085 & $* *$ & -0.157 & $* * *$ & -0.041 & \\
\hline & $(0.030)$ & & $(0.041)$ & & $(0.127)$ & \\
\hline \multirow[t]{2}{*}{ Percapita income } & -0.240 & $* * *$ & -0.121 & & -0.875 & $* * *$ \\
\hline & $(0.05)$ & & $(0.058)$ & & (0.174) & \\
\hline \multirow[t]{2}{*}{ State Appropriations } & 0.109 & & -0.104 & & 0.670 & $* *$ \\
\hline & $(0.049)$ & & $(0.063)$ & & $(0.189)$ & \\
\hline \multicolumn{7}{|l|}{ High School } \\
\hline \multirow[t]{2}{*}{ Graduates } & 0.914 & $* * *$ & 1.034 & $* * *$ & 0.606 & $* *$ \\
\hline & $(0.047)$ & & $(0.055)$ & & (0.193) & \\
\hline \multirow[t]{2}{*}{ Percentage Minority } & 0.033 & & 0.009 & & 0.136 & \\
\hline & $(0.024)$ & & $(0.030)$ & & (0.094) & \\
\hline \multirow[t]{2}{*}{ Merit aid } & -0.003 & & 0.004 & & -0.018 & $* *$ \\
\hline & $(0.002)$ & & $(0.003)$ & & $(0.006)$ & \\
\hline \multirow[t]{2}{*}{ Need Based Aid } & 0.001 & & 0.033 & & -0.044 & \\
\hline & $(0.012)$ & & $(0.024)$ & & $(0.041)$ & \\
\hline $\mathrm{N}$ & 650 & & 650 & & 650 & \\
\hline R-Squared & 0.99 & & 0.99 & & 0.99 & \\
\hline State Fixed Effects & Yes & & Yes & & Yes & \\
\hline Year Fixed Effects & Yes & & Yes & & Yes & \\
\hline
\end{tabular}

\section{Dynamic Effects Specification}

The discrete specification considered up to this point assumed that exit exams and the control variables only affect the current time period for which they were effective. In other words, they did not provide any idea about how enrollment can be impacted before 
the exit exams take into effect through anticipatory action and the dynamic effect that exit exams affect in subsequent years following implementation. The prior models did not take into consideration how quickly the impact of exit exams accelerated, reduced or remained the same following the adoption of exit exams.

Next, the study augmented the base model of exit exams and the control variables with leads and lags to determine if there was any anticipatory response or overtime effects of exit exams on enrollment. In order to do that, I created 8 indicator variables for 1 year, 2-year, 3-year, 4-year and 5-year before the adoption of exit exams. I also created another group of dummies indicator 1 year, 2-year, 3-year 4 year and 5 year after the adoption of exit exams. The lags are expected to indicate anticipatory impact of exit exams while the leads represents the spillover effects. As with many state level policy initiatives, the implementation year is often placed in the future to allow affected parties make the necessary changes prior to adaptation (Baker \& Lung, 2013). The typical incubation period of exit exams is 4 years which often start with cohort of students entering $9^{\text {th }}$ grade. At the same time, as states roll out exit exams, later cohorts' exposure may be different from the earlier group. As a result, dynamic models are used to incorporate the anticipatory and spillover effects. The leads and the lags in the dynamic effect are used to determine the differential timing effects of exposure to exit exams.

Table 8 presents the results of a dynamic modes. The results showed that no evidence of both anticipatory and direct effect. After incorporating dynamic model into the analysis, the effect of exit exams on college enrollment is not significant. The initial significant effect of exit exams on college enrollment is no longer significant after accounting for period after and period before. However, there appears to be short term 
impact just before the adoption. Warren (1999) explains that more resources are likely to be redirected towards new program implementation which can see greater impact just before the implantation. With exit exams that are announced years prior to the first effective date, schools district and teachers' direct resources towards it more than when it finally goes to effect. This could explain the significant impact 1-year before the implementation year.

Table 10

Effect of exit exams on college enrollment with dynamic model

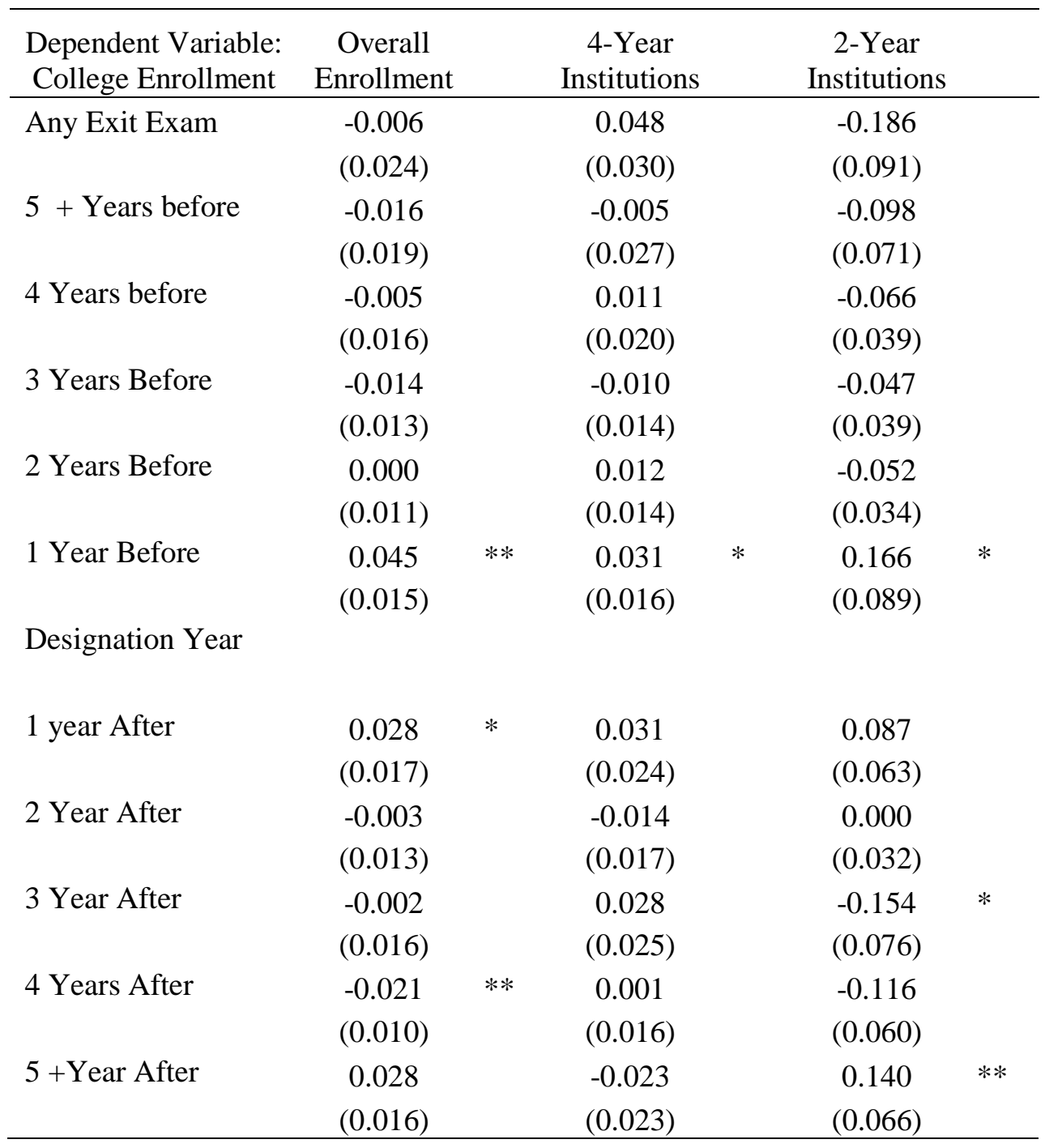




\begin{tabular}{|c|c|c|c|c|c|c|}
\hline Tuition & $\begin{array}{c}0.184 \\
(0.039)\end{array}$ & $* * *$ & $\begin{array}{c}0.129 \\
(0.057)\end{array}$ & & $\begin{array}{c}0.350 \\
(0.133)\end{array}$ & $* *$ \\
\hline Unemployment rate & $\begin{array}{c}-0.098 \\
(0.032)\end{array}$ & $* *$ & $\begin{array}{c}-0.164 \\
(0.048)\end{array}$ & $* * *$ & $\begin{array}{l}-0.063 \\
(0.132)\end{array}$ & \\
\hline Percapita income & $\begin{array}{c}-0.238 \\
(0.050)\end{array}$ & $* * *$ & $\begin{array}{c}-0.124 \\
(0.061)\end{array}$ & & $\begin{array}{c}-0.834 \\
(0.182)\end{array}$ & $* * *$ \\
\hline State Appropriations & $\begin{array}{l}0.106 \\
(0.049\end{array}$ & $* *$ & $\begin{array}{l}-0.111 \\
(0.067)\end{array}$ & $*$ & $\begin{array}{c}0.676 \\
(0.196)\end{array}$ & $* * *$ \\
\hline High School & & & & & & \\
\hline Graduates & $\begin{array}{c}0.919 \\
(0.045)\end{array}$ & $* * *$ & $\begin{array}{c}1.050 \\
(0.061)\end{array}$ & $* * *$ & $\begin{array}{c}0.610 \\
(0.196)\end{array}$ & $* * *$ \\
\hline Percentage Minority & $\begin{array}{c}0.036 \\
(0.024)\end{array}$ & & $\begin{array}{c}0.004 \\
(0.032)\end{array}$ & & $\begin{array}{c}0.163 \\
(0.095)\end{array}$ & $*$ \\
\hline Merit aid & $\begin{array}{c}-0.003 \\
(0.002)\end{array}$ & & $\begin{array}{c}0.004 \\
(0.003)\end{array}$ & & $\begin{array}{c}-0.018 \\
(0.006)\end{array}$ & $* *$ \\
\hline Need Based Aid & $\begin{array}{c}0.002 \\
(0.013)\end{array}$ & & $\begin{array}{c}0.028 \\
(0.024)\end{array}$ & & $\begin{array}{c}0.042 \\
(0.044)\end{array}$ & \\
\hline R-Squared & 0.99 & & 0.99 & & 0.99 & \\
\hline $\mathrm{N}$ & 650 & & 650 & & 650 & \\
\hline State Fixed Effects & Yes & & Yes & & Yes & \\
\hline Year Fixed Effects & Yes & & Yes & & Yes & \\
\hline
\end{tabular}

\section{Robustness Specifications}

Any quasi experimental analysis has a limitation in its ability to support causal findings (Shadish et al., 2002). The use of multiple comparison groups strengthens the estimates and reduces the possibilities of biases or random variation in the use of just one single comparison group (Meyer, 1995). Sensitivity analysis allowed the research to test whether the estimates are truly capturing the effect of the policy. The more similar potential comparison group are to treatment group, the better their use in validating the estimates in the primary analysis (Shadish et al., 2002; Meyer, 1995).

To test that the results were not obtained by chance but that the effects were truly the impact, two sensitivity analysis were analyzed. First, with large number of states that never implemented any exit exam policy within the time of study, their inclusion may 
have created some bias. Thus, the first sensitivity analysis only limit it to states that were in the treatment at one point in time. For the second method, the study adopted randomization process to test if by chance occurrences could produce the same results as the real data in which case the results obtained earlier would be rendered invalid.

\section{Effects based solely on the Timing}

Up to this time, all analysis had included states that did not implement exit exams within the period of study. Those states are primarily in the Midwest as shown earlier in figure 3. A potential source of bias could be that students in those states faced tougher graduation requirements that had been implemented locally at the school district level rather than the state level. For example, in Iowa, school districts implemented exit exams even though the state as a whole did not adopt that policy. With multiple states within a particular region operating the Iowa model, the results of their inclusion are likely to negatively impact the relationship between exit exams and college enrollment.

This section therefore limits analysis to only states that adopted exit exams at some point and only explored the differential timing of exit exams. The results in table 10 show identical effects of exit exams as earlier. They show that implementing exit exams increased enrollment in 4 -year institutions by $0.1 \%$ within states. The impact on overall and 2-year institutions were not significant. This is consistent with the earlier results that show that exit exams is significant for only 4-year institutions. By only selecting states that were in the treatment, the results validate the earlier findings. 
Table 11

Effects based on timing of treated states

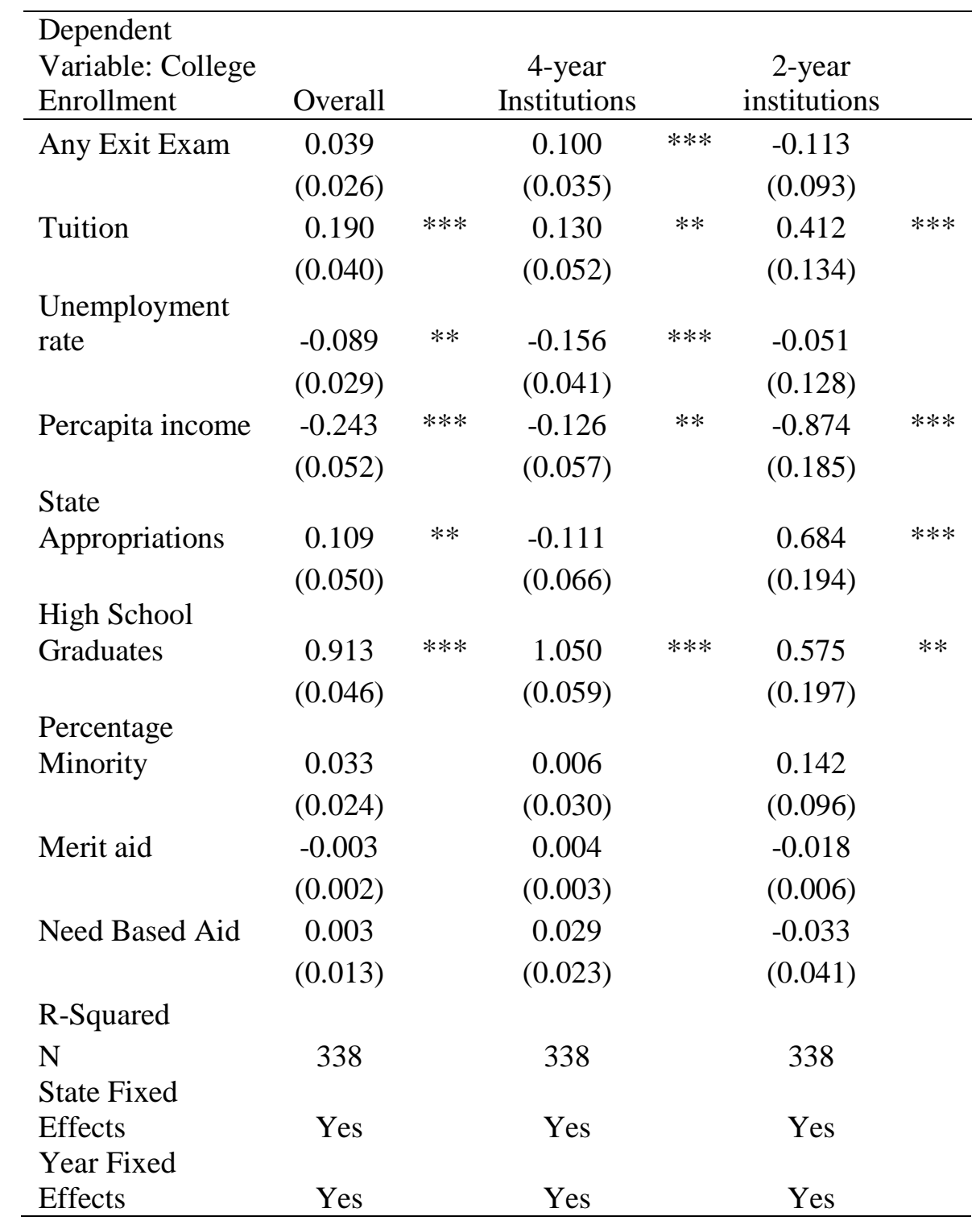

Parenthesis are the standard errors and fixed effects are clustered at the state level.

\section{Random assignment of treatment}

The baseline model attempted to minimize the bias in the estimates of effect of exit exams on college enrollment. In spite of the adding several state level covariates and state and time fixed effects, there was still the potential of bias as long as an experiment 
was not randomized. If the results of the earlier analysis are truly a reflection of the effect of exit exams, then randomly assigning treatment to states based on chance should not produce statistical significance of the variable of interest lest the earlier results would have to be rendered porous. To test randomization, I assigned treatment to states by chance based on excel generated output but ensured that the total number of pseudo treatment states match the actual number of treatment states. A similar action was repeated for the time of adoption to ensure that results truly mirror the trends. To test if the results are indeed random, I performed a correlation matrix and the coefficient was 0.03 which suggest that the results are truly not related. Then I repeated the main difference-in-differences procedure for the experiments. As can be seen in table 11, there is no statistical significance on the relationship between exit exams and college enrollment across the overall and the different types of institutions. This suggest that the results found in table 4 earlier are truly indicative of the effect of exams on college enrollment. This is due to the fact that those states that were randomly chosen had no bearing on their enrollment and thus they remain insignificant. 
Table 12

Effects of randomly Assigning Treatment

\begin{tabular}{|c|c|c|c|c|c|c|}
\hline $\begin{array}{l}\text { Dependent Variable: } \\
\text { College Enrollment } \\
\text { Overall }\end{array}$ & Overall & & $\begin{array}{c}\text { 4-year } \\
\text { Institutions }\end{array}$ & & $\begin{array}{c}\text { 2-year } \\
\text { institutions }\end{array}$ & \\
\hline \multirow[t]{2}{*}{ Any Exit Exam } & -0.021 & & -0.061 & & 0.052 & \\
\hline & $(0.031)$ & & $(0.047)$ & & $(0.111)$ & \\
\hline \multirow[t]{2}{*}{ Tuition } & 0.200 & $* * *$ & 0.158 & & 0.384 & $* *$ \\
\hline & $(0.040)$ & & $(0.050)$ & & $(0.129)$ & \\
\hline \multirow[t]{2}{*}{ Unemployment rate } & -0.083 & $* *$ & -0.141 & $* * *$ & -0.067 & \\
\hline & $(0.029)$ & & $(0.036)$ & & $(0.126)$ & \\
\hline \multirow[t]{2}{*}{ Percapita income } & -0.254 & $* * *$ & -0.156 & $* *$ & -0.843 & $* * *$ \\
\hline & $(0.051)$ & & $(0.055)$ & & $(0.178)$ & \\
\hline \multirow[t]{2}{*}{ State Appropriations } & 0.122 & & -0.077 & & 0.650 & \\
\hline & $(0.048)$ & & $(0.061)$ & & $(0.184)$ & \\
\hline \multirow[t]{2}{*}{ High School Graduates } & 0.901 & $* * *$ & 1.017 & $* * *$ & 0.609 & \\
\hline & $(0.045)$ & & $(0.056)$ & & $(0.191)$ & \\
\hline \multirow[t]{2}{*}{ Percentage Minority } & 0.041 & & 0.027 & & 0.119 & \\
\hline & $(0.023)$ & & $(0.028)$ & & $(0.095)$ & \\
\hline \multirow[t]{2}{*}{ Merit aid } & -0.002 & & 0.005 & & -0.019 & \\
\hline & $(0.002)$ & & $(0.003)$ & & $(0.006)$ & \\
\hline \multirow[t]{2}{*}{ Need Based Aid } & 0.002 & & 0.028 & & -0.033 & \\
\hline & $(0.013)$ & & $(0.024)$ & & $(0.042)$ & \\
\hline R-squared & 650 & & 650 & & 650 & \\
\hline $\mathrm{N}$ & 0.99 & & 0.99 & & 0.99 & \\
\hline State Fixed Effects & Yes & & Yes & & Yes & \\
\hline Year Fixed Effects & Yes & & Yes & & Yes & \\
\hline
\end{tabular}

Parenthesis are the standard errors and fixed effects are clustered at the state level.

\section{Summary of Results}

This chapter presented results of the effect of exit exams on college enrollment. My central conclusion is that exit exams do affect enrollment in the 4-year institutions. Exit exams do not affect enrollment into a 2-year institution. A possible reason is that four-year institutions require more rigorous foundation than 2-year institution. The result 
also demonstrates that there is no impact of exit exams on where students choose to attend college. The results further demonstrate that end-of-course exams had significant impact relative to no exit exams. Standard-based exit exams on the other hand relative to no exit exams, did not have significant effect. So end-of-course exams which happened to be the most prominent type been adopted in recent times has the most impact on affecting students' college enrollment decision.

These conclusions are resilient to different specifications. Robustness checks have validated the results presenting the same identical reports under different conditions. Most of the control variables show their expected signs and significance as stated in the theory. 


\section{CHAPTER 5: CONCLUSIONS AND IMPLICATIONS}

This final Chapter includes four parts. The first part is an overview of the study that restate the statement of purpose, the research design, research questions, data and methods adopted in the study. The second part is a summary and comparison of the research results framed within the two research questions. The third section describes the implications drawn from this study for higher education theory and institutional policy. The fourth part contains a discussion of the limitations of this study and the implications for future research. The final section contains conclusions as a result of this study.

\section{Overview of the Study}

The purpose of this study was to examine whether adopting exit exams improved the college going rate of students in higher education institution across the country. The two specific research questions this study asked were:

1. What was the relationship between state-level adoption of high school exit exams and postsecondary enrollment?

a. Did the adoption of exit exams have a differential relationship with enrollment at different postsecondary institutional types (i.e. 4-year and 2-year institutions)?

b. Did the adoption of exit exams have a differential relationship with instate and out-of-state postsecondary enrollment?

2. Was the relationship between exit exam adoption and enrollment different for different types of exit exams? 
This study was influenced by the limited research and inconsistent results of the relationship between exit exams and higher education outcomes. Coupled with that was the fast-paced of reorganization of exit exams across the country without rigorous studies as basis for proposal for new types of exit exams. Better knowledge of how exit exams affect college enrollment is critical for state holders to make decision.

This study relied on the student choice model proposed by DesJardins and Toutkoushian (2005) which posits that students will choose the most attractive combinations of education and other goods from a set of options that will maximize their utility. The theory speculated three ways that exit exams changes the balance between decision to attend or not to attend and what type of institution to attend. Firstly, exit exams increase the value of non-economic factors in the individual utility curve through higher level of preparation which positively shifts the utility curve. Second, the extra burden relating to passing exit exams increases stress which reduces utility and has a negative impact on enrollment. Finally, there is an opportunity cost component where students forgo income from working as result of time spend on preparing for exit exams. This also has a negative impact on enrollment. Based on the theory, the overall impact is based on the weight of each component which can be positive or negative.

This study adopted quantitative research methodology and utilized state level longitudinal data set that avoided the weaknesses of previous quantitative and qualitative studies that used single state or sample of states. The data source was from NCES which published information on the number of students from each state who enrolled in institution of higher education each year from 1992 to 2016. NCES database has been a reliable source of higher education information that has been used to study students' outcomes over the years. The dependent variable of this study was the total number of 
first-time degree-seeking undergraduate students who attend college from each state. The key independent variable was whether a state in any particular year had exit exams requirement for graduation in high school or not. Additionally, the study included eight vectors of variables that affect enrollment at a higher education institution as control variables. To effectively capture the impact of exit exams on college enrollment, the study utilized difference-in-differences regression approach with state and year fixed effects.

\section{Discussion of the Research Findings}

\section{Research Question One}

Research question one asked: What was the relationship between state-level adoption of high school exit exams and postsecondary enrollment? Based on the full population of all states (excluding Washington DC), the analytical results showed no statistical significance of exit exams on college enrollment as a whole. Thus, the study rejected the null hypothesis that exit exams increased college enrollment in favor of the alternative. From the theoretical framework perspective, the combined effect of stress component and opportunity cost component outweighs the positive benefits associated with better preparation. The results suggested that the stress component associated with exit exams decreased the utility associated with going to college and consequently affected the probability of enrollment.

This result is consistent with the findings of Chaney et al. (1997) and Clark and See (2011) that both found no noticeable impact of exit exams on college enrollment whether using only one state or sample of states. For Bishop and Mane (2001), exit exams does have an opposite and a negative significant effect on student's enrollment. Unlike the results in this study, Bishop and Mane (2001) found that exit exams decrease 
the probability of enrollment in higher education institution. This is in contrast to Polson (2014) and Bishop and Mane (1999) that found that exit exams rather increase the probability of enrollment.

Effect at Different Postsecondary institutional Types. When the results were analyzed by different sectors, a modest impact was obtained for the 4-year institutions. As compared to states without exit exams, enrollment of first-time students enrolled in a 4year institution increase by $1 \%$ as a result of adopting exit exams within a state. For the 2year institutions, though insignificant, the results indicated that there is a negative relationship between exit exams and enrollment. A potential reason is that students do not need the same level of preparation to attend a 2-year institution as they would in attending a 4-year institution. As a result, whether or not a state adopted exit exams that truly increased level of preparation did not affect the behavior of students attending a 2-year institution.

The differences in impacts of exit exams between a 4-year and 2-year also suggested the extent to which various factors within the utility curve affects different types of institutions. The college readiness component within exit exams are relevant to students who intended to attend 4-year institutions. The results also were consistent with theoretical framework that utility involved making choice including decision on whether or not to attend college and type of college to attend based on subjective satisfaction the individual expects to derive (DesJardins \& Toutkoushian, 2005).

The results were consistent with earlier research that documented the negative impact of exit exams on certain group of students. Kruger et al., (2016) documented the emotional impact of exit exams particularly on low ability students and its impact on their 
long-term academic pursuits. Students who fail exit exams have diminished motivation to enroll and even much lower probability of enrolling in 4-year institutions (Catterall, 1989). Exit exams also create social and psychological impacts on students on low income, ELL and low ability students who are usually community college bound (Farrington et al., 2012; Roderic \& Engel, 2001). The results of this study provided evidence of these implications for students.

Effect on Instate and Out-of-State Postsecondary Enrollment. The second sub-question asked if exit exams have differential relationship with instate and out-ofstate postsecondary enrollment. The results show that exit exams had no effect on whether students choose to attend home institution or out-of-state institution. This is consistent with earlier results that exit exams has no effect on college enrollment overall. As speculated by the theory, when the imposition of exit exams does not lead to higher utility, then it does not lead to positive impact on college enrollment.

This is also consistent with literature on out-out-state enrollment which consistently show that students who attend out-of-state institution are usually more achieving (Morgan, 1983; Tucker, 1970). With most exit exams testing materials that are far below the standard of most achieving students, it is not surprising that exit exams had no impact on out-of-state enrollment. Exit exams have far out reaching effect on students who stand on the margins than talented students who will pass anyway. To the best of my knowledge, this is the only study that has investigated this aspect of exit exams. Thus, this is a unique finding in the literature of student's migration. 


\section{Research Question Two}

Research question two asked: Was the relationship between exit exam adoption and enrollment different for different types of exit exams? This research question was intended to identify if the level of rigor was associated with different levels on enrollment. The results indicated a significant impact of end-of-course exams relative to no exit exams for the overall enrollment. It shows adopting end-of-course exit exams has a $0.78 \%$ increase to first time enrollment over minimum competency within a state.

This result is consistent with Chang et al., (2005) which posited that more rigorous types of exit exams had higher probability of increasing college enrollment. While this study found end-of-course only to be statistically significant as compared to no exit exams, Baker and Lang (2013) found standard-based exit exams to also be significant in addition to the end-of-course exams. The difference could be due to the different timings for the data use in this study and how exit exams has been classified.

Limiting to 4-year institutions only, the results indicate that adopting standardbased exit exams as compared to no exit exams is associated with $0.12 \%$ increase within a state. For 2-year institution, no type of exit exams is significant. A possible reason is that many 2-year institutions have lower rigorous admission criteria as compared to the 4year institutions and were generally open enrollment institutions.

\section{Implications for Theory and Institutional Policy}

\section{Implications for student choice Model}

The findings of this study reveal the dual dimension of the student choice model. The student choice model posits that students will choose the most attractive combinations of education and other goods from a set of options that will maximize their 
utility (DesJardins \& Toutkoushian, 2000). From the College Readiness perspective, the stress component and the opportunity cost dimension of the derived student choice model, exit exams changes the utility balance between going to college and the alternative of not going to college and the type of college to attend. When the impact is positive, according to the theory, the weight of college readiness is greater than the combined weight of stress and opportunity cost components. Through the participation in high level college preparatory course, student's personal characteristics begin to match college success attributes and increase the value of college relative to not attending any college. Also, when stress and the opportunity cost associated with taking exit exams outweigh the college readiness piece, a positive decision is made.

The study gives validity to the theory on the basis of analysis of the enrollment trends by types of institutions. By passing exit exams as stipulated by the theory, the nonfinancial individual characteristics ( $\mathrm{Si}$ ) improve but only applicable to where the level of academic preparation required to enroll matches the component of the utility function. In other words, while exit exams may increase the utility of college relative to non-college choice, they work through different channels with different types of institutions. This isbecause with community college which are generally open enrollment, the utility gained as a result of passing exit exams do not necessarily reflect in the needs to enroll. This study therefore has provided basis to eliminate the ambiguity relating to the type of institutions that students are likely to enroll. It implies that exit exams do not increase the utility of going to a community college. This implies that Si is not directly affected by students who want to attend community college.

The study gives validation for the theory of college choice espoused by Perna (2006) through the significance of the non-financial individual characteristics (Si) 
measured by percent minority. The individual habitus remains an important element to college access as exemplified in this study. Though this study did not disaggregate to specific race, it found that states with higher percent minority have significantly lower college access opportunities. The same can be extended to other SES characteristics though not directly revealed by this study.

Thus, this study has revealed the need to expand the utility theory of utility needs to incorporate the student preference and aspirations. The utility choice in its current form predicts common behavior for students irrespective of where they intend to attend higher education. This study suggests that the increase in utility from the more rigorous exit exams are applicable to only students who see a path in attending 4-year institutions.

\section{Implications for State Policy}

The study has revealed that the more rigorous exams of end-of-course has the biggest impact of enrollment. Currently, 5 states still have exit exams that tested knowledge of materials prior to high school. As shown in this study, these types do not affect enrollment. There is the need for state legislators in those states to reflect and propose new changes that will make exit exams much more effective than had been.

The findings of this study also reveal that exit exams do not have effect on enrollment of students in 2-year institutions. Even upon controlling for state variables, the results suggested that exit exams do not have impact on enrollment in 2-year institutions. This question the universality approach that exit exams has taken over the years. In the current state of exit exams, irrespective of the career paths of high school students, they are all required to take exit exam. The study suggest that state legislators relook at whether all students need to take exit exams particularly students enroute to community 
college. The study suggested that students who do not want to go to 4-year institutions should not be required to take exit exams.

Finally, this study established the need for each state to be more responsive to the changing landscape of education and modify existing laws to reflect the level of rigor that makes significant impact on higher education enrollment. With significance of end-ofcourse exams, it is important for state legislative to introduce exit exams policy that are more rigorous and that can have real impact on students' readiness.

\section{Limitations of This Study and Implications for Future Research}

All empirical studies have some limitations and this study is not an exception. These limitations primarily arise due to the unavailability of data on particular items which potentially could lead to different interpretations. In this study, it is mainly due to the use of aggregate state level data.

Students from different socioeconomic and racial/ethnic backgrounds may not respond to exit exams the same way across the board. Previous empirical evidence have demonstrated differences in the responses to college readiness programs based on family characteristics (Cabrera \& La Nasa, 2001: Wells \& Crain, 1994). However, given that this data contain only aggregate state counts, it is impossible to determine if one particular race, gender or socioeconomic background benefit more from exit exams than the rest. Without taking this into consideration, an important element of exit exams cannot be evaluated.

The study assumed identical effect of exit exams on college enrollment irrespective of how many times a student had to take the test to pass. Many states had no caps on the number of times a student can retake exams once they complete high school (Center of Educational Policy, 2012). Individual students who passed exit exams the 
first attempt may be different from those who take several times to pass the same exams. As an aggregate, this research was unable to group students by the number of times they have to take to pass exit exams. While some of the differences between different groups were captured using control factors, there was no way to determine if one group does better than the other.

The number of first-time freshmen from each state tested in this study does not necessarily reflect the actual number of students who graduated from high school in the last 12 months and now enrolled in college. Excluded in this study were those who took college level course while in high school (dual enrollment) and did not necessarily start as freshmen in college. Furthermore, the assumption that the number of students reported by institutions as residents of a particular state did not necessarily mean that they were all exposed to the graduation requirements of their state of residence as assumed in this study. Private and home school students are not required to fulfill the graduation requirements issued by the state. Thus, the actual number of students who were subjected to the exit exams requirement for the state may be lower than the number used in this study.

Finally, the way exit exams have been instrumented can be problematic. Even though some states do not have a state stature, the districts requirement are far more rigorous and therefore failing to categorize them as such may affect the number of students. This could potentially introduce where more students faced exit exams requirement than actually calculated in the study. As a result, the outcomes may be biased. 


\section{Conclusion}

The purpose of the study was to determine if exit exams affected enrollment in higher education. The study did find that overall there was no impact of exit exams on college enrollment. However, when limited to four-year institutions, the study did find modest effects of exit exams on college enrollment. It did also find that end-of-course exams has higher impact on college enrolment than any other type of exit exams compared to no exit exams. Thus, the study has achieved its research purpose of examining the relationship between exit exams and college enrolment. The study also validated the student choice model and extended part of it to be much comparable with exit exams.

Thus, the findings of this study have significance to both student choice model and higher education institutional policy-making. From the student choice angle, the study has validity that high rigorous high school preparations have significant impact on enrollment as reflective in the end-of-course exams. It further reveals that content rather than amount of time has the highest impact of increasing students' probability of enrolling in college. From the policy perspective, it is important that stake holders reconsider whether all high school graduates needs the same level of rigorous preparation before obtaining high school diploma. Students who do not plan to attend 4-year institutions may not need to be subjected to the same rigor of courses as those who plan to obtain bachelor's degrees.

For future research, this study recommends that scholars begin to analyze the new trends in exit exams where states are increasingly using SAT, ACT or a WorkKeys Assessment to analyze their impact on enrollment. By doing so, it will provide greater understanding of the overall impact especially in more recent times. Furthermore, this 
study recommends future studies to understand the long-term effects of exit exams using aggregate state data on wages. 


\section{REFERENCES}

Abraham, K. G., \& Clark, M. A. (2006). Financial Aid and Students' College Decisions: Evidence from the District of Columbia Tuition Assistance Grant Program. Journal of Human Resources, 41(3), 578-610

Abraham, S., \& Sun, L. (2018). Estimating Dynamic Treatment Effects in Event Studies with Heterogeneous Treatment Effects. Working Paper.

Adelman, C. (1999). Answers in the tool box. Academic intensity, attendance patterns, and bachelor's degree attainment. Washington, DC: U.S. Department of Education.

Allensworth, E., Nomi, T., Montgomery, N., \& Lee, V. E. (2009). College preparatory curriculum for all: Academic consequences of requiring algebra and english I for ninth graders in Chicago. Educational Evaluation and Policy Analysis, 31(4), 367-391.

Alm, J., \& Winters, J. V. (2009). Distance and intrastate college student migration. Economics of Education Review, 28(6), 728-738.

Altonji, J. G. (1995). The Effects of high school curriculum on education and labor market outcomes. The Journal of Human Resources, 30(3), 409-438.

Alva, S. A. (1995). Academic Invulnerability among Mexican-American students: The importance of protective resources and appraisals. In A.Padilla (Ed.), Hispanic psychology: Critical issues in theory and research(pp.288-302).Thousand Oaks, CA: Sage. 
Andrews, R. J., DesJardins, S., \& Ranchhod, V. (2010). The effects of the Kalamazoo Promise on college choice. Economics of Education Review, 29(5), 722-737. Angrist, J. D., \& Pischke, J.-S. (2009). Mostly harmless econometrics: An empiricist's companion. Princeton: Princeton University Press.

Ashenfelter, O., \& Krueger, A. (1994). Estimates of the economic return to schooling from a new sample of twins. American Economic Review, 84(5), 1157-1173

Athey, S., \& Imbens, G. W. (2017). The State of Applied Econometrics: Causality and Policy Evaluation. Journal of Economic Perspectives, 31(2), 3-32. doi:10.1257/jep.31.2.3

Attewell, P., \& Domina, T. (2008). Raising the Bar: Curricular Intensity and Academic Performance. Educational Evaluation and Policy Analysis, 30(1), 51-71.

Attewell, P., \& Domina, T. (2008). Raising the bar: Curricular intensity and academic performance. Educational Evaluation and Policy Analysis, 30(1), 51-71.

Aughinbaugh, A. (2012). The effects of high school math curriculum on college attendance: Evidence from the NLSY97. Economics of Education Review, 31(6), 861-870.

Baker, O., \& Lang, K. (2013). The effect of high school exit exams on graduation, employment, wages and incarceration. NBER Working Paper Series.

Baryla, E. A., \& Dotterweich, D. (2001). Student Migration: Do Significant Factors Vary by Region? Education Economics, 9(3), 269-280.

Baryla, E. A., \& Dotterweich, D. (2006). Institutional focus and non-resident student enrollment. International Journal of Educational Management, 20(4), 239-248. 
Baryla, E. A., \& Dotterweich, D. (2006). Institutional focus and non-resident student enrollment. International Journal of Educational Management, 20(4), 239-248.

Baum, S., Ma, J., \& Payea, K (2013). Education Pays, 2013: The Benefits of Higher Education for Individuals and Society. Trends in Higher Education Series.

Baum, S., \& Payea, K., (2004). Education pays 2004: The benefits of higher education for individuals and society. Washington, DC: The College Board.

Baum, S., Ma, J \& Payea, K. (2010). Education pays 2010: The benefits of higher education for individuals and society. Washington, DC: The College Board.

Becker, G., (1975). Human Capital: A Theoretical and Empirical Analysis, with Special Reference to Education. Chicago. University of Chicago Press

Bertrand, M., Duflo, E., \& Mullainathan, S. (2004). How much should we trust differences-in-differences estimates? The Quarterly Journal of Economics, 119(1), 249-275.

Bertrand, M., \& Mullainathan, S. (2004). Are Emily and Greg More Employable Than Lakisha and Jamal? A Field Experiment on Labor Market Discrimination. American Economic Review, 94(4), 991-1013.

Bertrand, M., \& Mullainathan, S. (2001). Are Ceos Rewarded For Luck? The Ones Without Principals Are. Quarterly Journal of Economics, 116(3), 901-932.

Bishop, J. H., \& Mane, F. (2001). The impacts of minimum competency exam graduation requirements on high school graduation, college attendance and early labor market success. Labour Economics, 8(2), 203-222.

Bishop, J. H. and Mane, F (2001). Impacts of Tougher Graduation Requirements on 
Course Selection and Learning in High School and Post High School Experiences of Vocational Students. (Cornell University, Center for Advanced Human Resources Discussion paper

Bishop, J. H., \& Mane, F. (2004). The impacts of career-technical education on high school labor market success. Economics of Education Review, 23(4), 381-402.

Bloom, H. S. (2003). Using "short" interrupted time-series analysis to measure the impacts of whole-school reforms. With applications to a study of accelerated schools. Eval Rev, 27(1), 3-49.

Bourdieu, P (1986). The Forms of Capital. Pp. 241-58 in Handbook of theory and research for the sociology of education, edited by J. G. Richardson. New York: Greenwood Press.

Bourdieu, P. (1998). Outline of a theory of practice (R. Nice, Trans.). Cambridge, UK:

Cambridge:University Press.

Bureau of Labor Statistics, U.S. Department of Labor (2019), The Economics Daily, Median weekly earnings $\$ 606$ for high school dropouts, $\$ 1,559$ for advanced degree holders:Retrieved

from https://www.bls.gov/opub/ted/2019/median-weekly-earnings-606-for-high$\underline{\text { school-dropouts-1559-for-advanced-degree-holders.htm }}$

Buss, C., Parker, J., \& Rivenburg, J. (2004). Cost, quality and enrollment demand at liberal arts colleges. Economics of Education Review, 23(1), 57-65. 
Butsic, V., Lewis, D. J., Radeloff, V. C., Baumann, M., \& Kuemmerle, T. (2017). Quasiexperimental methods enable stronger inferences from observational data in ecology. Basic and Applied Ecology, 19, 1-10.

Cabrera, A. F., \& La Nasa, S. M. (2001). On the path to college: Three critical tasks facing America's disadvantaged. Research in Higher Education, 42, 119-149

Cabrera, A., \& La Nasa S. (2000). Understanding the college choice process. New Directions for Institutional Research, 107, 5-22.

Catterall, J. S. (1989). Standards and School Dropouts: A National Study of Tests Required for High School Graduation. American Journal of Education, 98(1), 34.

Caves, K., \& Balestra, S. (2016). The impact of high school exit exams on graduation rates and achievement. The Journal of Educational Research, 111(2), 186-200.

Cawthon, S. W. (2007). Hidden Benefits and Unintended Consequences of No Child Left Behind Policies for Students Who Are Deaf or Hard of Hearing. American Educational Research Journal, 44(3), 460-492.

Ceja, M. (2016). Chicana College Aspirations and the Role of Parents: Developing Educational Resiliency. Journal of Hispanic Higher Education, 3(4), 338-362.

Cellini, S. R. (2008). Causal inference and omitted variable bias in financial aid research: Assessing solutions. The Review of Higher Education, 31(3), 329-354.

Cellini, S. R. (2008). Causal inference and omitted variable bias in financial aid research: Assessing solutions. The Review of Higher Education, 31(3), 329-354.

Center on Education Policy (2003). State high school exit exams: Put to the test.

Washington, DC: Author. Coates, R. D., \& Wilson-Sadberry, K. R. (1994). Minimum competency testing: Assessing the effects 
Chaney, B., Burgdorf, K., \& Atash, N. (1997). Influencing achievement through high school graduation requirements. Educational Evaluation and Policy Analysis, $19(3), 229-244$.

Chingos, M. M. (2012). The impact of a universal class-size reduction policy: Evidence from Florida's statewide mandate. Economics of Education Review, 31(5), 543562. doi:10.1016/j.econedurev.2012.03.002

Clark, D., \& See, E. (2011). The impact of tougher education standards: Evidence from Florida. Economics of Education Review, 30(6), 1123-1135.

Clotfelter, C. T., Hemelt, S. W., \& Ladd, H. F. (2019). Raising the Bar for College Admission: North Carolina's Increase in Minimum Math Course Requirements. Education Finance and Policy, 14(3), 492-521.

Cooke, T. J., \& Boyle, P. (2011). The Migration of High School Graduates to College. Educational Evaluation and Policy Analysis, 33(2), 202-213.

Cornwell, C., \& Mustard, D. B. (2004). Georgia's HOPE scholarship and minority and 1 ow-income students: Program effects and proposed reforms. In D. E. Heller \& P. Marin (Eds.), State merit scholarship programs and racial inequality. Cambridge, MA: The Civil Rights Project.

Cornwell, C., Mustard, D. B., \& Sridhar, D. J. (2006). The enrollment effects of meritbased financial Aid: Evidence from Georgia's HOPE program. Journal of Labor Economics, 24(4), 761-786.

Cortes, K. E., Goodman, J. S., \& Takako, N. (2015). Intensive Math Instruction and Educational Attainment. Journal of Human Resources, 50(1), 108-158. 
Costrell (1994). A Simple Model of Educational Standards. American Economic Review, (84), 956- 971

Creswell, J. (2009). Research design: Qualitative, quantitative, and mixed methods approaches (3rd ed.). Thousand Oaks, CA: Sage.

Crosby, O. \& Moncarz, R. ( 2006). The 2004-14 job outlook for college graduates. Retrieved from Bureau of Labor Statistics website: http://www.bls.gov/opub/ooq/2006/fall/art03.pdf

Curs, B., \& Singell, L. D. (2002). An analysis of the application and enrollment process for instate and out-of-state students at a large public university. Economics of Education Review, 21, 111-124.

Dee, T. S., \& Jacob, B. (2011). The impact of no Child Left Behind on student achievement. Journal of Policy Analysis and Management, 30(3), 418-446.

Dee, T. S., \& Jacob, B. A. (2006). Do high school exit exams influence educational attainment or labor market performance? (Working Paper 12199). Cambridge, MA: National Bureau of Economic Research.

Delgado-Gaitan, C. (1992). School matters in the Mexican-American home: Socializing children to education. American Educational Research Journal, 29(3), 495-513.

DesJardins, S. L., \& Bell, A. (2006). Using economic concepts to inform enrollment management. New Directions for Institutional Research, 2006(132), 59-74. 
DesJardins, S. L., \& McCall, B. P. (2014). The impact of the Gates Millennium Scholars Program on college and post-college related choices of high ability, low-income minority students. Economics of Education Review, 38, 124-138.

DesJardins, S. L., \& Toutkoushian, R. K. (2005). Are students really rational? The development of rational thought and its application to student choice. In Higher education: Handbook of theory and research (pp. 191-240). Springer Netherlands.

Domina, T. (2009). What works in college outreach: Assessing targeted and school? wide interventions for disadvantaged students. Educational Evaluation and Policy Analysis, 31, 127-152

Domina, T. (2013). Does Merit Aid Program Design Matter? A Cross-Cohort Analysis. Research in Higher Education, 55(1), 1-26. doi:10.1007/s11162-013-9302-y

Domina, T. (2016). Higher Education Policy as Secondary School Reform: Texas Public High Schools After Hopwood. Educational Evaluation and Policy Analysis, 29(3), 200-217.

Domina, T., \& Saldana, J. (2012). Does Raising the Bar Level the Playing Field? American Educational Research Journal, 49(4), 685-708.

Dotterweich, D., \& Baryla, E. A. (2005). Non-resident Tuition and Enrollment in Higher Education: Implications for Tuition Pricing. Education Economics, 13(4), 375385.

Doyle, W. R. (2010). Does Merit-Based Aid "Crowd Out" Need-Based Aid? Research in Higher Education, 51(5), 397-415.

Dynarski, S. (2003). Does aid matter? Measuring the effect of student aid on college attendance and completion. The American Economic Review, 93(1), 279-288. 
Fenske, R. H., Scott, S. K., \& Carmody, J. F., (1972). College Student Migration. Research and Development (9), 111-121

Ferriss, A. L (1973) Higher Educational Institutions and the Migration of Talent. College and University (49), 19-29.

Figlio, D \& Loeb, S. (2011). School Accountability. Handbook of the Economics of Education, ( 3),112-135

Frazer, J. (2014) The School in The United States. Routledge: New York

Gaertner, M. N., Kim, J., DesJardins, S. L., \& McClarty, K. L. (2013). Preparing Students for College and Careers: The Causal Role of Algebra II. Research in Higher Education, 55(2), 143-165.

Gamoran, A., \& Hannigan, E. C. (2000). Algebra for everyone? Benefits of collegepreparatory mathematics for students with diverse abilities in early secondary school. Educational Evaluation and Policy Analysis, 22(3), 241-254.

Gándara, P. (1982). Passing through the eye of the needle: High-achieving Chicanas. Hispanic Journal of Behavioral Sciences, 4(2), 167-179.

Goodman-Bacon, A. \& National Bureau of Economic, R. (2018). Difference-inDifferences with Variation in Treatment Timing. NBER Working Paper No. 25018. 
Görlitz, K., \& Gravert, C. (2016). The effects of the high school curriculum on school dropout. Applied Economics, 48(54), 5314-5328.

Griffith, A. (2011). Keeping up with the Joneses: Institutional changes following the adoption of a merit aid policy. Economics of Education Review, 30, 1022-1033.

Grodsky, E., Warren, J. R., \& Felts, E. (2008). Testing and Social Stratification in American Education. Annual Review of Sociology, 34, 385-404.

Hanushek, E. A., \& Raymond, M. E. (2005). Does school accountability lead to improved student performance? Journal of Policy Analysis and Management, 24(2), 297-327.

Hanushek, E. A., Warren, J. R., \& Grodsky, E. (2012). Evidence, Methodology, TestBased Accountability, and Educational Policy. Educational Policy, 26(3), 351368.

Hanushek, E. A., Warren, J. R., \& Grodsky, E. (2012). Evidence, Methodology, TestBased Accountability, and Educational Policy: A Scholarly Exchange between Dr. Eric A. Hanushek and Drs. John Robert Warren and Eric Grodsky. Educational Policy, 26(3), 351-368

Harper, S. R., \& Hurtado, S. (2007). Nine themes in campus racial climates and implications for institutional transformation. New Directions for Student Services, 2007(120), 7-24.

Heather, T. R.-K., Angela, D. B., \& Laura, W. P. (2008). Contextual Influences on Parental Involvement in College Going: Variations by Socioeconomic Class. The Journal of Higher Education, 79(5), 564-586.

Heller, D. E. (1997). Student price response in higher education: An update to Leslie and Brinkman. Journal of Higher Education, 68(6),624-59. 
schools. American Educational Research Journal, 24, 287-310.

Heller, D. E. (2004). State merit scholarship programs: An overview. In D. E. Heller \& P. Marin (Eds.), State merit scholarship programs and racial inequality (pp. 13-23). Cambridge, MA: The Civil Rights Project, Harvard University.

Hemelt, S. W., \& Marcotte, D. E. (2011). The Impact of Tuition Increases on Enrollment at Public Colleges and Universities. Educational Evaluation and Policy Analysis, $33(4), 435-457$.

Hemelt, S. W., \& Marcotte, D. E. (2013). High School Exit Exams and Dropout in an Era of Increased Accountability. Journal of Policy Analysis and Management, 32(2), 323-349.

Hoffer, T. (1997). High school graduate requirements: Effects on dropping out and student achievement. The Teachers College Record,98(4), 584-607

Hones, D. F. (1997). Resourcefulness, Relationship, Respect: Learning from the Life of a Hmong American.

Hossler, D., Braxton, J., \& Coopersmith, G. (1989). Understanding Student College Choice. In J.C. Smart (Ed.), Higher education: Handbook of theory and research (Vol. 5). New York: Agathon Press

Holme, J. J., Richards, M. P., Jimerson, J. B., \& Cohen, R. W. (2010). Assessing the Effects of High School Exit Examinations. Review of Educational Research, 80(4), 476-526.

Hursh, D. (2007). Assessing No Child Left Behind and the Rise of Neoliberal Education Policies. American Educational Research Journal, 44(3), 493-518.

Hyslop, A.(2014). The Case against Exit Exams. New America Education, Policy Brief. Retrieved fromhttps://www.newamerica.org/downloads/ExitExam_FINAL.pdf 
Iatarola, P., \& Rubenstein, R. (2007). New stakes and standards, same ol' spending? Evidence from New York city high Schools. Education Finance and Policy, 2(1), 74-99.

Imbens, G. W., \& Wooldridge, J. M. (2009). Recent Developments in the Econometrics of Program Evaluation. Journal of Economic Literature, 47(1), 5-86.

Jackson, G. A. (1978). Financial aid and student enrollment. The Journal of Higher Education, 49, 548-574.

Jackson, C. K. (2014). Do College-Preparatory Programs Improve Long-Term Outcomes? Economic Inquiry, 52(1), 72-99.

Kane, Thomas J.(2003). A Quasi-Experimental Estimate of the Impact of Financial Aid on College-Going. National Bureau of Economic Research (NBER) Working Paper 9703.

Kane, T. J., Orszag, P. R., Gunter, D. L., Brookings Institution, W. D. C., \& Urban Inst, W. D. C. (2003). State Fiscal Constraints and Higher Education Spending: The Role of Medicaid and the Business Cycle. Discussion Paper

Kyung, W. (1996). In-Migration of College Students to the State of New York. Journal of Higher Education, 67(3), 349-358.

Kane, T. J. (1995). Rising public college tuition and college entry: How well do public subsidies promote access to college? NBER working paper 5164. National Bureau of Economic Research, Inc.

Kane, T. J. (1999). The price of admission: Rethinking how Americans pay for college. Washington, DC: Brookings Institutions Press. 
Lee, J., \& Reeves, T. (2012). Revisiting the Impact of NCLB High-Stakes School Accountability, Capacity, and Resources: State NAEP 1990-2009 Reading and Math Achievement Gaps and Trends. Educational Evaluation and Policy Analysis, 34(2), 209-231.

Lee, S. J. (2001). More than 'model minorities' or 'delinquents': A look at Hmong American high school students. Harvard Educational Review, 71(3), 505-528.

Lee, J. (2017). Is Test-Driven External Accountability Effective? Synthesizing the Evidence From Cross-State Causal-Comparative and Correlational Studies. Review of Educational Research, 78(3), 608-644.

Leeds, D. M., \& DesJardins, S. L. (2014). The Effect of Merit Aid on Enrollment: A Regression Discontinuity Analysis of Iowa's National Scholars Award. Research in Higher Education, 56(5), 471-495. doi:10.1007/s11162-014-9359-2

Levine, P. B., \& Zimmerman, D. J. (1995). The Benefit of additional high-school math and science classes for young men and women. Journal of Business \& Economic Statistics, 13(2), 137-149.

Levy, F., \& Murnane, R. J. (2004). The new division of labor: How computers are creating the next job market. Princeton, NJ: Princeton University Press.

Leslie, L. L., \& Brinkman, P. T. (1987). Student price response in higher education: The student demand studies. The Journal of Higher Education, 58, 181-204.

Linn, R. L. (2010). A New Era of Test-Based Educational Accountability. Measurement: Interdisciplinary Research \& Perspective, 8(2-3), 145-149.

Lillard, D.R., \& DeCicca, P.P. (2001). Higher standards, more dropouts? Evidence within and across time. Economics of Education Review, 20, 459-473. 
Long, M. C., Conger, D., \& Iatarola, P. (2012). Effects of high school course-taking on secondary and sostsecondary Success. American Educational Research Journal, 49(2), 285-322.

Long, B. T. (2004). How do financial aid policies affect colleges? The institutional impact of the Georgia HOPE Scholarship. Journal of Human Resources, 39, 1045-1066.

Ma, J., Pender, M., Welch, M., \& College, B. (2016). Education Pays 2016: The Benefits of Higher Education for Individuals and Society. Trends in Higher Education Series. Retrieved from http://proxy.mul.missouri.edu/login?url=http://search.ebscohost.com/login.aspx?d irect=true $\& \mathrm{db}=$ eric $\& A N=E D 572548 \&$ site=eds-live $\&$ scope $=$ site

Mak, J., \& Moncur, J. E. T. (2003). Interstate migration of college freshmen. The Annals of Regional Science, 37(4), 603-612.

McDill, E. L., Natriello, G. \& Pallas, A. M. (1986). A population at risk: potential consequences of tougher school standards for student dropouts. American Journal of Education, 94, 135-181.

McLendon, M. K., Hearn, J. C., \& Mokher, C. G. (2009). Partisans, Professionals, and Power: The Role of Political Factors in State Higher Education Funding. Journal of Higher Education, 80(6), 686-713.

McDonough, P. M. (1997). Choosing colleges: How social class and schools structure opportunity. Albany, NY: State University of New York Press

McDonough, P. M. (2004). The School-to-College Transition: Challenges and Prospects. Washington, D.C.: American Council on Education, Center for Policy Analysis 
Meyer, B. (1995). Natural and quasi-experiments in economics. Journal of Business \& Economic Statistics, 13(2), 151-161.

Morgan, J. N. (1983). Tuition policy and the interstate migration of college students. Research in Higher Education, 19(2), 183-195.

Monks, J. (2009). The impact of merit-based financial aid on college enrollment: A field experiment. Economics of Education Review, 28(1), 99-106.

Muñoz, J., Harrington, J. R., Curs, B. R., \& Ehlert, M. (2016). Democratization and Diversion: The Effect of Missouri's A+ Schools Program on Postsecondary Enrollment. Journal of Higher Education, 87(6), 801-830

National Commission on Excellence in Education. (1983). A nation at risk: The imperative for Educational reform. Washington, DC: Government Printing Office National Center for Education Statistics (2004). Digest of Education Statistics 2003. Washington, DC: Author.

Nomi, T., \& Allensworth, E. M. (2013). Sorting and Supporting. American Educational Research Journal, 50(4), 756-788.

Nomi, T. (2012). The Unintended consequences of an algebra-for-all policy on high-skill students: Effects on instructional organization and students' academic outcomes. Educational Evaluation and Policy Analysis, 34(4) 489-505.

Noorbakhsh, A., \& Culp, D. (2000). The demand for higher education: Pennsylvania’s nonresident tuition experience. Economics of Education Review, 21(3), 277-286.

Nutting, A. W. (2008). Costs of attendance and the educational programs of first-time community college students. Economics of Education Review, 27(4), 450-459. 
Papay, J. P., Murnane, R. J., Willett, J. B., \& National Bureau of Economic, R. (2008). The Consequences of High School Exit Examinations for Struggling Low-Income Urban Students: Evidence from Massachusetts. NBER Working Paper No. 14186.

Papay, J. P., Murnane, R. J., \& Willett, J. B. (2010). The Consequences of High School Exit Examinations for Low-Performing Urban Students: Evidence From Massachusetts. Educational Evaluation and Policy Analysis, 32(1), 5-23.

Pascarella, E. T., \& Terenzini, P. T. (1991). How College Affects Students: Findings and Insights from Twenty Years of Research. San Francisco, CA: Jossey-Bass.

Paul, F. G. (2016). Grouping Within Algebra I: A Structural Sieve With Powerful Effects for Low-Income, Minority, and Immigrant Students. Educational Policy, 19(2), 262-282.

Paulsen, M. B., \& St. John, E. P. (2002). Social Class and College Costs: Examining the Financial Nexus Between College Choice and Persistence. The Journal of Higher Education, 73(2), 189-236. doi:10.1353/jhe.2002.0023

Perna, L. W., Leigh, E. W., \& Carroll, S. (2017). “Free College:” A New and Improved State Approach to Increasing Educational Attainment? American Behavioral Scientist, 61(14), 1740-1756.

Perna, L. W., May, H., Yee, A., Ransom, T., Rodriguez, A., \& Fester, R. (2013). Unequal Access to Rigorous High School Curricula. Educational Policy, 29(2), 402-425.

Perna, L. W., Rowan-Kenyon, H. T., Thomas, S. L., Bell, A., Anderson, R., \& Li, C. (2008). The Role of College Counseling in Shaping College Opportunity: Variations across High Schools. The Review of Higher Education, 31(2), 131-159.

Perna, L. W., \& Thomas, S. L. (2007). Barriers to College Opportunity. Educational Policy, 23(3), 451-479. 
Perna, L. W., \& Titus, M. A. (2004). Understanding Differences in the Choice of College Attended: The Role of State Public Policies. The Review of Higher Education, 27(4), 501-525.

Perna, L. W. (2006). Studying college choice: A proposed conceptual model. In J. C. Smart (Ed.), Higher Education: Handbook of theory and research, Vol. XXI (pp. 99-157).

Perna, L. W., May, H., Yee, A., Ransom, T., Rodriguez, A., \& Fester, R. (2013). Unequal access to rigorous high school curricula: An exploration of the opportunity to benefit from the international baccalaureate diploma programme (IBDP). Educational Policy, 29(2), 402-425.

Perna, L.W. (2000). Differences in the decision to enroll in college among African Americans, Hispanics, and Whites. Journal of Higher Education, 71, 117-141

Paul, F. G. (2005). Grouping within algebra I: A structural sieve with powerful effects for low-income, minority, and immigrant students. Educational Policy, 19(2), 262-282.

Perna, L. W. (2006). Studying college choice: A proposed conceptual model. In J. C. Smart (Ed.), Higher Education: Handbook of theory and research, Vol. XXI (pp. 99-157).

Peterson, P \& West, M (2003). No Child Left Behind? The Politics and Practice of School Accountability. Brookings Institution Press: New York

Plunk, A. D., Tate, W. F., Bierut, L. J., \& Grucza, R. A. (2014). Intended and unintended effects of state-mandated high school science and mathematics course graduation requirements on educational attainment. Educ Res, 43(5), 230-241. 
Pomeranz, D. (2016). Impact Evaluation Methods in Public Economics. Public Finance Review, 45(1), 10-43.

Psacharopoulos, G., \& Patrinos, H. A. (2018). Returns to investment in education: a decennial review of the global literature. Education Economics, 26(5), 445-458.

Reardon, S. F. (1996). Eighth Grade Minimum Competency Testing and Early High School Dropout Patterns. Retrieved from http://proxy.mul.missouri.edu/login?url=http://search.ebscohost.com/login.aspx?d irect=true \&AuthType=ip,cookie, url,uid \&db=eric \&AN=ED400273\&site=ehostlive \&scope $=$ site

Reardon, S. F., Arshan, N., Atteberry, A., \& Kurlaender, M. (2010). Effects of Failing a High School Exit Exam on Course Taking, Achievement, Persistence, and Graduation. Educational Evaluation and Policy Analysis, 32(4), 498-520.

Reardon, S. F., \& Galindo, C. (2002). Do high stakes tests affect students 'decisions to drop out of school? Evidence from NELS. Paper presented at the annual meeting of the American Educational Research Association, New Orleans, L

Reed, J. A (2009). Active Education: Lessons for Integrating Physical Activity with Language Arts, Math, Science and Social Studies. New York: Nova Science Publishers

Reynolds, G. L. (2007). The impact of facilities on recruitment and retention of students. New Directions for Institutional Research, 2007(135), 63-80.

Rose, H., \& Betts, J. R. (2004). The Effect of High School Courses on Earnings. Review of Economics \& Statistics, 86(2), 497-513.

Rosenbaum, P. R., \& Rubin,D.(1983).The central role of the propensity score in observational studies for causal effects.Biometrika,70 , 41-55. 
Rouse, C. E. (1999). Further estimates of the economic return to schooling from a new sample of twins. Economics of Education Review, 18, 149-157.

Rumberger, R. W. (1987). High school dropouts: A review of issues and evidence.

Review of Educational Research, 57(2), 101-121.

Rumberger, R. (1987). High school dropouts: a review of issues and evidence. Review of Educational Research, 57, 101-121.

Rowan-Kenyon, H., Bell, A. D., \& Perna, L. W. (2008). Contextual influences on parental involvement in college going. Journal of Higher Education, 79(5), 564586.

Schultz, T. W (1961). Investment in Human Capital. The American Economic Review, 51 (1), 1-17

Shadish, W., Cook, T., and D. Campbell (2002). Experimental and Quasi-Experimental Design for Generalized Causal Inference, W., Boston: Houghton Mifflin Company.

Shuster, K. (2012). Re-Examining Exit Exams: New Findings from the Education Longitudinal Study of 2002. Education Policy Analysis Archives, 20(3).

Slater, M., and Iler, E. (1991). A program to prepare minority students for careers in medicine,science, and other high-level professions. Academic Medicine 66(4): $220-225$.

Smith, M. J. (2001). Low-SES African American parents: Playing the college choice game on an unlevel playing field. Journal of College Admissions, 171, 16-21 students navigate the path to college: What high schools can do: A practice guide (NCESS \#2009-4066). Washington, DC: National Center for Education 
Evaluation and Regional Assistance, Institute of Education Sciences, U. S. Department of Education

Shadish, W., Cook, T., \& Campbell, D. (2002). Experimental and quasi-experimental design for generalized causal Inference, Boston, MA: Houghton Mifflin Company.

St. John, gE. P., Paulsen, M. B., \& Starkey, J. B. (1996). The nexus between college choice and persistence. Research in Higher Education, 37(2), 175-220.

St. John, E. P. (2003). Refinancing the college dream: Access, equal opportunity, and Justice for taxpayers. Baltimore, MD: Johns Hopkins University Press.

Shin, J.-c., \& Milton, S. (2006). Rethinking Tuition Effects on Enrollment in Public Fouryear Colleges and Universities. The Review of Higher Education, 29(2), 213-237.

Sjoquist, D. L., \& Winters, J. V. (2015). State Merit-Based Financial Aid Programs and College Attainment. Journal of Regional Science, 55(3), 364-390.

Steinberg, L. (1996). Beyond the classroom: Why school reform has failed and what parents need to do. New York: Simon \& Schuster

Stoddard, C., \& Kuhn, P. (2008). Incentives and effort in the public sector: Have US education reforms increased teachers' work hours? Economics of Education Review, 27(1), 1-13.

Teitelbaum, P. (2003). The influence of high school graduation requirement policies in mathematics and science on student course-taking patterns and achievement. Educational Evaluation and Policy Analysis, 25(1), 31-57.

Terenzini, P. T., Cabrera, A. F., \& Bernal, E. M. (2001). Swimming against the tide: The poor in American higher education. New York, NY: College Board 
Tierney, W.G. (2002). Parents and families in precollege preparation: The lack of connection between research and practice. Educational Policy, 16, 588-606

Tierney, W.G., Bailey, T., Constantine, J., Finkelstein, N., \& Hurd, N. F. (2009). Helping

Tierney, W. G. (2016). Parents and Families in Precollege Preparation: The Lack of Connection between Research and Practice. Educational Policy, 16(4), 588-606.

Titus, M. A., \& Pusser, B. (2011). States' Potential Enrollment of Adult Students: A Stochastic Frontier Analysis. Research in Higher Education, 52(6), 555-571.

Toutkoushian, R. K., \& Hillman, N. W. (2012). The Impact of State Appropriations and Grants on Access to Higher Education and Outmigration. The Review of Higher Education, 36(1), 51-90.

Toutkoushian, R. K., Hossler, D., DesJardins, S. L., McCall, B., \& Canche, M. G. (2015). The Effect of Participating in Indiana’s Twenty-first Century Scholars Program on College Enrollments. The Review of Higher Education, 39(1), 59-95.

Tuckman, H. P. (1970). Determinants of college student migration. Western Economic Journal, 37(2), 184-189

U.S. Department of Education, National Center for Education Statistics, (2014) Integrated Postsecondary Education Data System (IPEDS), Enrollment component. Digest of Education Statistics, Retrived from http://nces.ed.gov/programs/coe/indicator_cha.asp

Wang, X. (2013). Why Students Choose STEM Majors. American Educational Research Journal, 50(5), 1081-1121. 
Warne, R. T., Larsen, R., Anderson, B., \& Odasso, A. J. (2015). The Impact of Participation in the Advanced Placement Program on Students' College Admissions Test Scores. The Journal of Educational Research, 108(5), 400-416.

Warren, J. R., \& Edwards, M. R. (2005). High School Exit Examinations and High School Completion: Evidence from the Early 1990s. Educational Evaluation and Policy Analysis, 27(1), 53-74

Warren, J. R., \& Edwards, M. R. (2005). High School Exit Examinations and High School Completion: Evidence from the Early 1990s. Educational Evaluation and Policy Analysis, 27(1), 53-74.

Warren, J. R., Grodsky, E., \& Lee, J. C. (2008). State High School Exit Examinations and Postsecondary Labor Market Outcomes. Sociology of Education, 81(1), 77-107.

Warren, J. R., Jenkins, K. N., \& Kulick, R. B. (2006). High School Exit Examinations and State-Level Completion and GED Rates, 1975 through 2002. Educational Evaluation and Policy Analysis, 28(2).

Warren, J. R., Jenkins, K. N., \& Kulick, R. B. (2006). High School Exit Examinations and State-Level Completion and GED Rates, 1975 through 2002. Educational Evaluation and Policy Analysis, 28(2)

Warren, J. R., \& Kulick, R. B. (2007). Modeling States' Enactment of High School Exit Examination Policies. Social Forces, 86(1), 215-229.

Weerts, D. J., \& Ronca, J. M. (2012). Understanding Differences in State Support for Higher Education Across States, Sectors, and Institutions: A Longitudinal Study. The Journal of Higher Education, 83(2), 155-185. 
Wells, A. S., \& Crain, R. L. (1994). Perpetuation Theory and the Long-Term Effects of School Desegregation. In (Vol. 64, pp. 531-555): Review of Educational Research.

Weisbrod, B. A., Ballou, J. P., \& Asch, E. D. (2008). Mission and money: Understanding the university. New York, NY: Cambridge University Press.

William, G. T., \& Kristan, M. V. (2009). Finding Money on the Table: Information, Financial Aid, and Access to College. The Journal of Higher Education, 80(4), 363-388.

Wooldridge, J.M. (2012). Introductory econometrics: A modern approach, $\left(5^{\text {th }} \mathrm{ed}.\right)$. Cambridge, MA: MIT Press.

Zeng, X. (2009). The goals for regulating college tuition. Frontiers of Education in China, 4(2), 175-187.

Zhang, L. (2007). Nonresident Enrollment Demand in Public Higher Education: An Analysis at National, State, and Institutional Levels. The Review of Higher Education, 31(1), 1-25.

Zhang, L., Hu, S., \& Sensenig, V. (2013). The Effect of Florida's Bright Futures Program on College Enrollment and Degree Production: An Aggregated-Level Analysis. Research in Higher Education, 54(7), 746-764.

Zhang, L., \& Ness, E. C. (2010). Does State Merit-Based Aid Stem Brain Drain? Educational Evaluation and Policy Analysis, 32(2), 143-165. 


\section{VITA}

Jude Kyoore was born in Nandom, Upper West Region in Ghana. He completed his Bachelor of Economics in 2007 at the University of Ghana. He earned his Master's in Economics at the University of Akron in Ohio in 2010. He currently works as a Research Analyst IV in the office of Post-Secondary Policy at the Missouri Department of Higher Education and Workforce Development. 